\title{
Mad212 in primordial germ cell development and pluripotency
}

\author{
Dissertation \\ for the award of the degree \\ "Doctor of Philosophy" \\ in the doctoral program (Genes and Development) \\ of the Georg-August University School of Science (GAUSS)
}

Submitted by:

Mehdi Pirouz

From:

Kermanshah, Iran

Göttingen, 2013 


\section{Members of the Thesis Committee}

\section{Reviewer 1: Professor Dr. Michael Kessel}

Department of Molecular Cell Biology, Research Group Developmental Biology, Max Planck Institute for Biophysical Chemistry

Reviewer 2: Professor Dr. Wolfgang Engel

Department of Human Genetics, Göttingen University Medical School

Professor Dr. Gregor Eichele

Department of Genes and Behavior, Max Planck Institute for Biophysical Chemistry

\section{Members of the Extended Thesis Committee}

\section{Professor Dr. Ernst Wimmer}

Department of Developmental Biology, Georg-August-University Göttingen

\section{Professor Dr. Reinhard Schuh}

Department of Molecular Developmental Biology, Max Planck Institute for Biophysical Chemistry

\section{Dr. Roland Dosch}

Department of Developmental Biochemistry, Göttingen University Medical School

Date of the oral examination: $22^{\text {nd }}$ February 2013 


\section{Affidavit}

Here I declare that my doctoral thesis entitled "Mad212 in primordial germ cell development and pluripotency" has been written independently with no other sources and aids than quoted.

Mehdi Pirouz, Göttingen, January 2013 
To my family, and my soul mate, Farnaz 


\section{Table of content}

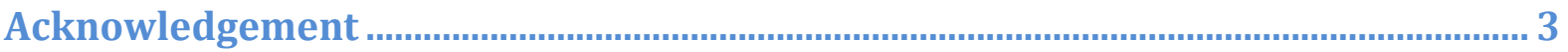

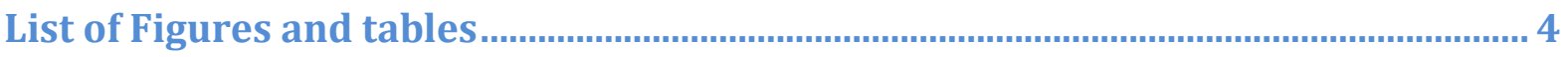

Abbreviations and nomenclature

Summary

Introduction

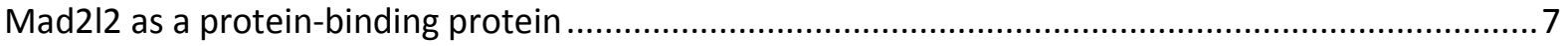

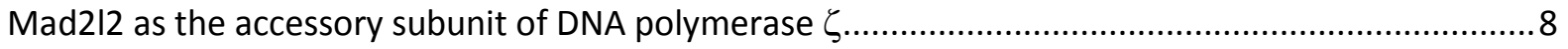

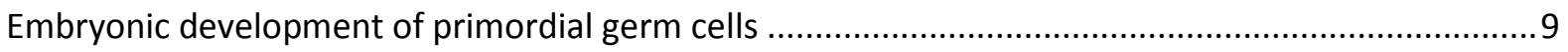

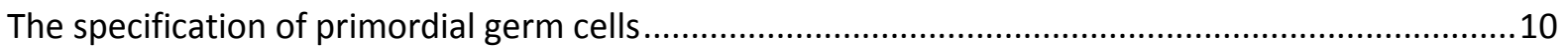

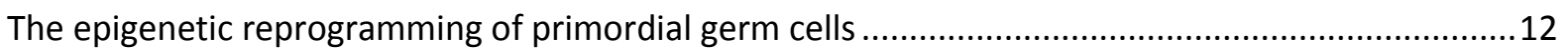

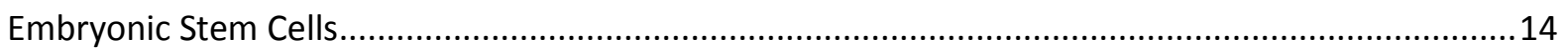

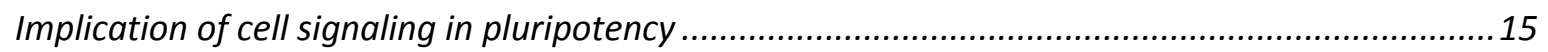

Chromatin configuration in ESCs versus differentiated cells ...................................................... 16

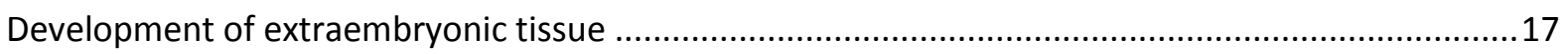

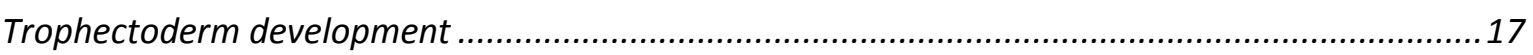

Development of extraembryonic endoderm ............................................................................. 18

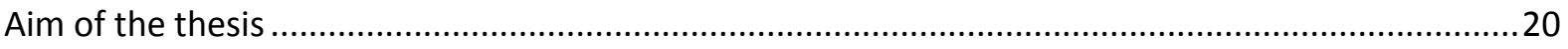

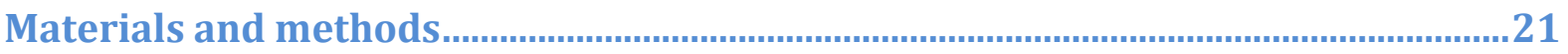

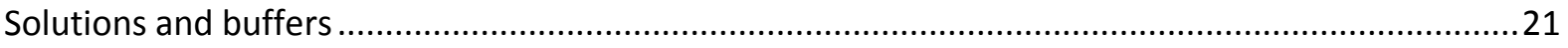

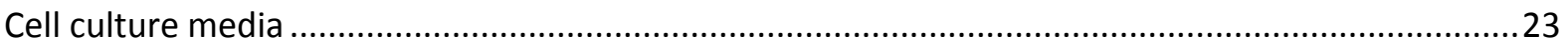

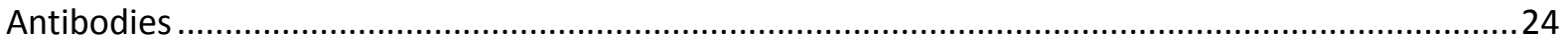

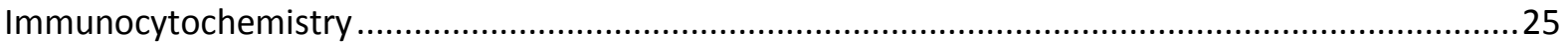

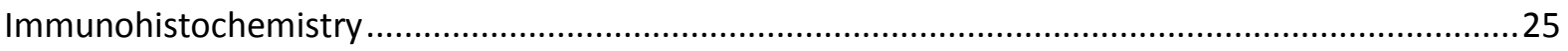

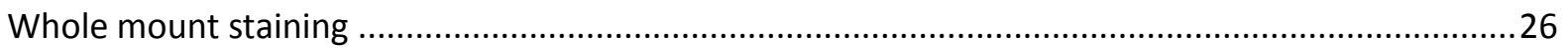

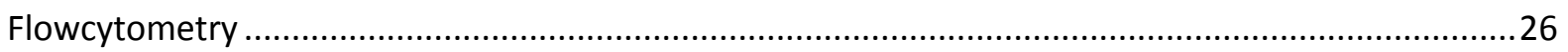

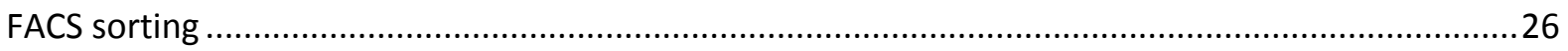

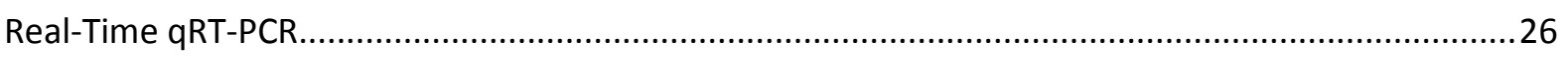

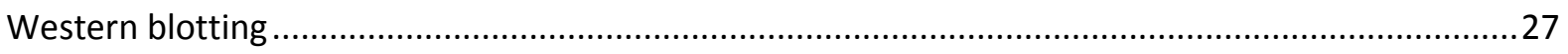

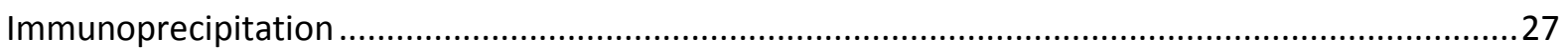

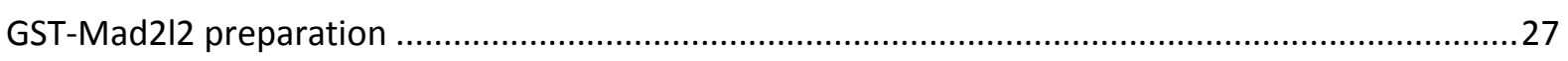

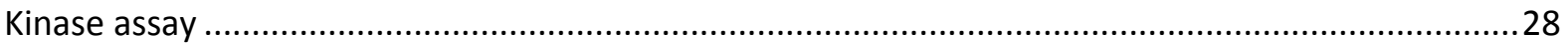




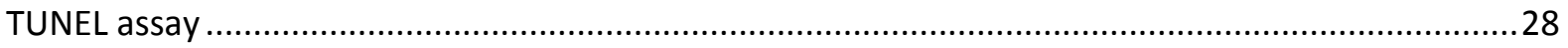

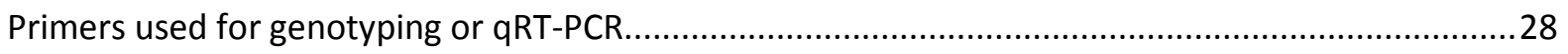

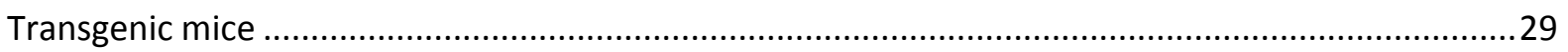

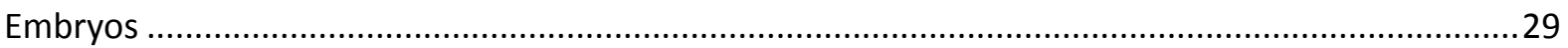

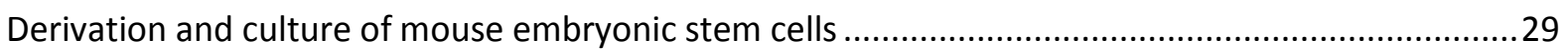

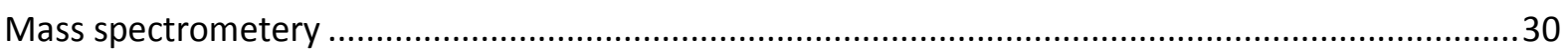

ReSultS:

Mad2I2 deficient fibroblasts fail to arrest after DNA damage ....................................................... 31

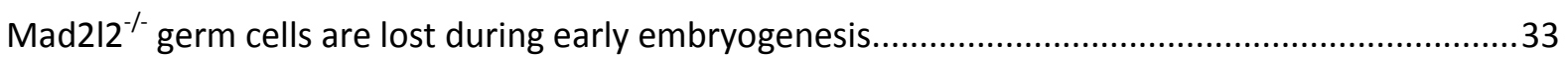

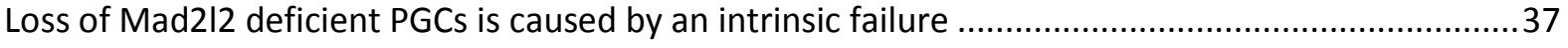

Mad2I2 downregulates H3K9me2 via inhibitory binding to G9a and GLP .......................................39

Mad2/2 regulates the cell cycle via inhibitory binding to Cdk1 .......................................................42

Mad2I2 facilitates H3K27me3 upregulation via blocking Ezh2 phosphorylation ................................44

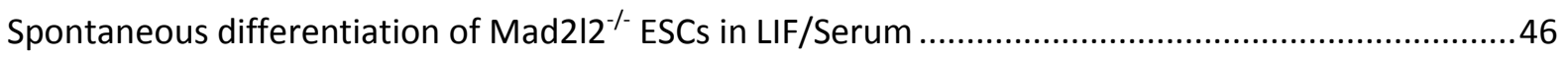

Figure 18. Characterization of various knockout ESC lines..................................................................48

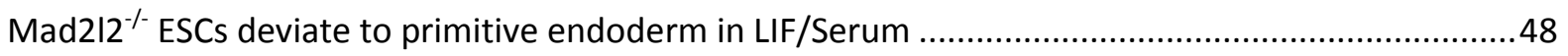

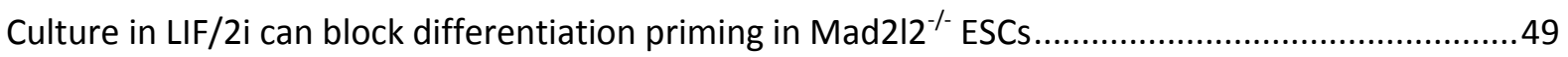

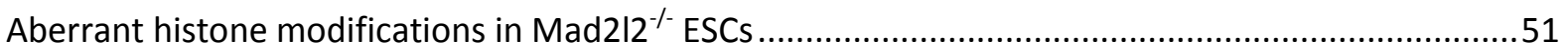

FGF/Erk inhibitor is sufficient to block differentiation in Mad2/2 ${ }^{-/}$ESCs ...........................................51

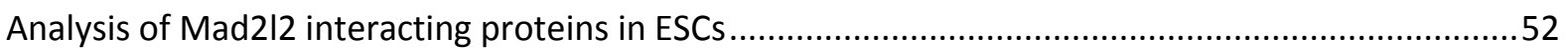

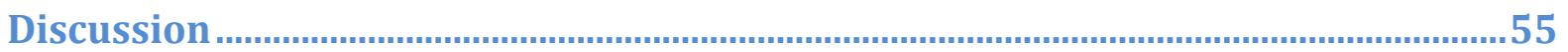

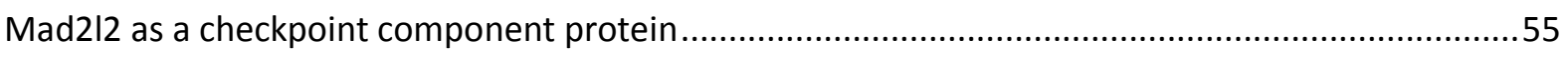

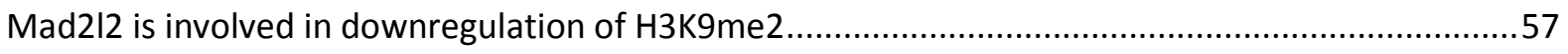

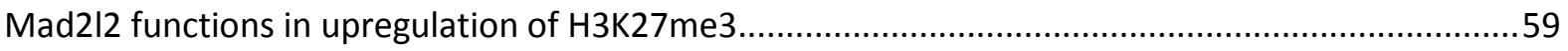

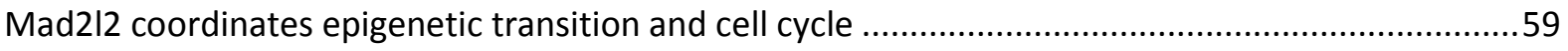

Mad212 ${ }^{-1-}$ ESCS are unstable and deviate into primitive endoderm cells.............................................60

Mad2l2 association with stem cell coactivator complex may safeguard Nanog expression and

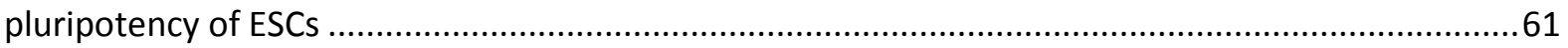

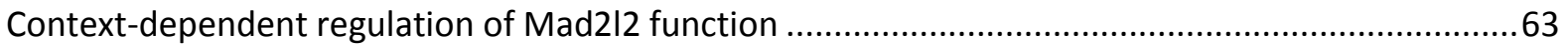

Mad212: a connection between DNA damage, epigenetic reprogramming, and pluripotency ...........64

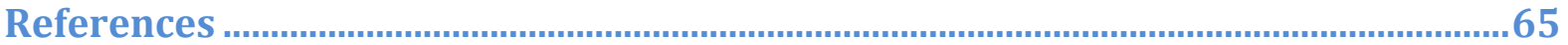

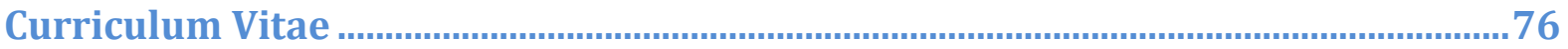




\section{Acknowledgement}

I would like to thank my supervisor Prof. Dr. Michael Kessel for giving me the great opportunity to work in his laboratory on this interesting project. He was always supporting new ideas and meanwhile guiding me through the projects. I enjoyed a lot having fruitful discussions with him, which was a valuable step in building my scientific career and also my personal development.

I would like to thank Prof. Dr. Wolfgang Engel and Prof. Dr. Gregor Eichele, the members of my thesis committee for their helpful advices, guidance and comments during committee meetings. In addition, I would like to thank GGNB office staffs, especially, Christina Bach, and Kirsten Pöhlker for their helpfulness and untiring dedication. I also thank Prof. Dr. Ernst Wimmer, Prof. Dr. Reinhard Schuh, and Dr. Roland Dosch to accept being members of the extended thesis committee.

Furthermore, I am thankful to the members of the Molecular Cell Biology Department, Prof. Dr. Anastassia Stoykova, Prof. Dr. Ahmed Mansouri, Dr. Kamal Chowdhury, Sharif Mahsur, and Dr. Tamara Rabe for their help, scientific discussions, and technical advice. I would like to have a special thank to Dr. Ulrike Teichmann, Daniela Wollradt, and Stefanie Thiel for their help and advice concerning the mice. Moreover, I am grateful to Prof. Dr. Henning Urlaub, and his colleagues Monika Raabe and Uwe Plessmann for mass spectrometry analysis and Sabrina Becker for flowcytometry and FACS analysis.

Moreover, my thanks go to all my current and former lab mates in Prof. Kessel's lab. I am very thankful to Dr. Sven Pilarski, Dr. Alexander Klimke, Petra Rus, Ali Rahjouei and Dr. Golnaz Tabrizi for all their technical help, discussions and sharing good and bad times.

I would like to thank Farnaz Shamsi and Dr. Mostafa Bakhti, for their scientific and non-scientific helps, patiently listening to my problems, discussions, sharing experiences and proofreading parts of the present thesis.

I am grateful to my parents Maliheh and Alimohammad, my family members Farid, Navid, Leila, Maryam, and Houram for all their continuous support, advice and love. Last, but not the least, I would like to thank my soul mate, Farnaz, for all her patience, kindness, help and love. 


\section{List of Figures and tables}

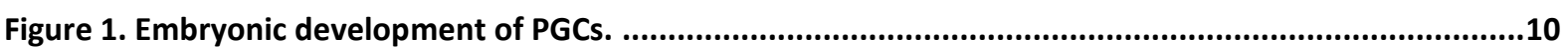

Figure 2. Transcriptional regulation of PGC specification. .................................................................12

Figure 3. Chromatin configuration changes upon differentiation of ESCs...................................................17

Figure 4. Different stages of preimplantation development in mice. ......................................................18

Figure 5. The underlying molecular mechanism of preimplantation development. .......................................19

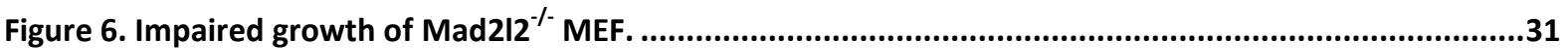

Figure 7. The response of Mad2/2 ${ }^{-/-}$MEFs to cisplatin treatment. .........................................................32

Figure 8. Mad2/2 expression and loss of germ cells from mutant ovaries and testes. ..................................33

Figure 9. Loss and apoptosis of PGCs early after specification. ..........................................................34

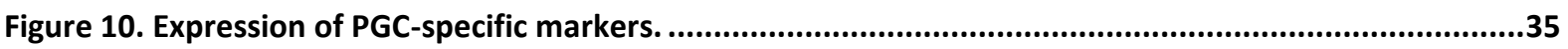

Figure 11. No activation of DNA damage response in apoptotic Mad212 ${ }^{-/-}$PGCs. ........................................36

Figure 12. Intrinsic failure of Mad2I2 deficient PGCs..............................................................................38

Figure 13. Mad2I2 deficient PGCs fail to downregulate H3K9me2 .........................................................40

Figure 14. Mad2I2 is associated with downregulation of H3K9me2. .......................................................41

Figure 15. Mad212 deficiency affects the cell cycle in PGCs. ..............................................................43

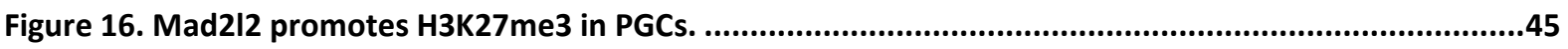

Figure 17. Mad212 ${ }^{-/-}$ESCs are unstable and lose their pluripotency..............................................................47

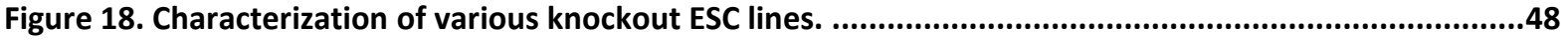

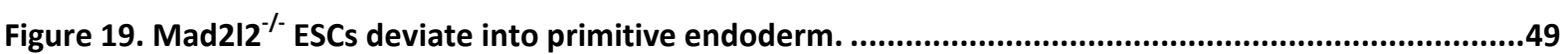

Figure 20. Growth of ESC cultures in LIF/2i eliminates differentiation. .....................................................50

Figure 21. Inhibition of Erk pathway by PD is sufficient to block primitive endoderm differentiation in

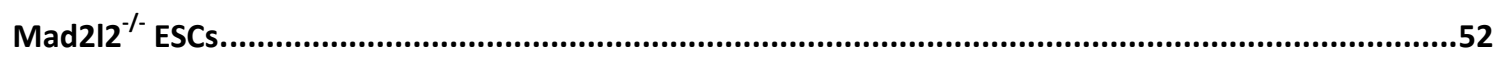

Figure 22. A model describing the function of Mad2I2 in PGC development...........................................60

Figure 23. A model for function of Mad2/2 in pluripotency of mouse ESCs .............................................63

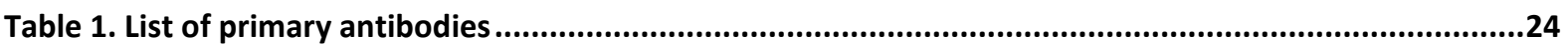

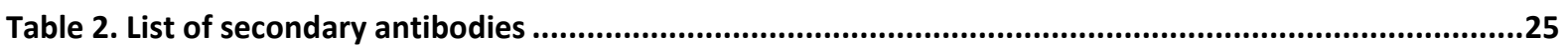

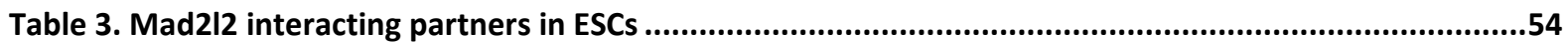




\section{Abbreviations and nomenclature}

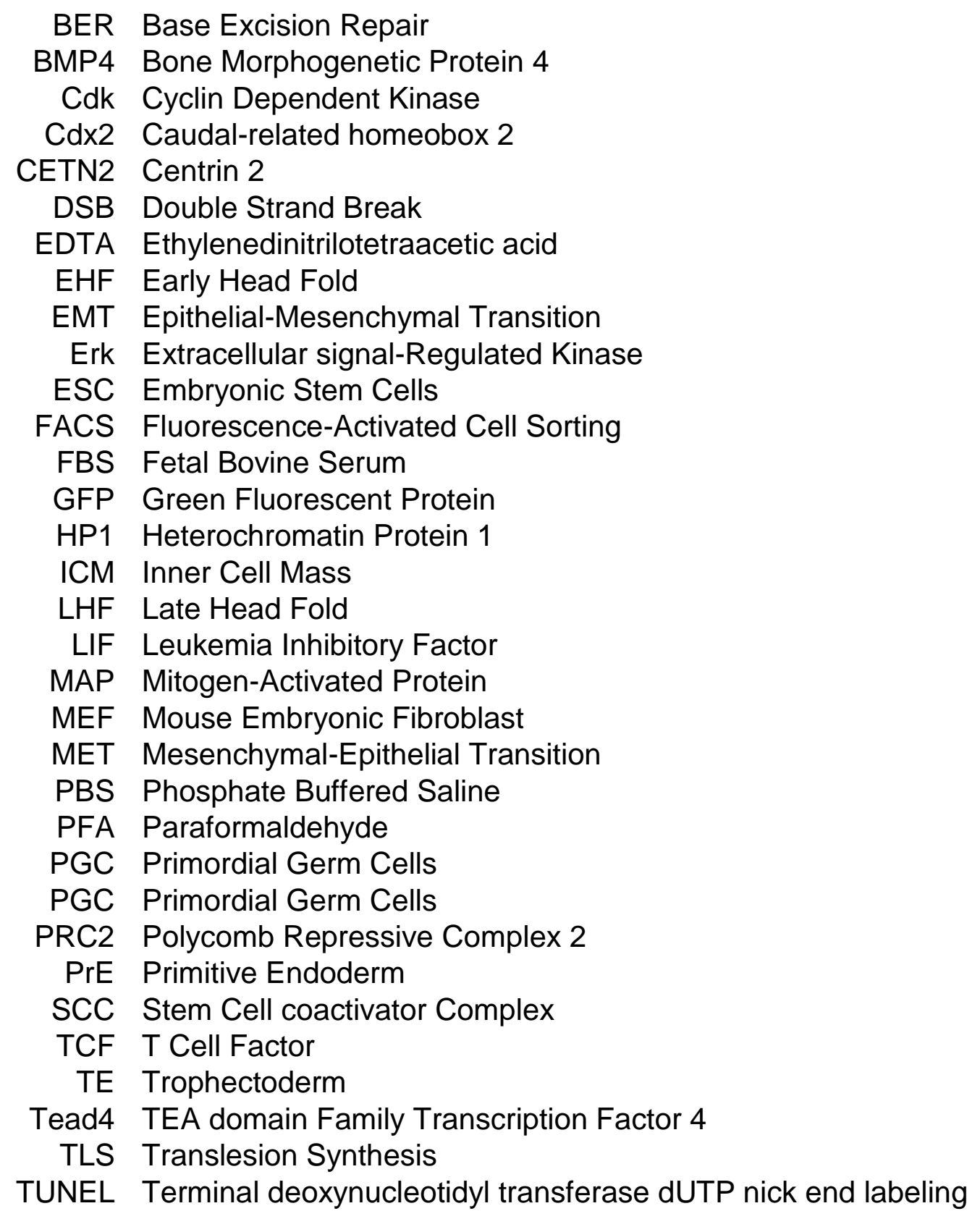




\section{Summary}

The development of primordial germ cells (PGCs) involves several waves of epigenetic reprogramming. A major step is the transition from the stably suppressive histone modification $\mathrm{H} 3 \mathrm{~K} 9 \mathrm{me} 2$ to the more flexible, still repressive H3K27me3, while the cells are arrested in the G2 phase of their cell cycle. The significance and underlying molecular mechanism of these events were so far unknown. In this study, a role of the Mad2l2 (Mad2B, Rev7) gene product in development of PGCs was investigated. Mad2l2 is a HORMA domain protein, which is involved in proteinprotein interaction. Mad2I2 is essential for PGC, but not for somatic development. PGCs were specified normally in Mad212/- embryos, but their chromatin did not proceed from the H3K9me2 to H3K27me3 state. Mad2/2/- PGCs failed to arrest in the G2 phase, and were eliminated by apoptosis. Co-immunoprecipitation analysis showed that Mad2I2 could interact with the histone methyltransferases G9a and GLP, and thus lead to a downregulation of $\mathrm{H} 3 \mathrm{~K} 9 \mathrm{me} 2$. It also interacts physically with Cdk1, which together with Cyclin B1 is the main driving force for mitotic entrance and progression. The inhibitory binding of Mad2l2 to Cdk1 could arrest the cell cycle in the G2 phase, and therefore allow the other histone methyltransferase, Ezh2, to upregulate H3K27me3. In conclusion, Mad2l2 is essential for epigenetic reprogramming in mouse PGCs.

Mad2I2/- ESC lines cultured in conventional condition (LIF/Serum) showed evidence for a spontaneous differentiation into epithelial-like cells with the molecular characteristics of primitive endoderm. They had a cell cycle similar to that of differentiated cells, failed to incorporate into chimeras, and deviated to primitive endoderm at the expense of pluripotency. They also manifested an epigenetic configuration distinct from normal ESCs, namely elevated H3K9me2 and H3K27me3 levels. Differentiating cells disappeared once the cultures were shifted to the chemically defined medium supplemented with two inhibitors of MEK and Wnt pathways (LIF/2i). Co-immunoprecipitation of Mad2/2 in ESCs followed by mass spectrometry identified CETN2 as its interacting partner. This interaction might be involved in regulation of Nanog expression and thus in sustaining self-renewal of ESCs. Altogether, these data point to essential role of Mad2I2 in pluripotent ESCs. 


\section{Introduction}

\section{Mad2l2 as a protein-binding protein}

Mad2l2 is a protein-binding protein involved in several biological processes including cell cycle control and DNA repair (Aravind and Koonin, 1998; Chen and Fang, 2001; Pfleger et al., 2001). It mainly comprises of a conserved HORMA domain by which it binds to a diverse spectrum of proteins. Several, but not all of these partners bind through their conserved sequence motif PXXXPP (Hanafusa et al., 2010). Reported binding partners include Cdh1 and Cdc20, the substrate binding proteins of the APC/C complex, Rev 1, Rev 3, the transcription factors Elk-1 and TCF4, the clathrin light chain A, Mad2I2 itself, and other proteins (Chen and Fang, 2001; Hong et al., 2009; Medendorp et al., 2009; Medendorp et al., 2010; Murakumo et al., 2001; Pfleger et al., 2001; Zhang et al., 2007).

Mad2I2 interacts with three cell signaling components c-JNK, Elk1, and TCF4. It interacts physically with two downstream molecules of mitogen-activated protein (MAP) kinase pathway: c-JNK kinase and transcription factor Elk1. MAP kinases are involved in directing cellular responses to a wide variety of extrinsic stimuli, including mitogens, proliferative signals, osmotic and heat shock stresses, regulating cell proliferation, gene expression, cell survival, and apoptosis (Chang and Karin, 2001; Kyriakis and Avruch, 2001). These signals are further transduced via either extracellular signal-regulated kinase (ERK) pathway or c-Jun $\mathrm{N}$-terminal protein kinase (c-JNK) kinase and p38 pathways (Roux and Blenis, 2004; Yang et al., 2003). Mad2I2 serves as an adapter to facilitate Elk1 phosphorylation by JNK and consequently increases its transcription activation potential. As a result, Mad2I2 upregulates the expression of Elk1-downstream targets such as egr1 and c-foc (Zhang et al., 2007). Following introduction of DNA damage by methyl methanesulfonate (MMS) treatment or UV irradiation, a large increase is observed in the kinase activity of protein extracts, including JNK. By this, Mad2I2 functions as an adaptor to ensure the maximal JNK-mediated phosphorylation and Elk1 transactivation following exposure of cells with DNA-damaging agents. In this context,

Mad2l2 was suggested to act as a scaffold protein to co-localize the kinase and the substrate (Zhang et al., 2007). 
Mad212 was found to interact with T cell factor 4 (TCF4). Downstream in the Wnt signaling pathway, TCF4 associates with $\beta$-catenin and binds to TCF-binding sites TBSs in promoters of the Slug gene family and trans-activates the expression of Slug genes (i.e. Slug and Snail). This, in turn, inhibits the transcription of Ecadherin and thereby induces epithelial-mesenchymal transdifferentiation (EMT) in SW480 colorectal cancer cells (Hong et al., 2009). Mad2l2-TCF4 interaction hampers DNA binding potential of TCF and consequently blocks TCF4-mediated gene expression. As a result, Mad2I2-TCF4 interaction abolishes EMT and rather induces mesenchymal-epithelial transdifferentiation (MET) in these cells (Hong et al., 2009). Thus, Mad212 is probably involved in the modulation of Wnt and Erk signaling, and regulates cellular responses to these pathways.

\section{Mad212 as the accessory subunit of DNA polymerase $\zeta$}

Originally, Mad212 was identified as an accessory, non-catalytic subunit of the translesion DNA polymerase zeta (DNA Pol $\zeta$ ) in budding yeast Saccharomyces cerevisiae, where it is called "Rev7" (Lawrence et al., 1985; Torpey et al., 1994). Mad2l2 homologues are also identified in mice and humans (Murakumo et al., 2001; Murakumo et al., 2000). Translesion synthesis (TLS) is an error-prone DNA repair mechanism to bypass DNA lesions, when other error-free DNA replication systems including base excision repair, nucleotide excision repair, mismatch repair, and recombination repair (Hanawalt, 1994; Sancar, 1994) are ineffective or impaired. In TLS, normal DNA polymerases are stalled on a DNA damage site and displaced by translesion polymerase(s), which synthesize a short patch of nucleotides, before the replicative polymerases resume DNA synthesis. Since TLS frequently induces mutations, it is considered as the last resort for DNA repair (Bridges, 1999; Friedberg and Gerlach, 1999).

In human cancer cell lines, Mad2l2 knockdown leads to hypersensitivity towards double strand break (DSB) introduced by $\gamma$-irradiation or DNA-crosslink induced by cisplatin treatment represented by increased phosphorylation of H2AX $(\gamma \mathrm{H} 2 \mathrm{AX})$. This also increases cell death indicated by increased cleavage of caspase 3 (Cheung et al., 2006; Gan et al., 2008; Sharma et al., 2012). Mad2l2 knockdown induces accumulation of HeLa cells in G2/M phase of cell cycle, especially following introduction of DSB, implying the involvement of Mad2/2 in the G2/M DNA damage checkpoint (Sharma et al., 2012). Mad2l2 interacts physically with two catalytic 
translesion polymerases Rev1 and Rev3, forming a ternary complex which resolves DSBs and facilitates homologous recombination repair and translesion repair (Kikuchi et al., 2012; Murakumo et al., 2001; Sharma et al., 2012; Xie et al., 2012).

Mutations of the mouse Rev3 gene result in embryonic lethality at E8.5-E12.5 or severe delay/retardation of the embryos (Bemark et al., 2000; Esposito et al., 2000; Van Sloun et al., 2002; Wittschieben et al., 2000). Rev1-deficient mice become infertile after backcrossing for two generations to C57BL/6 mice (Jansen et al., 2006). While elimination of Mad2l2 in lower organisms like yeasts results in reduced rate of mutations upon treatment with DNA-damaging agents (Baynton et al., 1999), function of Mad2l2 in higher organisms is unknown due to the lack of Mad2/2 mutant mice.

\section{Embryonic development of primordial germ cells ${ }^{1}$}

When this project was started, it had been shown that Mad2l2-deficient mice are infertile due to early loss of germ cells (Dr. Sven Pilarski). In the next chapters, development of the germline is introduced. Germ cells are unique cells present during almost the entire life span. They function to carry the genetic material safely into the next generation. For that, they develop distinctly from all other cells of the body, and probably their genomes undergo particularly critical quality controls. Primordial germ cells (PGCs) arise early in embryogenesis, and develop further in the genital ridge at midgestation, whereas the male and female gametes are only formed after the birth. The germ cell cycle culminates by the fusion of a haploid oocyte with a spermatozoon, giving rise to a diploid one-cell embryo (De Felici and Farini, 2012). During the first cell divisions of a mouse embryo there is no separate development of somatic cells from the germline. Only at the onset of gastrulation a small set of PGC progenitors is induced in the epiblast in response to instructive BMP signals (de Sousa Lopes et al., 2007; Hopf et al., 2011; Ohinata et al., 2009). The first bona fide germ cells, the PGCs, leave the epiblast with the extraembryonic mesoderm at the posterior primitive streak, and thus in mice a group of around 40 PGCs locates at the base of the allantois. From here the PGCs migrate within the definitive endoderm of the prospective hindgut, then exit from the hindgut endoderm, and migrate via the dorsal mesentery towards the genital ridges. Here, they

\footnotetext{
${ }^{1}$ Some parts of this chapter are modified from (Pirouz et al., 2012).
} 
accumulate in the gonad anlagen, and ovaries and testes become morphologically distinguishable around midgestation (Saga, 2008; Saitou, 2009a, b; Saitou et al., 2012). Murine PGC precursor cells in the epiblast divide very rapidly with a doubling time of 5-7h, comparable to their surrounding cells (McLaren, 2000; McLaren and Lawson, 2005; Tam and Snow, 1981). However, they slow down drastically to a regular 16-hour cell cycle after emigration of the extraembryonic mesoderm. Thus, PGC numbers increase to around 250 at embryonic day E9.5, to 1000 at E10.5, and to 26000 in the gonad primordia at E13.5 (Tam and Snow, 1981). Massive cell biological and molecular changes occur in PGCs after their induction and before gonad formation (Figure 1). They affect the developmental potential, the cell cycle, the transcriptional program, and the epigenetic set up of the chromatin.

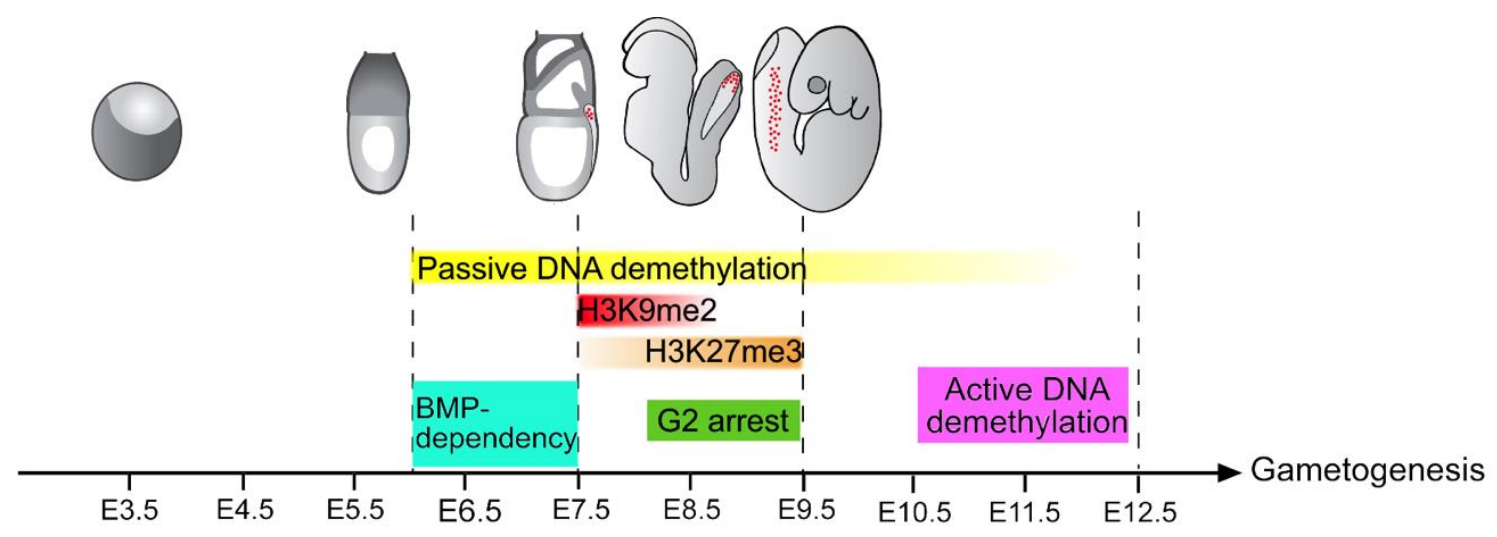

Figure 1. Embryonic development of PGCs.

PGCs (red dots) are induced in the epiblast by BMP4 and at E7.5, specified PGCs start epigenetic reprogramming by the passive erasure of DNA methylation. Then, from E8.0 to $\mathrm{E} 9.5$, they undergo epigenetic transition from $\mathrm{H} 3 \mathrm{~K} 9 \mathrm{me} 2$ to $\mathrm{H} 3 \mathrm{~K} 27 \mathrm{me}$ s state while migrating in the hindgut endoderm. PGCs become transiently arrested in G2 phase of the cell cycle and once they arrive in the genital ridges, an active DNA demethylation occurs via base excision repair-mediated mechanism. As a result, PGCs reset their genome and become ready for future gametogenesis. Modified from (Pirouz et al., 2012).

\section{The specification of primordial germ cells}

Once induced in the most proximal epiblast by bone morphogenetic protein 4 (BMP4) emanating from extraembryonic ectoderm, PGC precursors start to express two essential genes for PGC development: Prdm1 (Blimp1) start to express at around E6.25 and subsequently Prdm14 at E6.5, (Ohinata et al., 2005; Yamaji et al., 2008). A major function of Blimp1 in PGCs is the transcriptional repression of typical 
somatic genes like Hox, Snail, and others (Lin et al., 1997; McLaren and Lawson, 2005). It also controls the reduction of the doubling time via downregulation of c-Myc (Lin et al., 1997; McLaren and Lawson, 2005). Blimp1 is responsible for suppression of cell cycle regulators including Ccne1, Ccnd1 and Cdc25a (Kurimoto et al., 2008a; Yamaji et al., 2008). Both Blimp1 and Prdm14 are required for the activation of germ cell development-related genes like Stella, E-cadherin, Fragilis, and the pluripotency markers Sox2, Klf2 and Nanog, which had been suppressed in the early epiblast and their renewed transcription indicates the re-acquisition of potential pluripotency. Blimp1 and Prdm14 are synergistically involved in downregulation of histone- and DNA-methyltransferases GLP, and Dnmt3a, Dnmt3b, respectively (Kurimoto et al., 2008b; Yamaji et al., 2008). All together, at E7.25, PGCs upregulate around 500 "germ cell specification" genes and downregulate around 330 "somatic program" genes (Kurimoto et al., 2008a).

AP2 $\mathrm{y}$, which is induced by Blimp1 and encoded by the Tcfap2c gene at E6.75, is also critical for PGC development, as AP2y-mutants lose their PGCs soon after specification probably due to a failure in suppression of somatic mesodermal genes. With the program orchestrated by the two PRDM genes and AP2 $\gamma$, the unique germ cell fate of the PGCs is established (Figure 2), and they are usually considered to be "specified" (Kurimoto et al., 2008b). This implies that they are clearly bearing the characteristics of germ cells, and will continue as such, if no further influences will affect their fate. However, in order to secure this fate against external cues, a further fixation of the identity is necessary. This is achieved by epigenetic modifications of the chromatin and of the DNA, introducing inheritable marks that guarantee the commitment to a germ cell fate (Figure 2). 


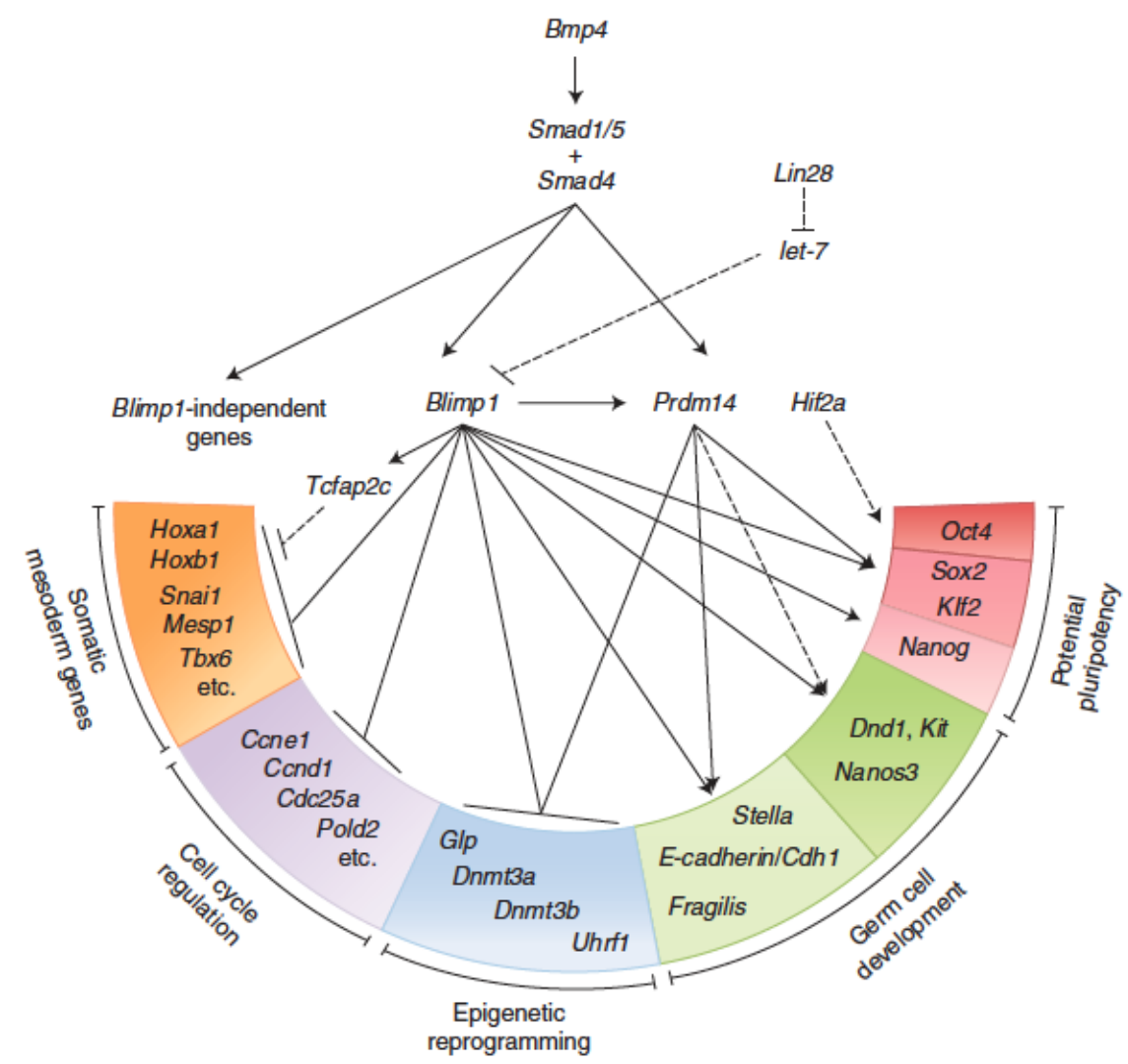

Figure 2. Transcriptional regulation of PGC specification.

A genetic network involved in specification of PGCs suggested from in vivo experiments (Kurimoto et al., 2008a; Yamaji et al., 2008). Arrows indicate activation and lines with terminal ends point suppression. Dotted arrows and lines are suggested from in vitro experiments (Covello et al., 2006; Weber et al., 2010; West et al., 2009). The figure is from (Saitou and Yamaji, 2012).

\section{The epigenetic reprogramming of primordial germ cells}

Following specification, PGCs undergo epigenetic reprograming that can be generally divided into two phases: (i) changes in histone modification between E8.0E9.5, and (ii) DNA demethylation occurring mainly at E10.5-E12.5. At the first phase, PGCs arrest their cell cycle in the G2 phase and stall Pol II-mediated de novo transcription relatively early after their specification for about 36h (Seki et al., 2007). It seems that this phase is used for initiation of significant changes in the epigenetic status (Figure 1). The repressive histone mark H3K9me2 now decreases progressively, and finally becomes effectively removed. This genome-wide effect correlates with the Blimp1- and Prdm14-dependent downregulation of the histone methyltransferase GLP, which together with G9a is critical for H3K9 di-methylation (Kurimoto et al., 2008a; Seki et al., 2005). In parallel, expression of the histone de- 
methylase Jmdm2a is maintained (Seki et al., 2007; Yamane et al., 2006). The downregulation of the methyltransferases, and the maintenance of the demethylase explain the gradual loss of H3K9me2 over time. A different suppressive histone mark, H3K27me3, is introduced by the polycomb repressive complex 2 (PRC2). PRC2 consists of the core components Ezh2, Eed and Suz12, all of which are present in PGCs (Yabuta et al., 2006). The replacement of one inhibitory modification by another alters the molecular configurations at the affected loci. H3K9me2 recruits heterochromatin protein 1 (HP1) and causes DNA methylation, whereas H3K27me3 is a histone mark conferring more plasticity (Hawkins et al., 2011; Smallwood et al., 2007). PGCs have significant levels of both the activating H3K4me3 and the repressive H3K27me3 modification. Therefore, they might in principle generate bivalent loci, i.e. configurations that are often located on developmentally critical promoter regions in ESCs (see the next chapter), and can be quickly activated in response to differentiation stimuli (Bernstein et al., 2006). In PGCs they may facilitate the epigenetic resetting of the chromatin in preparation for future differentiation steps in the genital ridges. Further histone modifications occur later, in parallel to the demethylation of DNA (Hajkova et al., 2008). They include a transient loss of $\mathrm{H} 3 \mathrm{~K} 9 \mathrm{me} 3$ and $\mathrm{H} 3 \mathrm{~K} 27 \mathrm{me} 3$, whereas the histone variants H4/H2AR3me2s and H3K9ac are persistently lost.

In the second phase (Figure 1), in addition to the modification of histones, significant changes of DNA methylation patterns are introduced in migratory and post-migratory PGCs (Hackett et al., 2012a; Hackett et al., 2012b; Hajkova, 2011; Saitou et al., 2012; Seki et al., 2007). Genome-wide DNA demethylation occurs passively by repressing the DNA methyltransferases, and results in a gradual loss of $5 \mathrm{mC}$ with every cell division (Kurimoto et al., 2008a; Seki et al., 2005). In addition, methyl groups can also be removed from DNA directly, e.g. by employing the cytidine deaminase Aid (Popp et al.). The critical mechanism for genome-wide DNA demethylation in PGCs is DNA repair through the base excision repair (BER) pathway (Hajkova et al., 2010). Only later, also repetitive regions and transposable elements become in part demethylated, while they remain highly methylated and silenced in somatic cells. Imprinting of genes is erased, and becomes re-established after sex determination to adjust the dosage according to the sex of the cells (Bartolomei and Ferguson-Smith, 2011; Hackett et al., 2012b). Between E11.5 and E13.5, the $X$ chromosome reactivation in female PGCs, which was initiated already 
during migration, is completed (Mochizuki and Matsui, 2010; Saitou et al., 2012; Sasaki and Matsui, 2008). Taken together, the extensive remodeling of the chromatin in PGCs reprograms the epigenome in preparation for totipotency (Hajkova, 2011; Hajkova et al., 2008).

\section{Embryonic Stem Cells}

Since PGCs and pluripotent stem cells have a reciprocal relationship (Pirouz et al., 2012), the function of Mad2l2 in mouse embryonic stem cells was addressed in the second phase of the PhD.

Mouse embryonic stem cells (ESCs) are pluripotent cells derived from preimplantation embryos (Evans and Kaufman, 1981). Pluripotency is defined as the potential of cells for indefinite self-renewal and multi-lineage differentiation. ESCs also manifest unique genetic and epigenetic characteristics. Several transcription factors build the core pluripotency circuit favoring the undifferentiated state of the cells. In parallel, histone modifiers and chromatin remodeling chaperones ensure maintenance of proper epigenetic signature in ESCs. Mutations in some of these regulators compromise the epiblast or ESCs, which in turn results in early embryo lethality or loss of pluripotency (Surani et al., 2007; Young, 2011). Namely, Oct4, Nanog and Sox2, comprising core transcription factors, play critical roles in supporting self-renewal and inhibiting differentiation in ESCs. They function to regulate their own expression in a positive, auto-regulatory loop. They also cooccupy and upregulate the expression of genes necessary for maintenance of ESCs in an undifferentiated state, or suppress the expression of lineage-specific transcription factors (Jaenisch and Young, 2008). Apart from core transcription factors, several other proteins are essential for maintenance of ESC, including Tcf3 functioning in Wnt signaling to core circuit, Klf4, Stat3 and Tbx3 in LIF signaling, Smad1/2/3 in TGF- $\beta$ signaling, C-Myc in proliferation, Ronin in ESC metabolism, Prdm14 in ESC identity, Zfx in self-renewal, Sall4 in pluripotency, and etc. (Young, 2011).

While self-renewing, ESCs retain the capacity to undergo multi-lineage differentiation. At the molecular level, this balance is tuned finely by simultaneously suppressing and activating chromatin at the regulatory regions of lineage-specific transcription factors (Azuara et al., 2006). This phenomenon is called "bivalency", and refers to a situation in which an individual locus is occupied by both activating 
(e.g. H3K4me3 and H3K9Ac) and repressive (e.g. H3K27me3) histone marks. This places lineage-affiliated genes in a "stand-by" state that represses their expression, and ensures their activation upon exit from self-renewal and onset of differentiation.

\section{Implication of cell signaling in pluripotency}

Several signaling pathways are involved in regulation of self-renewal or differentiation of embryonic stem cells (Li et al., 2012; Miki et al., 2011; Sokol, 2011; Takahashi et al., 2005; Tanaka et al., 2011; Watanabe and Dai, 2011). Traditionally, mouse ESCs are cultured on mitotically inactivated mouse embryonic fibroblasts (MEFs) as a feeder with a medium comprised mainly of leukemia inhibitory factor (LIF) and serum. LIF induces pluripotency-related genes via at least two routs: firstly, it activates its transducer STAT3 that in turn induces Klf4, and secondly, it maintains Nanog expression via the PI3K pathway (Niwa et al., 2009). In this culture system, serum can be replaced by BMP4 even in the absence of MEF feeder cells (Ying et al., 2003). BMP4 activates the Smad pathway to induce inhibitor of differentiation (Id) genes. Additionally, it inhibits ERK and p38 MAP kinase pathways that are responsible for differentiation (Qi et al., 2004). Taken together, in the conventional so-called "LIF/serum" culture regime, LIF and BMP4 synergistically maintain selfrenewing ESCs via induction of pluripotency and inhibition of differentiation, respectively.

More recently, a new serum-free regime for ESC culture was developed applying a chemically defined medium supplemented with LIF and two inhibitors (PD0325901 and CHIR99021) of the ERK signaling pathway and the GSK3 $\beta$, respectively. This so-called "LIF/2i" medium supports ESCs in the "ground state" in the absence of MEF feeder cells and serum (Ying et al., 2008). Although they show a great similarity to LIF/serum-cultured cells, ESCs adapted in LIF/2i manifest also some distinctive features: (1) while in LIF/serum ESCs, the expression of pluripotency markers like Nanog fluctuate, LIF/2i cells express these markers more uniformly; (2) LIF/2i ESCs express less c-Myc and lineage priming transcripts and more metabolic genes than LIF/serum cells; (3) in general, the total number of transcribed genes is less in LIF/2i, where the transcription is referred as "pausing" compared to LIF/serum, which is referred as "pause release"; (4) and finally in LIF/2i, polycomb repressive complex (PRC) targets are less occupied by the histone mark H3K27me3 (Marks et al., 2012). Apart from these differences, ESCs cultured in both 
conditions fulfill all the pluripotency-attributed criteria including indefinite self-renewal capacity, multi-lineage differentiation, and chimera formation.

\section{Chromatin configuration in ESCs versus differentiated cells}

The chromatin in the pluripotent stem cells is often considered as "open" in comparison to differentiated cells, which possess "closed" chromatin (Figure 3). This points to a higher ratio of euchromatin to heterochromatin observed in pluripotent cells. Euchromatin is associated with transcriptionally active loci, whereas heterochromatin specifies compacted and transcriptionally silenced genomic regions (Efroni et al., 2008; Gaspar-Maia et al., 2011; Park et al., 2004).

Mouse ESCs and ICM cells have a more dispersed chromatin than their progenies emerging during differentiation (Ahmed et al., 2010; Schaniel et al., 2009). Several histone modifications are distributed differentially over euchromatic and heterochromatic regions in ESCs and differentiated cells. For example, H3K9me3, which is enriched in heterochromatin, is less abundant in ESCs than differentiated cells (Meshorer et al., 2006). ChIP-chip experiments have shown that H3K9me2 is progressively distributed in chromatin during differentiation (Wen et al., 2009). ChIPseq analysis has revealed that H3K9me3 and H3K27me3 coverage in ESCs genome expands from $4 \%$ to $12 \%$ and $16 \%$, respectively, in differentiated cells (Hawkins et al., 2010). In comparison to low levels of these suppressive histone marks in ESCs, higher levels of active histone modifications, including H3K4me3 and acetylation, are distributed in their genome (Azuara et al., 2006; Meshorer et al., 2006), explaining open chromatin and active transcription in ESCs (Figure 3). ESCs have developed a unique strategy to suppress expression of multi-lineage differentiation genes and at the same time poise them for activation. This would prevent premature differentiation of ESCs and also sustain their ability to start differentiation upon receiving stimuli. At the onset of differentiation, repressive H3K27me3 is removed and activating H3K4me3 facilitates accessibility of the lineage-differentiation loci to RNA polymerase, launching the transcription.

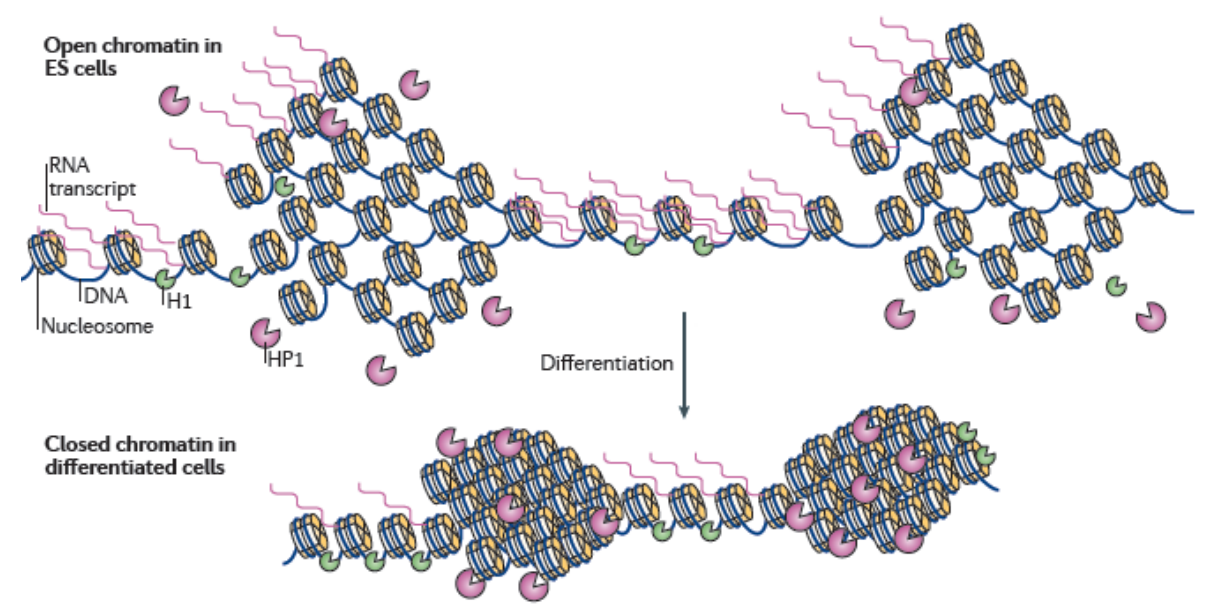




\section{Figure 3. Chromatin configuration changes upon differentiation of ESCs.}

Undifferentiated ESCs possess an open chromatin with a high accessibility for RNA polymerase to start transcription. As a result, the chromatin is less condensed and internucleosomal regions are covered by histone $\mathrm{H} 1$ (Upper scheme). Following differentiation, the configuration of chromatin is changed into a condensed heterochromatin containing more heterochromatin protein HP1, less active marks and more repressive histone modifications. Consequently, the related genomic regions are less transcribed or become silenced. Modified from (Gaspar-Maia et al., 2011)

\section{Development of extraembryonic tissue}

\section{Trophectoderm development}

The first fate decision in mouse embryo is made when segregation of extraembryonic trophectoderm (TE) and pluripotent inner cell mass (ICM) by morula stage at E2.5 (Figure 4). Following three rounds of cell division, the eight-cell stage is reached, where it undergoes compaction (Hyafil et al., 1980; Plusa et al., 2005; Vinot et al., 2005). Further cell cleavages would form 16-, 32-cell and finally blastocyst stages, in which outer cells surround the inner cells. This inside-outside polarity results in activation of Hippo signaling only in inner cells that eventually establishes pluripotent ICM (Nishioka et al., 2009). On the other hand, in the absence of Hippo signaling in the outer cells, TEA domain family transcription factor 4 (Tead4) activates TE-specific genes including caudal-related homeobox 2 (Cdx2) and GATA-binding protein 3 (Gata3) that triggers differentiation toward TE and formation of placenta (Dietrich and Hiiragi, 2007; Niwa et al., 2005). This finally establishes the mutually exclusive expression of $\mathrm{Cdx} 2$ in the TE and pluripotencyrelated transcription factors Oct4, Nanog, and Sox2 in the pluripotent ICM (Figure $5 A)$. 


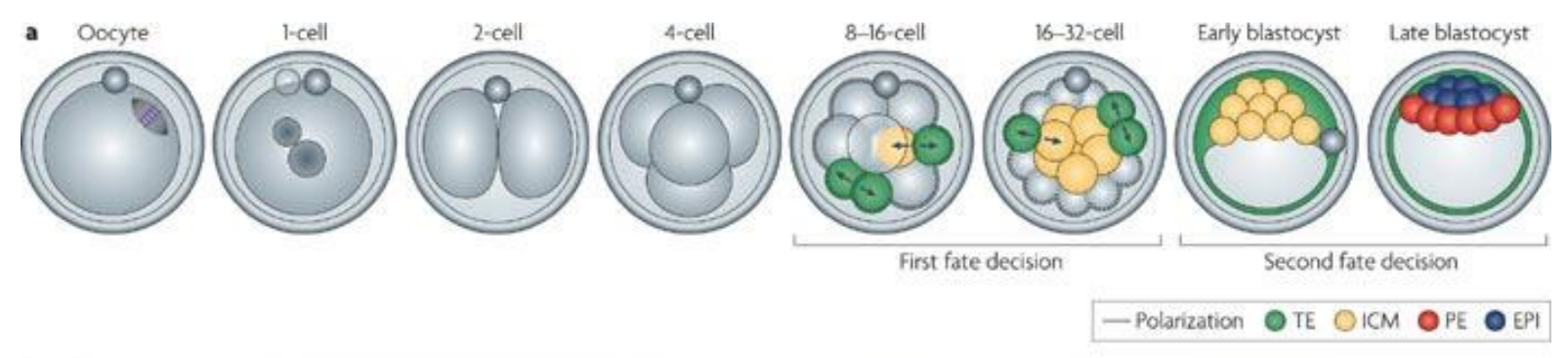

Figure 4. Different stages of preimplantation development in mice.

As the consequence of two successive waves of asymmetric cell division starting at the 8-16cell stage transition, pluripotent ICM cells are set aside from outer cells. The outer cells turn into trophectoderm (TE) in the first cell fate decision. In the second cell fate decision, primitive endoderm (PE) is formed at the surface of the ICM and in the deeper layers epiblast (EPI) cells are developed. Modified from (Zernicka-Goetz et al., 2009).

\section{Development of extraembryonic endoderm}

The second fate decision is made in the ICM and segregates primitive endoderm (PrE) from the epiblast. Epiblast cells locate inside the ICM, express pluripotency markers Nanog and Oct4 and contribute to the formation of derivatives of somatic lineages (i.e. ectoderm, mesoderm, and endoderm) as well as germ cell, while PrE cells line underneath the ICM, face the blastocoel cavity, express Gata6 and Gata4, and give rise to visceral and parietal endoderm. Originally, Nanog and Gata6 are coexpressed in 8- to 16-cell stage morula, until in the late blastocyst their expression is restricted to epiblast and PrE cells, respectively (Guo et al., 2010). This segregation is controlled by FGF-mediated activation of MAP kinase signaling and a differential distribution of FGF4, SH2/SH3 adaptor (Grb2), FGF receptor 2 (Ffgr2) expression during blastocyst formation (Chazaud et al., 2006). The involvement of FGF signaling in the formation of PrE is confirmed using Erk inhibitor that results in the elimination of Gata4-expressing PrE cells in the blastocysts (Nichols et al., 2009). Epiblast- and PrE-progenitors are distributed randomly in early blastocysts. FGF4 expression is increased in the putative epiblast progenitors. In parallel, Fgfr2 expression is elevated in PrE-fated cells (Guo et al., 2010). This triggers MAP kinase signaling in these cells, which in turn launches differentiation program toward PrE (Figure 5B). Thus, the development of the PrE and the ICM cells are finely tuned by mutual inhibition of Nanog and Gata4 expression, respectively. 
A

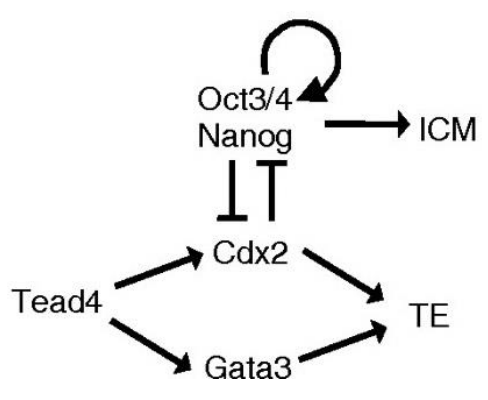

B

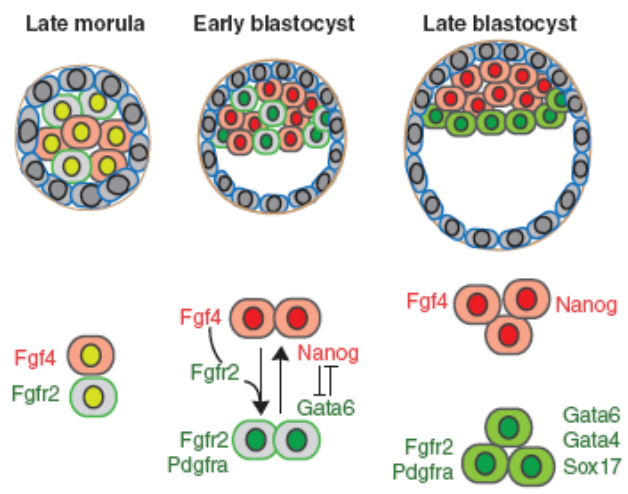

Figure 5. The underlying molecular mechanism of preimplantation development.

(A) The transcriptional network regulating specification of ICM and TE. Tead4 induces Cdx2 and Gata3, which together act to specify TE. A reciprocal inhibition between $\mathrm{Cdx} 2$ and Oct4/Nanog restricts Cdx2 expression to TE cells, while the expression of Oct4 and Nanog is gradually confined to ICM cells. Modified from (Takaoka and Hamada, 2012).

(B) Upper panel: Heterogeneous populations in the ICM of the early blastocyst comprising of epiblast (Epi, red) and primitive endodermal (PE, green) progenitors. These cells express Nanog or Gata6, respectively, in a mutually exclusive manner. Lower panel: Nanog and Gata6 inhibit each other, leading to the segregation of the two lineages, which is derived by Fgf4/Erk signaling. Although the fate of the cells can still be modulated after initial expression of Nanog and Gata6, this plasticity is gradually lost at E4.0. Trophectoderm is depicted in gray. Figures are from (Lanner and Rossant, 2010). 


\section{Aim of the thesis}

This study was initiated to unravel function of Mad2l2 in the development of mouse PGCs, and in the pluripotency of mouse ESCs. The following questions were in the focus of project:

1. What is the precise time window of PGC loss in Mad2/2 ${ }^{-/}$embryos?

2. How is the epigenetic reprogramming affected in Mad2/2/- PGCs?

3. How is the cell cycle affected in Mad212 ${ }^{-/}$PGCs?

4. What is the molecular mechanism of Mad2/2 function in the epigenetic reprogramming and cell cycle progression in PGCs?

5. How is the pluripotency affected in Mad2/2 ${ }^{-/-}$ESCs?

6. What is the identity of differentiated cells in Mad212 ${ }^{-1-} \mathrm{ESC}$ cultures?

7. What is the molecular mechanism of Mad2I2 function in the maintenance of pluripotency? 


\section{Materials and methods}

\section{Solutions and buffers}

\section{PBS buffer (20X)}

\begin{tabular}{|l|c|}
\hline Ingredients & Final concentration (g/L) \\
\hline $\mathrm{NaCl}$ & 160 \\
\hline $\mathrm{KCl}$ & 4 \\
\hline $\mathrm{Na}_{2} \mathrm{HPO}_{4} \cdot 2 \mathrm{H}_{2} \mathrm{O}$ & 28.8 \\
\hline $\mathrm{KH}_{2} \mathrm{PO}_{4}$ & 4.8 \\
\hline
\end{tabular}

\section{Gelatin (0.1\%)}

$1 \mathrm{~g}$ Gelatin type A (from porcine skin; Sigmaaldrich) was dissolved in 1 litter $\mathrm{dH}_{2} \mathrm{O}$ and then autoclaved. Culture dishes were coated by this solution for at least $30 \mathrm{~min}$.

\section{ES/Trypsin}

$50 \mathrm{ml}$ Trypsin solution was mixed with $150 \mathrm{ml}$ Saline/EDTA, filtered, and was frozen.

\section{Trypsin solution}

\begin{tabular}{|l|c|}
\hline Ingredients & Final concentration (g/L) \\
\hline $\mathrm{NaCl}$ & 8.0 \\
\hline $\mathrm{KCl}$ & 0.4 \\
\hline $\mathrm{Na}_{2} \mathrm{HPO}_{4}$ & 0.1 \\
\hline Glucose & 1.0 \\
\hline Tris base & 3.0 \\
\hline Trypsin & 2.5 \\
\hline \multicolumn{2}{|c|}{ Adjust $\mathrm{pH}$ to 7.6; aliquot and freeze } \\
\hline
\end{tabular}

\section{Saline/EDTA}

\begin{tabular}{|l|c|}
\hline Ingredients & Final concentration $(\boldsymbol{g} / \mathbf{L})$ \\
\hline $\mathrm{EDTA}$ & 0.2 \\
\hline $\mathrm{NaCl}$ & 8.0 \\
\hline $\mathrm{KCl}$ & 0.2 \\
\hline $\mathrm{Na}_{2} \mathrm{HPO}_{4}$ & 1.36 \\
\hline $\mathrm{KH}_{2} \mathrm{PO}_{4}$ & 0.2 \\
\hline \multicolumn{2}{|c|}{ Adjust pH to 7.2; aliquot and freeze } \\
\hline
\end{tabular}

\section{DNA lysis buffer}

\begin{tabular}{|l|c|}
\hline Ingredients & Final concentration \\
\hline Tris. $\mathrm{HCl} \mathrm{pH}=8.0$ & $100 \mathrm{mM}$ \\
\hline $\mathrm{EDTA}$ & $5 \mathrm{mM}$ \\
\hline $\mathrm{NaCl}$ & $200 \mathrm{mM}$ \\
\hline $\mathrm{SDS}$ & $0.2 \%$ \\
\hline \multicolumn{2}{|c|}{ Autoclave, and add Proteinase $\mathrm{K}$ before use. } \\
\hline
\end{tabular}


RIPA buffer for protein lysis

\begin{tabular}{|l|c|}
\hline Ingredients & Final concentration \\
\hline $\mathrm{NP}-40$ & $1 \%$ \\
\hline $\begin{array}{l}\mathrm{NaDOC} \\
\text { (Natriumdeoxycholate) }\end{array}$ & $0.25 \%$ \\
\hline Tris. $\mathrm{HCl} \mathrm{pH=7.4}$ & $50 \mathrm{mM}$ \\
\hline $\mathrm{NaCl}$ & $150 \mathrm{mM}$ \\
\hline EDTA $\mathrm{pH}=8.0$ & $1 \mathrm{mM}$ \\
\hline
\end{tabular}

\section{Electrophoresis buffer (10X) for WB}

\begin{tabular}{|l|c|}
\hline Ingredients & Amount \\
\hline Tris base & $30.2 \mathrm{~g}$ \\
\hline Glycine & $144 \mathrm{~g}$ \\
\hline SDS $10 \%$ & $100 \mathrm{ml}$ \\
\hline Up to 1 litter dH2O \\
\hline
\end{tabular}

\section{Transfer buffer for WB}

\begin{tabular}{|l|c|c|}
\hline Ingredients & Amount & Final concentration \\
\hline Tris & $29 \mathrm{~g}$ & $48 \mathrm{mM}$ \\
\hline Glycine & $14.5 \mathrm{~g}$ & $3.9 \mathrm{mM}$ \\
\hline SDS $10 \%$ & $18.5 \mathrm{ml}$ & $0.037 \%$ \\
\hline Methanol & $1 \mathrm{I}$ & $20 \%$ \\
\hline \multicolumn{2}{|l|}{ First the powders were dissolved in $\mathrm{dH} 2 \mathrm{O}$ and then methanol was added. } \\
\hline
\end{tabular}

Stacking buffer (4X) for WB

\begin{tabular}{|l|c|c|}
\hline Ingredients & Amount (for $\mathbf{5 0} \mathbf{~ m l}$ ) & Final concentration \\
\hline Tris & $3.025 \mathrm{~g}$ & $0.5 \mathrm{M}$ \\
\hline $\mathrm{SDS} 10 \%$ & $2 \mathrm{ml}$ & $0.4 \%$ \\
\hline Adjust $\mathrm{pH}$ at 6.8 & \multicolumn{2}{|l}{} \\
\hline
\end{tabular}

\section{Separation buffer (4X) for WB}

\begin{tabular}{|l|c|c|}
\hline Ingredients & Amount (for $\mathbf{5 0} \mathbf{~ m l}$ ) & Final concentration \\
\hline Tris & $9.08 \mathrm{~g}$ & $1.5 \mathrm{M}$ \\
\hline $\mathrm{SDS} 10 \%$ & $2 \mathrm{ml}$ & $0.4 \%$ \\
\hline Adjust $\mathrm{pH}$ at 8.8 & \\
\hline
\end{tabular}

Stacking gel (5\%) for WB

\begin{tabular}{|l|c|}
\hline Ingredients & Amount \\
\hline 4X stacking buffer & $1.25 \mathrm{ml}$ \\
\hline Polyacrylamide $30 \%$ & $830 \mu \mathrm{l}$ \\
\hline $\mathrm{dH}_{2} \mathrm{O}$ & $2.92 \mathrm{ml}$ \\
\hline $\mathrm{APS} 10 \%$ & $30 \mu \mathrm{l}$ \\
\hline TEMED & $10 \mu \mathrm{l}$ \\
\hline
\end{tabular}

Separation gel (12\%) for WB

\begin{tabular}{|l|c|}
\hline Ingredients & Amount \\
\hline 4X stacking buffer & $3.75 \mathrm{ml}$ \\
\hline Polyacrylamide $30 \%$ & $6 \mathrm{ml}$ \\
\hline
\end{tabular}




\begin{tabular}{|l|c|}
\hline $\mathrm{dH}_{2} \mathrm{O}$ & $5.25 \mathrm{ml}$ \\
\hline APS $10 \%$ & $100 \mu \mathrm{l}$ \\
\hline TEMED & $20 \mu \mathrm{l}$ \\
\hline
\end{tabular}

\section{ECL developing solution}

\begin{tabular}{|l|c|}
\hline Solution A (keep at $4{ }^{\circ} \mathrm{C}$ ) & Amount \\
\hline Ingredients & $200 \mathrm{ml}$ \\
\hline Tris. $\mathrm{HCl}(\mathrm{pH}=8.6)$ & $50 \mathrm{mg}$ \\
\hline Luminol (Sigma A4685) & Amount \\
\hline Solution B (keep at room temperature) & $20 \mathrm{ml}$ \\
\hline Ingredients & $22 \mathrm{mg}$ \\
\hline DMSO & \\
\hline Para-Hydroxycoumarin acid (Sigma C9008) & Mix 5 ml solution A, a.5 $\mathrm{ml} \mathrm{H2O2} \mathrm{(30 \% ),} \mathrm{and} 500 \mu$ solution B for 2 minutes before use. \\
\hline
\end{tabular}

\section{Paraformaldehyde (PFA) 4\%}

$40 \mathrm{~g}$ paraformaldehyde was dissolved entirely in 1 litter pre-warmed PBS (around 65 ${ }^{\circ} \mathrm{C}$ ) with 7-8 drops of $10 \mathrm{M} \mathrm{NaOH}$. The $\mathrm{pH}$ was adjusted at 7.8 by addition of $1 \mathrm{M}$ $\mathrm{NaOH}$ or $\mathrm{HCl}$.

\section{Alkaline Phosphatase (AP) staining buffers}

\section{AP buffer for cell culture}

\begin{tabular}{|l|c|}
\hline Ingredients & Final concentration \\
\hline Tris. $\mathrm{HCl} \mathrm{pH}=9.5$ & $100 \mathrm{mM}$ \\
\hline $\mathrm{NaCl}$ & $100 \mathrm{mM}$ \\
\hline $\mathrm{MgCl}_{2}$ & $50 \mathrm{mM}$ \\
\hline
\end{tabular}

\section{AP buffer for whole mount}

\begin{tabular}{|l|c|}
\hline Ingredients & Final concentration \\
\hline Tris. $\mathrm{HCl} \mathrm{pH}=9.5$ & $100 \mathrm{mM}$ \\
\hline $\mathrm{NaCl}$ & $100 \mathrm{mM}$ \\
\hline $\mathrm{MgCl}_{2}$ & $50 \mathrm{mM}$ \\
\hline Tween 20 & $0.1 \%$ \\
\hline
\end{tabular}

\section{Cell culture media}

Ingredients of different culture media were as following. For N2B27 ESC medium (LIF/2i), DDM and B27 media were mixed (1:1). LIF, CHIR 99021 (3 $\mu \mathrm{M})$ and PD $0325901(1 \mu \mathrm{M})$ were added and filtered.

\section{Components of MEF medium}

\begin{tabular}{|l|c|}
\hline \multicolumn{1}{|c|}{ Ingredients } & Final concentration \\
\hline DMEM & $1 \mathrm{x}$ \\
\hline Fetal Bovine Serum (FBS) & $10 \%$ \\
\hline Sodium Pyruvate & $1 \mathrm{mM}$ \\
\hline Penicillin & $10^{4} \mathrm{Units} / \mathrm{ml}$ \\
\hline Streptomycin & $10 \mathrm{mg} / \mathrm{ml}$ \\
\hline
\end{tabular}


Components of conventional ESC medium (LIF/Serum condition)

\begin{tabular}{|l|c|}
\hline \multicolumn{1}{|c|}{ Ingredients } & Final concentration \\
\hline KO-DMEM & $1 \mathrm{x}$ \\
\hline Fetal Bovine Serum (FBS) & $20 \%$ \\
\hline Sodium Pyruvate & $1 \mathrm{mM}$ \\
\hline MEM Non-essential amino acids & $0.1 \mathrm{mM}$ \\
\hline L-Glutamine & $2 \mathrm{mM}$ \\
\hline 2-mercaptoethanol & $100 \mu \mathrm{M}$ \\
\hline Penicillin & $10^{4} \mathrm{Units} / \mathrm{ml}$ \\
\hline Streptomycin & $10 \mathrm{mg} / \mathrm{ml}$ \\
\hline Leukemia Inhibitory Factor (LIF) & $10^{3} \mathrm{Units} / \mathrm{ml}$ \\
\hline
\end{tabular}

Components of N2B27 ESC medium (LIF/2i condition)

\begin{tabular}{|c|c|}
\hline \multicolumn{2}{|l|}{ DDM medium } \\
\hline Ingredients & Final concentration \\
\hline DMEM:F12 with Glutamax & $1 \mathrm{x}$ \\
\hline Sodium Pyruvate & $1 \mathrm{mM}$ \\
\hline MEM Non-essential amino acids & $0.1 \mathrm{mM}$ \\
\hline 2-mercaptoethanol & $100 \mu \mathrm{M}$ \\
\hline Penicillin & $10^{4}$ Units $/ \mathrm{ml}$ \\
\hline Streptomycin & $10 \mathrm{mg} / \mathrm{ml}$ \\
\hline Bovine serum albumin fraction $\mathrm{V}$ & $1 / 150(\mathrm{v} / \mathrm{v})$ \\
\hline N2 supplement & $1 \mathrm{x}$ \\
\hline \multicolumn{2}{|l|}{ B27 medium } \\
\hline Ingredients & Final concentration \\
\hline Neurobasal medium & $1 \mathrm{x}$ \\
\hline B27 supplement & $1 \mathrm{x}$ \\
\hline L-Glutamine & $2 \mathrm{mM}$ \\
\hline
\end{tabular}

\section{Antibodies}

Following antibodies were used in this study:

Table 1. List of primary antibodies

\begin{tabular}{|c|c|c|c|c|}
\hline Antibody & Host & Dilution for IF & $\begin{array}{l}\text { Dilution } \\
\text { for WB }\end{array}$ & Company/source \\
\hline Anti-Cyclin B1 & Rabbit & $1: 100$ & $1: 1000$ & Sigma-Aldrich \\
\hline $\begin{array}{c}\text { Anti-phospho-Histone H3 } \\
\text { (ser10) }\end{array}$ & mouse & $1: 200$ & $1: 2000$ & Cell Signaling \\
\hline anti-HA & rat & $1: 100$ & $1: 1000$ & Roche \\
\hline anti- $\gamma$ Tubulin & mouse & $1: 200$ & & Abcam \\
\hline anti-Cdk1 & mouse & $1: 50$ & $1: 500$ & Santa Cruz \\
\hline anti-pCdk1 & rabbit & $1: 50$ & & Cell Signaling \\
\hline anti-Oct4 & mouse & $1: 100$ & $1: 1000$ & BD \\
\hline anti-Oct4 & rabbit & $1: 100$ & $1: 1000$ & Abcam \\
\hline anti-SSEA1 & mouse & $1: 100$ & & Santa Cruz \\
\hline anti-Nanog & rabbit & $1: 100$ & $1: 1000$ & abcam \\
\hline anti-Sox2 & rabbit & $1: 200$ & $1: 1000$ & Millipore \\
\hline anti-H3K9me2 & rabbit & $1: 100$ & $1: 1000$ & Upstate \\
\hline anti-H3K9me2 & rabbit & $1: 100$ & $1: 1000$ & Millipore \\
\hline anti-G9a & rabbit & $1: 25$ & $1: 500$ & Cell Signaling \\
\hline anti-GLP & mouse & $1: 50$ & $1: 500$ & Abcam \\
\hline anti-Mad2l2 & rabbit & $1: 100$ & $1: 2000$ & Abcam \\
\hline
\end{tabular}




\begin{tabular}{|c|c|c|c|c|}
\hline anti-Mad2I2 & Mouse & $1: 100$ & $1: 1000$ & BD \\
\hline anti- $\gamma$ H2AX & mouse & $1: 200$ & $1: 2000$ & Millipore \\
\hline anti-pChk2 & rabbit & $1: 200$ & & Cell Signaling \\
\hline anti-Ezh2 & rabbit & $1: 200$ & $1: 2000$ & Cell Signaling \\
\hline anti-pEzh2 T487 & rabbit & $1: 100$ & $1: 1000$ & Epitomics \\
\hline anti-H3K4me2 & rabbit & $1: 100$ & $1: 1000$ & Active Motif \\
\hline anti-H3K27me3 & rabbit & $1: 100$ & $1: 1000$ & Active Motif \\
\hline anti-Dppa3 & rabbit & $1: 500$ & & Abcam \\
\hline anti-H3K4me3 & rabbit & & $1: 1000$ & Abcam \\
\hline anti- $\beta$-actin & mouse & & $1: 2000$ & Sigmaaldrich \\
\hline anti-Tubulin & mouse & & $1: 2000$ & Sigmaaldrich \\
\hline Anti-Erk1/2 & rabbit & $1: 2000$ & Cell Signaling \\
\hline Anti-phospho-Erk1/2 & rabbit & $1: 2000$ & Cell Signaling \\
\hline
\end{tabular}

Table 2. List of secondary antibodies

\begin{tabular}{|c|c|c|c|}
\hline Antibody & Host & Dilution & Company/source \\
\hline Alexa Fluor ${ }^{\circledR} 568$ anti-mouse IgM & Goat & $1: 1000$ & Invitrogen \\
\hline Alexa Fluor ${ }^{\circledR} 594$ anti-mouse IgG & Goat & $1: 1000$ & Invitrogen \\
\hline Alexa Fluor ${ }^{\circledR} 488$ anti-mouse IgM & Goat & $1: 1000$ & Invitrogen \\
\hline Alexa Fluor ${ }^{\circledR} 594$ anti-rabbit IgG & Goat & $1: 1000$ & Invitrogen \\
\hline Alexa Fluor ${ }^{\circledR} 488$ anti-rabbit IgG & Goat & $1: 1000$ & Invitrogen \\
\hline Alexa Fluor ${ }^{\circledR} 488$ anti-rat IgG & Goat & $1: 1000$ & Invitrogen \\
\hline Alexa Fluor ${ }^{\circledR} 594$ anti-rat IgG & Goat & $1: 1000$ & Invitrogen \\
\hline Alexa Fluor ${ }^{\circledR} 647$ anti-rabbit IgG & Goat & $1: 500$ & Invitrogen \\
\hline HRP-conjugated anti-mouse & Goat & $1: 10000$ & Abcam \\
\hline HRP-conjugated anti-rat & Goat & $1: 10000$ & Abcam \\
\hline HRP-conjugated anti-rabbit & Goat & $1: 10000$ & $\begin{array}{c}\text { Jackson Immuno } \\
\text { Research }\end{array}$ \\
\hline HRP-conjugated anti-goat & Rabbit & $1: 10000$ & $\begin{array}{c}\text { Jackson Immuno } \\
\text { Research }\end{array}$ \\
\hline
\end{tabular}

\section{Immunocytochemistry}

Cells on chamber slides were washed twice, fixed for 20 min with formaldehyde, permeablized with $0.1 \%$ Tween 20 , and blocked for 1 hour in $10 \%$ normal goat serum $/ 1 \%$ bovine serum albumin. Primary antibodies were prepared in blocking solution and applied for 1-2h at room temperature. Alexa Fluor 594 goat anti-mouse lgG, Alexa Fluor 488 goat anti-mouse IgM, Alexa Fluor 488 goat anti-rabbit IgG, Alexa Fluor 594 goat anti-rabbit IgG, Alexa Fluor 594 goat anti-rat IgG, or Alexa Fluor 488 goat anti-rat lgG were used as secondary antibodies (all from Molecular Probes). The nucleus was counterstained with 4,6-Diamidin-2-phenylindol (DAPI, Vectashield).

\section{Immunohistochemistry}

Embryos were washed, fixed for 1 hour at $4^{\circ} \mathrm{C}$ in formaldehyde, washed three times, treated with $30 \%$ sucrose, immersed in a $1: 1$ mixture of Tissue Freezing 
Medium (Jung) and 30\% sucrose for 30-60 min, and then embedded. $10 \mu \mathrm{m}$ cryosections were washed, and permeablized for $10 \mathrm{~min}$ in $0.1 \%$ PBSTx (phosphate buffered saline/0.1\% Triton X-100). Blocking was performed for 1 hour with 10\% normal goat serum $/ 1 \%$ BSA. The incubation with the primary antibody was always performed overnight at $4^{\circ} \mathrm{C}$. Secondary antibodies were used as above, or the $A B C$ staining system (Santa Cruz) was applied.

\section{Whole mount staining}

Embryos were dissected in PBS and were fixed by PFA 4\% on ice for 30 minute to 1 hour, depending on the size of the embryo. PGC-containing portions of the embryos were further cut into smaller pieces to ease antibody penetration. Embryo pieces were permeablized by $1 \%$ PBSTx for 45 minutes on ice and then were incubated for 4 days with primary antibodies diluted in blocking solution (BSA 1\%, normal goat serum $10 \%$ in PBSTx 1\%). After washing, embryo pieces were incubated for two days with secondary antibodies and Hoechst 33258 in blocking solution then washed and mounted on slides and were finally studied by confocal microscopy (Leica, SP5). To quantify the number of PGCs, the posterior portion of the embryos was subjected to alkaline phosphatase (AP) staining by incubation in NBT/BCIP substrate solution for 4-5 min at room temperature according to the manufacturer (Roche).

\section{Flowcytometry}

Cells were fixed for at least $30 \mathrm{~min}$ in $70 \%$ ethanol, stained with propidium iodide, treated for 30 min with RNase, and analyzed by flowcytometry (FACS Calibur).

\section{FACS sorting}

Two days after transfection of NIH3T3 cells with GFP-Mad2l2 expressing vector, they were trypsinized, washed with PBS, and then sorted by FACS Aria II (BD). Sorted cells were lysed in RIPA buffer (for protein isolation) or in RLT buffer (for RNA isolation). For ESCs, in order to sort GFP-expressing cells, they were washed and trypsinized and cell suspensions were subjected to FACS. Sorted cells were either cultured back on inactivated MEF feeders, or were lysed in RIPA buffer.

\section{Real-Time qRT-PCR}

Total RNA from GFP-Mad2l2 FACS-sorted samples was extracted with RNeasy kit (Qiagen), and DNA was digested by DNasel (Qiagen). cDNA was synthesized from 
$1 \mu \mathrm{g}$ RNA by reverse transcriptase (Omniscript, Qiagen) and a combination of random hexamere and oligo dT primers (Promega). $25 \mathrm{ng}$ cDNA per reaction was amplified by KAPA SYBR ${ }^{\circledR}$ FAST qPCR Master Mix (KAPA biosystems) in Real-time PCR with an Applied Biosystems 7300 Sequence Detection system. The Ct values were determined using default threshold settings. The expression levels of samples were normalized to GAPDH.

\section{Western blotting}

Protein extracts or immunoprecipitates were dissolved on gels by SDS-PAGE and then transferred to the nitrocellulose membranes. Unspecific antigens were masked by 1 -hour incubation with blocking solution ( $5 \%$ low-fat milk dissolved in $0.1 \%$ PBSTw). Membranes were incubated with primary antibodies diluted in blocking solution overnight at $4^{\circ} \mathrm{C}$ on shaking plate. After three times washing with $0.1 \%$ PBSTw, membranes were incubated for 1 hour at room temperature with HRPconjugated secondary antibodies diluted in blocking solution. Membranes were washed and developed after treating with Pico chemiluminescent substrate (Thermo Scientific).

\section{Immunoprecipitation}

Whole cell extracts from ESCs or HA-Mad2I2 transfected NIH 3T3 cells were precleared with normal control IgG antibodies (Upstate), and incubated for 1 hour at $4^{\circ}$ $C$ with primary antibodies. Precipitation was performed using Protein A/G PLUSAgarose Immunoprecipitation Reagent according to the manufacturer (Santa Cruz).

\section{GST-Mad212 preparation}

GST-fused Mad2l2 protein was prepared after Dr. Sven Pilarski (PhD thesis, Goettingen University). Briefly, it was expressed in and purified from E. coli. Full length Mad2l2 cDNA was cloned in frame with the N-terminal GST-tag into the pGEX-KT vector. Expression was induced by the addition of $1 \mathrm{mM}$ IPTG (isopropyl$\beta$-D-thiogalactopyranoside, Sigma). Bacterial cells were harvested; proteins were lysed on ice in $50 \mathrm{mM}$ Tris, pH 7.5, $500 \mathrm{mM} \mathrm{NaCl}, 2 \mathrm{mM}$ EDTA, $5 \mathrm{mM}$ DTT, 10\% glycerol, freshly added $1 \mathrm{mM}$ PMSF and Complete ${ }^{\mathrm{TM}}$-EDTA protease inhibitor tablet (Roche). Glutathione Sepharose 4B (Amersham Biosciences) was used to purify the GST-fused protein. The elution was done twice, each time with $2 \mathrm{ml}$ elution buffer 
(500 mM Tris, pH 8.0, 100 mM Glutathione supplemented with protease inhibitor). The protein was dialyzed in dialysis buffer $(20 \mathrm{mM}$ Tris- $\mathrm{HCl} \mathrm{pH} 7.5)$ using a dialysis cassettes (Pierce) at $4^{\circ} \mathrm{C}$ overnight. The protein concentrations were measured and determined according to the standard curve.

\section{Kinase assay}

Kinase activity of Cdk1-cyclin B1 was analyzed using purified, recombinant proteins (CycLex), and a human Cdc7 peptide as substrate, applying an assay system from CycLex (Zhan et al., 1999). To test effect of Mad2l2 on kinase activity of Cdk1-Cyclin B1, dilutions of GST-Mad2I2 or GST alone protein were incubated for 15 min at $37^{\circ}$ C with 12.5 mUnits of recombinant kinase. These protein mixes were individually given into substrate-coated wells, and incubated for $45 \mathrm{~min}$ at $37^{\circ} \mathrm{C}$. For detection of phospho-Cdc7 a specific monoclonal antibody (TK-3H7) and HRP-conjugated antimouse IgG was applied, and the absorbance at $450 \mathrm{~nm}$ was measured.

\section{TUNEL assay}

Programmed cell death was analyzed using the TUNEL assay (Millipore) on chamber slides or embryo cryosections. The assay was followed by immunostaining against SSEA1.

\section{Primers used for genotyping or qRT-PCR}

Genotyping was performed using following primers:

\section{Primer used for genotyping Mad2I2 locus}

\begin{tabular}{|l|l|}
\hline Primer \#1 & GCTCTTATTGCCTTGACATGTGGCTGC \\
\hline Primer \#2 & GGACACTCAGTTCTGGAAAGGCTGG \\
\hline Primer \#3 & CTGCAGCCCAATTCCGATCATATTCAATAAC \\
\hline
\end{tabular}

\section{Primer used for genotyping Cre transgene}

\begin{tabular}{|l|l|}
\hline Transgene Forward & ATGCTTCTGTCCGTTTGCCG \\
\hline Transgene
\end{tabular}

\begin{tabular}{l|l} 
Transgene Reverse & CCTGTTTTGCACGTTCACCG
\end{tabular}

\section{Primer used for genotyping GFP transgene}

\begin{tabular}{|l|l|}
\hline Transgene Forward & GCC GAG GTG CGC GTC AGT AC \\
\hline Transgene Reverse & CTGAACATGTCCATCAGGTTCTTG \\
\hline Internal Positive Control Forward & CTAGGCCACAGATTGAAAGATCT \\
\hline Internal Positive Control Reverse & GTAGGTGGAATTCTAGCATCATCC \\
\hline
\end{tabular}




\section{Primer used for qRT-PCR}

\begin{tabular}{|l|l|}
\hline GLP-forward & TCTGACCTGAGTTCTGAATCC \\
\hline GLP-reverse & TTTCTACTTCTCCGCCTCCT \\
\hline G9a-forward & CTCCATGCTGTCAACTACCA \\
\hline G9a-reverse & GTGTCTCCTTCTTTGTTCCGA \\
\hline
\end{tabular}

\section{Transgenic mice}

Oct4-GFP transgenic mice were kindly provided by H.R. Schöler (Szabo et al., 2002) The Prdm1-Cre mouse line was purchased from the Jackson Laboratory (B6.CgTg(Prdm1-cre)1Masu/J).

\section{Embryos}

The day of the vaginal plug was taken as E0.5, and embryos were dissected accordingly. Embryos were staged (Seki et al., 2007) by corresponding time and morphology as follows: before E8.0 (EHF), E8.0 (LHF), E8.25 (less than 5 somites), E8.5 (before turning, 6 to 8 somites), E8.75 (turning embryos, 10 to 12 somites), E9.0, (after turning, 14 to 18 somites, with only the first branchial arch obvious, and with open otic vesicles, E9.5 (two branchial arches, closed otic vesicles, 20-24 somites).

\section{Preparation of mouse embryonic fibroblasts (MEFs) and induction of}

\section{DNA damage}

MEFs were prepared from individual, genotyped E13.5 littermate embryos, and cultured as passage 0 (P0) in MEF medium and frozen. Cells not older than passage 1 were seeded on $0.1 \%$ gelatin-coated chamber slides (Nunc). MEFs were treated with cisplatin $(150 \mu \mathrm{g} / \mathrm{ml})$ for $1 \mathrm{~h}$, washed twice, and cultured in fresh medium for $19 \mathrm{~h}$ before analysis. NIH 3T3 fibroblasts were cultured in the same medium, and were transfected by Lipofectamine (Invitrogen) with an expression vector for the generation of N-terminally tagged HA-Mad2I2 based on pCMV-HA (Clontech).

\section{Derivation and culture of mouse embryonic stem cells}

Mouse ESCs were generated through the mating of OG2; Mad212 ${ }^{+/}$couples. 89 blastocysts were individually plated on mitomycin C-inactivated MEFs cultured in gelatin-coated 24-well culture dishes (day 0). N2B27 medium supplemented with LIF, 2i, and 20\% serum (LIF/Serum/2i) was used to feed the blastocysts (Ying et al., 
2008). During the first three days of culture, the dishes were kept in a completely inert position to avoid detachment of blastocysts. At day 3, the first medium change was done. At day 4, cells were trypsinized by $100 \mu \mathrm{l}$ ES-trypsin and single-cell suspension was made by pipetting up and down (with either $2 \mathrm{ml}$ pipette). The trypsin was neutralized with $1 \mathrm{ml}$ medium and then suspensions were plated individually in the same well of 4 -well culture dish. At day 6 or 7 , the first colonies emerged (passage \#1, P1) and the cultures were numbered based on the order of ESC colony appearance. At day 9, cultures were washed with PBS and were trypsinized with $175 \mu \mathrm{l}$ ES-trypsin, neutralized with $1 \mathrm{ml}$ medium and then plated on 12-well plates pre-cultured with fresh MEFs and pre-fed with $1 \mathrm{ml}$ ES medium (P2). Once get confluent, the cultures were either frozen or spitted to fresh MEFs and fed with fresh medium every other day. MEFs were eliminated by differential adhesion to gelatin-coated dishes and supernatant, which consisted of pure ESCs was used for DNA extraction and genotyping. ESCs were kept in LIF/2i/Serum regime up to the third passage, after which they were shifted to either LIF-Serum culture condition on MEFs or feeder-free LIF/2i condition.

\section{Mass spectrometery}

The Mad2l2 interaction analysis was performed using ESCs lysate from Mad212 ${ }^{+/}$ and Mad2l ${ }^{-/}$(negative control) cultures in $1 \mathrm{ml}$ RIPA buffer including a proteinase inhibitor cocktail (Roche). All the steps were performed at $4{ }^{\circ} \mathrm{C}$. The lysates were centrifuged for $10 \mathrm{~min}$ at $13000 \mathrm{rpm}$ to exclude non-digested cells. The supernatant was pre-cleared with normal mouse IgG together with protein $A / G$-agarose beads according to the manufacturer. Mouse anti-Mad2l2 antibody was used to precipitate Mad212 and the interacting proteins. Then, the beads were washed three times for five minutes with $500 \mu \mathrm{l}$ cold PBS buffer. Finally, the beads were incubated for 15 minutes at room temperature with $40 \mu \mathrm{l}$ elution buffer (2.5 ul 20\% SDS, $5 \mu \mathrm{l} 1 \mathrm{M}$ $\mathrm{NaHCO} 3$ and $42.5 \mu \mathrm{ldd} \mathrm{H}_{2} \mathrm{O}$ ).

The samples were suspended in NuPage loading buffer and resolved in a commercial SDS gel (Novex NuPage Bis-Tris gel, $4-12 \%$ gradient, Invitrogen) in department of Prof. Dr. Henning Urlaub. The individual columns were then cut into six squares for mass spectrometric analysis. The parameters for the identification of proteins were set to the following values: limit $=95 \%$ probability of detection, limit of unique peptides detected $=1$, threshold detection probability of peptides $=80 \%$. 


\section{Results:}

\section{Mad212 deficient fibroblasts fail to arrest after DNA damage}

To test the function of Mad212 in DNA damage response, mouse embryonic fibroblasts (MEFs) from E13.5 Mad2l2 ${ }^{-/}$embryos were investigated. These MEFs were completely devoid of Mad2l2 RNA and protein, and their proliferation was significantly impaired as indicated by a flattened growth curve and a significant decrease in the number of Ki-67 expressing cells (Dr. Sven Pilarski; PhD thesis, Göttingen University and Figure 6).

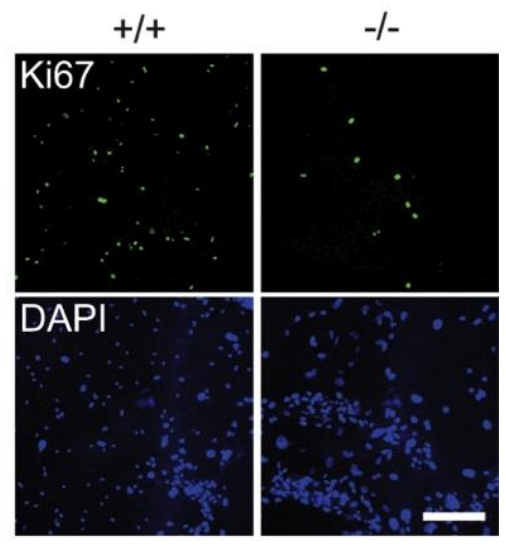

Figure 6. Impaired growth of Mad212-/ MEF.

Immunofluorescent staining of MEFs with anti-Ki67 antibody shows a decreased proliferation in Mad2l2/- MEFs.

In order to trigger their G2/M checkpoint, wild type and mutant MEFs were exposed to the DNA cross-linking agent cisplatin (Grossmann et al., 1999). The cell cycle status was checked by flow cytometry, mitotic entry by $\mathrm{pH} 3$ and nuclear Cyclin $\mathrm{B} 1$, the occurrence of DNA damage with an antibody against $\gamma \mathrm{H} 2 \mathrm{AX}$, and the activation of the checkpoint kinase cascade with an antibody against pChk2 (Grossmann et al., 1999; Hendzel et al., 1997; Nyberg et al., 2002; Pines and Hunter, 1991; Yuan et al., 2010). The observed differences between wild type and mutant MEFs were moderate, but became significant and obvious after DNA damage induction. Thus, the number of Mad212 ${ }^{-/}$cells in the G2/M fraction was significantly increased as compared to wild type cells (Figure 7A-C). More mutant than wild type MEFs had entered mitosis, had accumulated DNA double strand 
breaks, and activated the G2/M DNA damage checkpoint (Figure 7A-D). Many of the mutant MEFs did not survive a cisplatin exposure (Figure 7D), the majority of the remaining cells were simultaneously positive for $\gamma \mathrm{H} 2 \mathrm{AX}$ and pChk2, and the apoptotic cells were usually also positive for nuclear Cyclin B1 (Figure 7E). Thus, mutant cells did not arrest at the G2/M checkpoint, but continued to proceed into mitosis, and finally apoptosis.

A
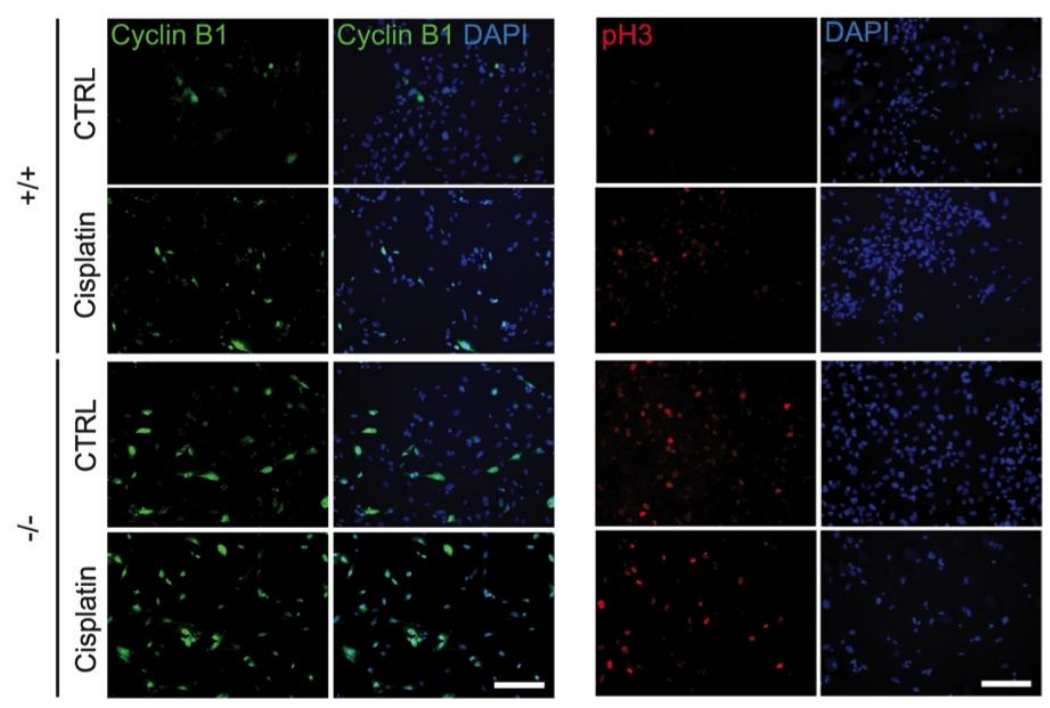

E
B
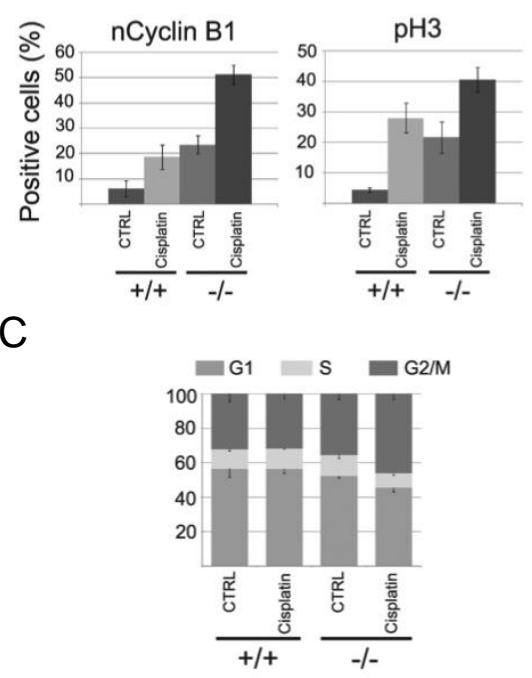

D
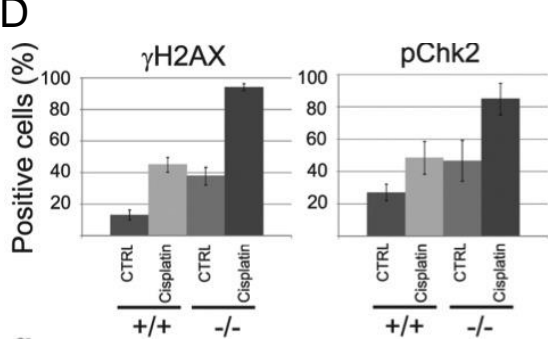

TUNEL
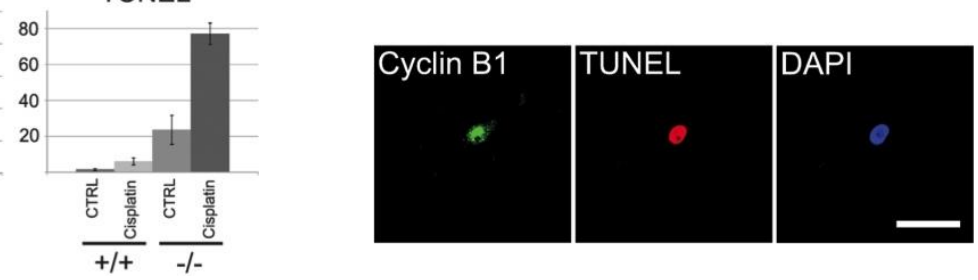

Figure 7. The response of $\mathrm{Mad}_{212^{-/-}} \mathrm{MEFs}$ to cisplatin treatment.

Mutant or wild type MEFs were exposed to cisplatin for 1 hour, and cultured for further 19 hours, unexposed cells were analyzed as controls (CTRL). (A) Representative immunostaining against Cyclin B1 and pH3. (B) Mean values of four independent experiments and standard deviations are indicated. (C) Cell cycle distribution of MEFs as determined by flowcytometry. (D) Quantification of cells with DNA damage $(\gamma \mathrm{H} 2 \mathrm{AX})$, activated DNA damage checkpoint (pChk2), and apoptosis (TUNEL). (E) Apoptotic cells, as identified in the TUNEL assay, express nuclear Cyclin B1 indicating cell death in mitosis. 


\section{Mad212\% germ cells are lost during early embryogenesis}

Low levels of Mad212 mRNA are widely expressed in adult and E14.5 embryonic cells, with a particularly high level in testis. High levels of Mad2l2 protein were detected in primary spermatocytes by immunohistochemistry (Dr. Sven Pilarski, unpublished data), while the antibody did not lead to specific signals above background in other tissues, including PGCs (Figures 8A, D).

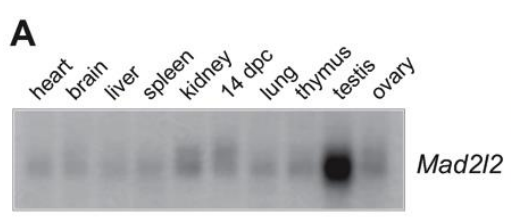

B

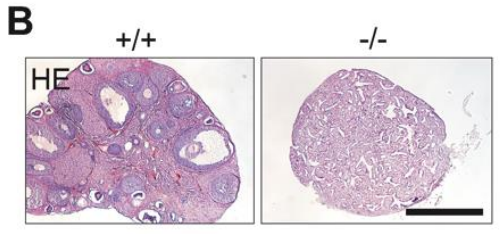

C

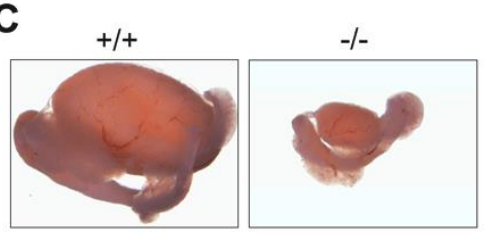

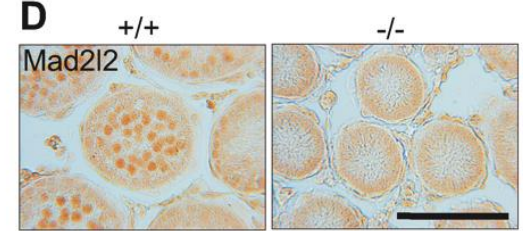
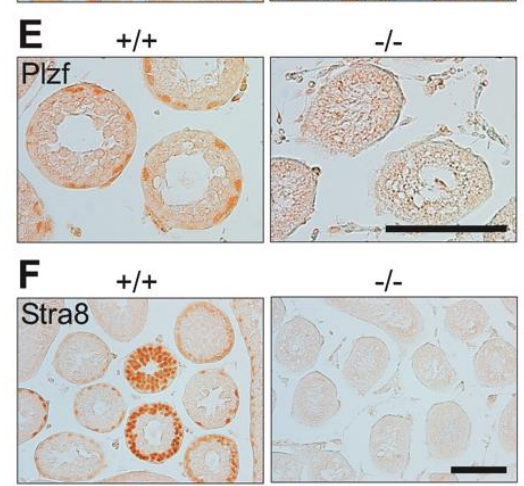
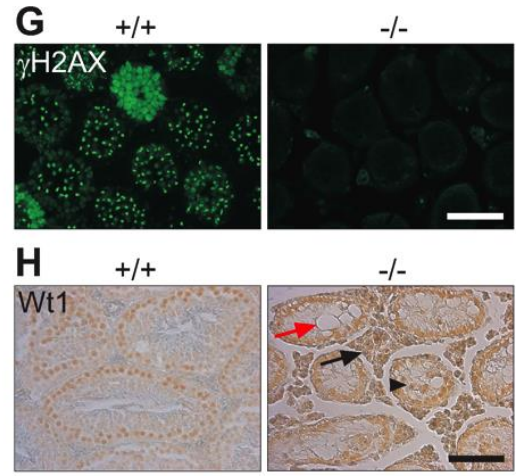

Figure 8. Mad2I2 expression and loss of germ cells from mutant ovaries and testes.

(A) Mad212 mRNA expression in adult murine organs and E14.5 embryos. For an actin loading control of this northern blot see (Pitulescu et al., 2009).

(B) Mad2I2 ${ }^{-/}$ovaries (P80) are smaller, and do not contain follicular or germ cells.

(C) Testes (P70) are significantly smaller in Mad212/- animals.

(D) Mad2l2 protein is expressed in differentiating, wild type spermatogonial cells.

(E-G) Mad2l2 ${ }^{-/}$seminiferous tubules lack spermatogonial stem cells as identified by Plzf, spermatogonial cells as identified by Stra8, and peri-meiotic cells as identified by $\gamma \mathrm{H} 2 \mathrm{AX}$.

(H) Mad2l2 ${ }^{-/}$seminiferous tubules contain highly vacuolated (red arrow) and miss-localized (arrowhead) Sertoli cells as identified by Wt1. Note hyperplasia of Leydig cells between seminiferous tubules (black arrow). Panels A, C-D are obtained by Dr. Sven Pilarski.

Scale bars in A, D-H $100 \mu \mathrm{m}$, in B, $400 \mu \mathrm{m}$.

Heterozygous Mad2l2 mutants were viable, healthy and fertile. Homozygous embryos and postnatal mice were significantly smaller than their littermates. They were born in sub-Mendelian ratio, but there was no evidence for increased postnatal lethality (Dr. Sven Pilarski; PhD thesis, Göttingen University). Homozygous males and females were infertile, and gonads were significantly underdeveloped. Ovaries of mutant females were small and lacked ovarian follicles or germ cells, or were not generated at all (Figure 8B). Mutant testes were drastically smaller than control 
organs of the same age, and seminiferous tubules were devoid of germ cells (Figure $8 \mathrm{E}-\mathrm{G})$. Leydig cells appeared hyperplastic, and Sertoli cells, identified by WT1 (Dame et al., 2006; Rogatsch et al., 1996), were mislocalized and highly vacuolated (Figure $8 \mathrm{H}$ ). Together, these findings suggest that Mad2l2 deficiency affects early germ cells before the separation of male and female development.

For the determination of PGC numbers, embryos were collected at different time points during early development, staged as outlined under experimental procedures, and PGCs were identified by the presence of alkaline phosphatase (AP) or Oct4 (Figure 9A).

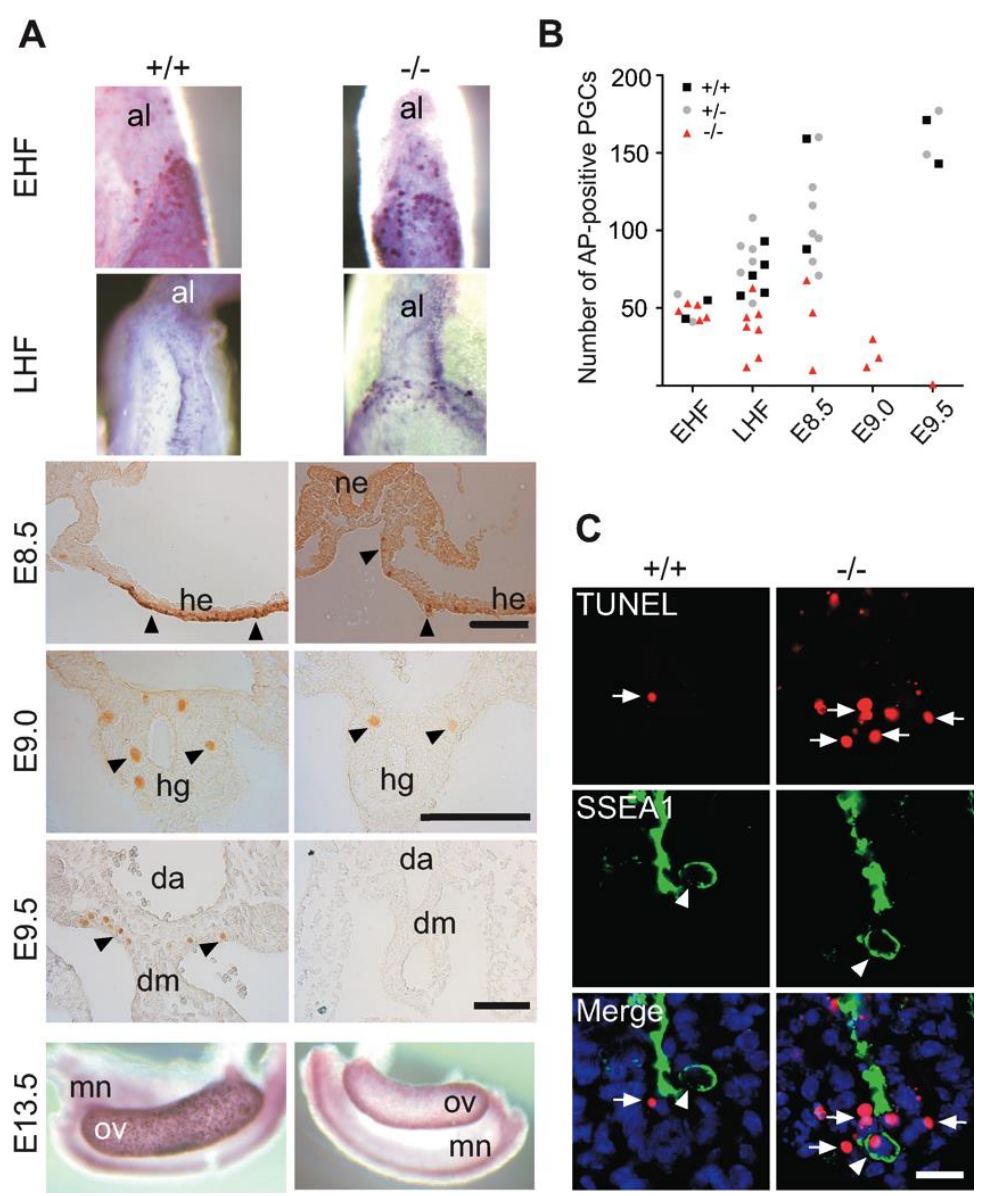

Figure 9. Loss and apoptosis of PGCs early after specification.

(A) AP-positive Mad2I2+/+ or Mad2I2-/- PGCs were detected in EHF and LHF stages. From E8.5 to E9.5, PGCs were detected by Oct4-immunostaining (arrowhead). At E13.5, Mad212-/- ovaries were devoid of germ cells detected by AP staining. Al: allantois; ne: neuroepithelium; he: hindgut epithelium; hg: hindgut; da: dorsal aorta; dm: dorsal mesentery; mn: mesonephros; ov: ovary. Scale bars, $100 \mu \mathrm{m}$.

(B) Quantification of PGCs detected by AP-staining in different developmental stages.

(C) Apoptosis (TUNEL assay) of SSEA1-expressing PGCs (arrowhead), and of surrounding, SSEA1-negative cells, putatively representing apoptotic PGCs (arrow) in E9.0 hindgut endoderm. Scale bar, $20 \mu \mathrm{m}$. 
At the early head fold (EHF) stage, the numbers of PGCs at the base of the allantois were similar in wild type, heterozygous and homozygous embryos. However, while the number of normal PGCs increased at the late head fold (LHF) stage, the number of Mad2l2/- PGCs fell behind (Figure 9A, B). It was decreased drastically from E8.5 onward, and at E9.0 only few instead of normally ca. 120 PGCs were found in the hindgut endoderm. At E9.5 and E10.5 Oct4-positive PGCs were no longer detected (Figure 9A, B). At E8.25, both wild type and remaining mutant PGCs co-expressed Oct4 together with Dppa3, indicating a normal specification of mutant PGCs (Figure 10A). Oct4 and Sox2 were co-expressed in all wild type PGCs with no exception. In contrast, above $40 \%$ of Oct4-positive Mad212/- PGCs did not express Sox2 at E9.0, and thus had either failed to reactivate, or at least to maintain its expression (Figure 10B). Emigration to the dorsal mesentery did not occur, and as a result, gonad primordia at E13.5 were completely devoid of germ cells (Figure 9A, B). All E9.0 Mad2I2/- PGCs had accumulated active, acetylated p53 protein (Figure $11 \mathrm{~A}$ ), reflecting an activated stress response and impending apoptosis (Sakaguchi et al., 1998). As judged by the TUNEL assay, some SSEA1-positive PGCs undergoing cell death were detected in E9.0 hindgut endoderm (Figure 9C). In addition, the same territory contained accumulations of SSEA1-negative, apoptotic cells suspiciously representing germ cells having lost already expression of their typical marker. In summary, Mad2I2/- PGCs were specified normally, but their numbers decreased progressively, and no PGCs survived to E9.5.

A

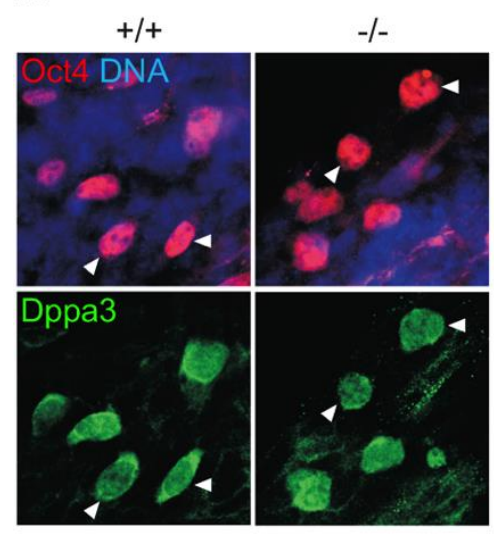

B

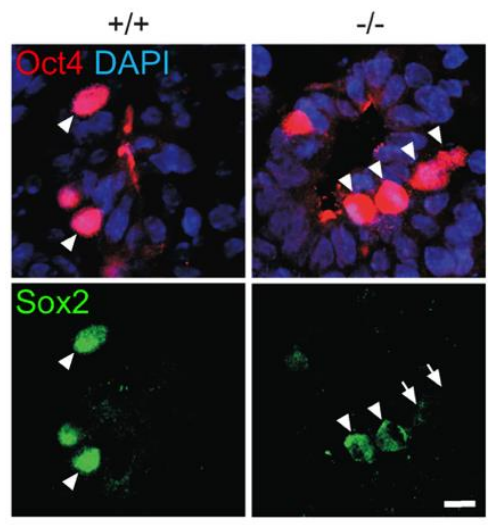

Figure 10. Expression of PGC-specific markers.

(A) Both wild type and knock out PGCs express Dppa3 and Prdm1 at E8.5. Scale bars: $20 \mu \mathrm{m}$. (B) Sox2 expression characterizes all Mad212 ${ }^{+/+}$PGCs at E9.0 $(100 \%$, 17/17). Many Mad2l2/- PGCs of the same stage were negative for Sox2 (44\%, 8/18; arrows), or were only weakly positive (arrowheads). 
Since Mad2I2 is the subunit of a repair DNA polymerase, we asked if Mad2l2 deficient PGCs are affected by DNA damage. We applied an antibody detecting phosphorylated ATM/ATR substrates (pATM/ATR-S) including Chk1, Chk2, and MDM2, as well as specific antibodies against pChk1 and pChk2, respectively. No positive PGCs were detected in either wild type or knockout embryos (Figure 11BD). Together, these observations indicate that Mad2l2 deficient PGCs are not lost due to DNA damage.

A

Oct4 DAP

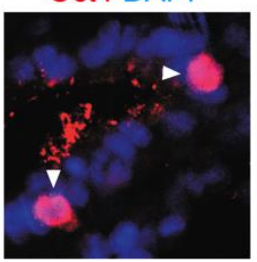

B

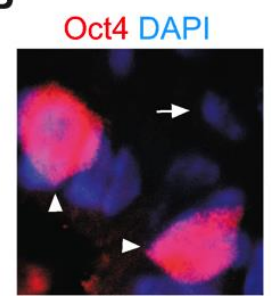

p53-Ac

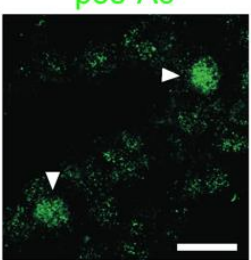

PATM/ATR-S

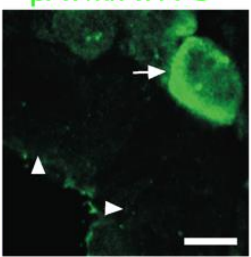

C

Oct4 DAPI
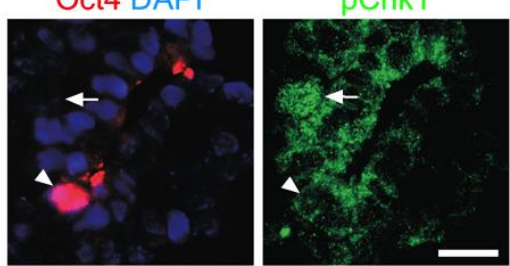

D

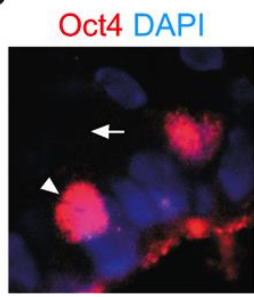

pChk2

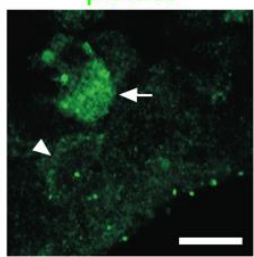

Figure 11. No activation of DNA damage response in apoptotic Mad2/2 ${ }^{-/}$PGCs.

(A) Mad212 ${ }^{-/}$PGCs expressed active, acetylated p53 (arrowheads, 100\%, 6/6). PGCs were identified by Oct4 immunohistochemistry on transverse sections of E9.0 embryos (arrowheads).

(B) No Oct4- and phospho ATM/ATR substrate-double positive PGCs were detected in Mad2I $2^{-/}$embryo section at E9.0 (arrowheads). Arrow indicates a positive somatic cell implying the proper staining.

(C, D) No Oct4- and phospho-Chk1 (C) or phospho-Chk2 (D) double positive Mad2/2/PGCs were detected at E9.0 (arrowheads). In contrast, occasionally, some somatic cells showed expression of these active DNA damage response markers (arrows). Scale bars: A and C, $20 \mu \mathrm{m}, \mathrm{B}$ and D, $10 \mu \mathrm{m}$. 


\section{Loss of Mad212 deficient PGCs is caused by an intrinsic failure}

Proper development of PGCs relies on their endogenous program as well as on exogenous signals emanating from surrounding somatic cells that support their induction, migration or survival in various organisms (Doitsidou et al., 2002; Goudarzi et al., 2012; Gu et al., 2009; Saitou, 2009b). To address the cause of early PGC loss in Mad2l2 deficient embryos, the Mad2l2 gene was deleted specifically in nascent PGCs taking the advantage of a Prdm1-Cre mouse line (Ohinata et al., 2005). The TUNEL assay demonstrated apoptosis in SSEA1-positive PGCs of Prdm1-Cre+, Mad212 ${ }^{\text {fl/fl }}$ embryos at E8.75 (Figure 12A). Moreover, TUNEL-positive, SSEA1negative cells with a high nuclear to cytoplasmic ratio were observed in the hindgut, probably representing more advanced, apoptotic PGCs (Figure 12A). Also some TUNEL-negative, SSEA1-positive PGCs were found, which is explained by the incomplete efficiency of Prdm1-Cre mediated deletion (Ohinata et al., 2005). In contrast, no appreciable apoptosis was observed in Prdm1-Cre; Mad2l ${ }^{\mathrm{f} / \mathrm{fl}}$ tissue sections of the same age (Figure 12A). Together, these findings demonstrated that Mad2I2 deficient PGCs did not survive even in a wild-type somatic environment.

A rescue assay was performed using mouse embryonic stem (ES) cells carrying a GFP reporter under the PGC-specific promoter of the Oct4 gene (Szabo et al., 2002). Mad212 ${ }^{+/}$, Oct4-GFP ${ }^{+/-}$ES cells manifested typical ES cell characteristics as judged by morphology, by expression of the pluripotency markers Nanog and Sox2, and by germline chimera formation (See ESC chapter of results). They were injected to 8-cell-stage embryos with wild type, heterozygous, or knockout genotypes, originating from mating of Mad2l2 heterozygous couples. Dissections of the re-transferred embryos at E10.5 showed the presence of Oct4-GFP positive germ cells in both heterozygous and knockout embryos. At E12.5 the numbers of PGCs in Mad2I2-deficient gonads resembled those in the heterozygote gonads (Figure 12B, C). These results suggest that normal ES cells can develop into germ cells in the microenvironment provided mainly by knockout somatic cells. Thus, the observed early loss of PGCs in Mad212 ${ }^{-1}$ embryos is caused by an intrinsic failure in PGCs, and does not result from deficits of the surrounding somatic cells. 
A
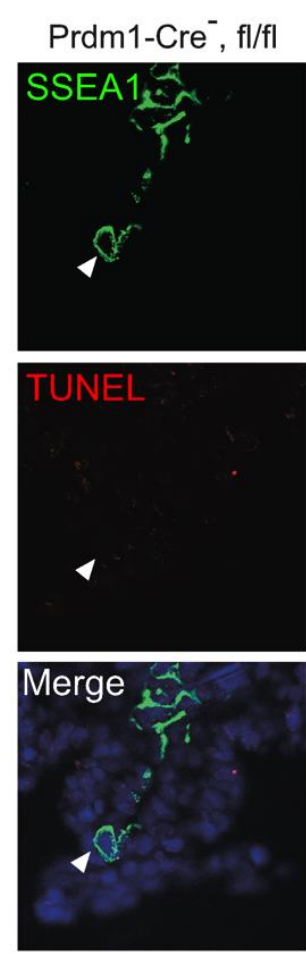

Prdm1-Cre ${ }^{+}$, fl/fl
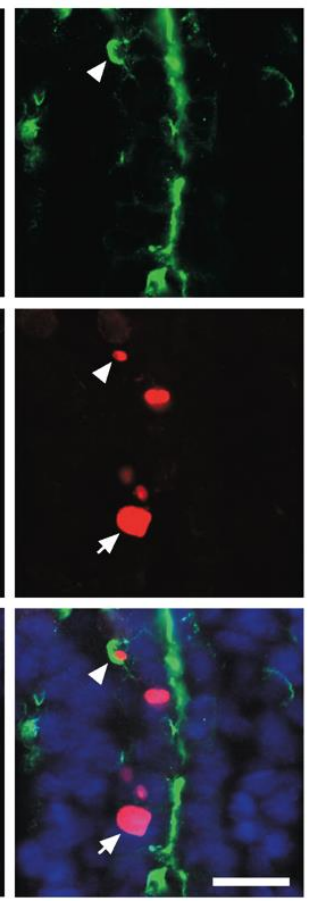

B

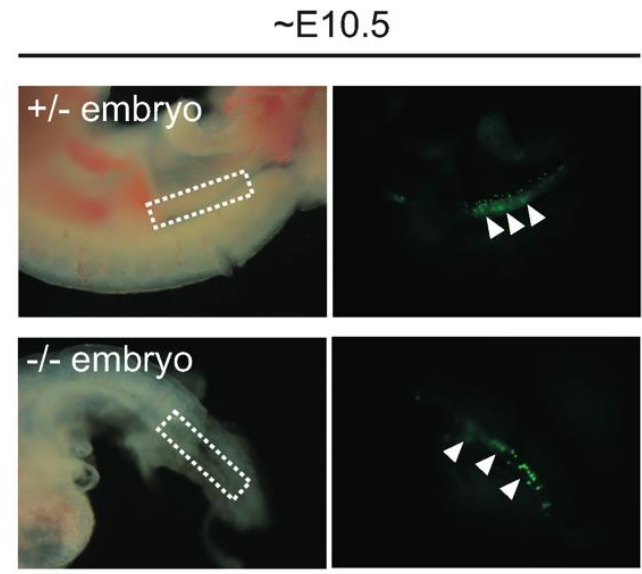

C

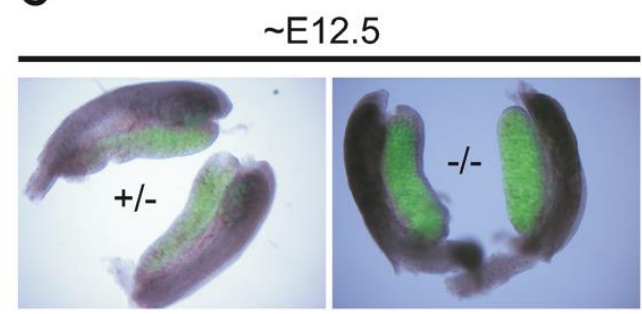

Figure 12. Intrinsic failure of Mad2l2 deficient PGCs.

(A) Apoptosis (TUNEL assay) of SSEA1-expressing PGCs (arrowhead) in a conditional knock out in Prdm1-expressing PGCs. Arrow points to an apoptotic cell with a high nuclear to cytoplasmic ratio, presumably representing a PGC which has lost the SSEA1 expression. Scale bar: 20 $\mu \mathrm{M}$.

(B) Representative heterozygous (upper panel) and homozygous (lower panel) E10.5 embryos which received Mad212 ${ }^{+/}$, Oct4-GFP ESCs at the morula stage. Note that also Mad2l2-deficient hindgut endoderm is colonized by GFP-expressing PGCs. Arrowheads point to migratory PGCs (dashed box).

(C) Representative heterozygous (left panel) and homozygous (right panel) gonads, from E12.5 embryos, which received Mad212 ${ }^{+/}$, Oct4-GFP ESCs at the morula stage. Note that also Mad2I2-deficient ovaries are colonized by GFP-expressing PGCs. 


\section{Mad212 downregulates H3K9me2 via inhibitory binding to G9a and}

GLP

The majority of mutant Oct4-positive PGCs had not downregulated H3K9me2, the repressive histone, which should have been lost during the cell cycle arrest between E7.75 and E9.25 (Figure 13A). Correspondingly, also G9a and GLP, two H3K9 methyltransferases, were still found in mutant, but not in wild type PGCs (Figure 13B, 14A-D). In order to explore a physical interaction between Mad2l2 and G9a or GLP, NIH3T3 fibroblasts were transfected with a plasmid encoding HA-Mad212. Coimmunoprecipitation of NIH3T3 protein extract with anti-G9a, anti-GLP or anti-HA antibodies demonstrated that Mad2l2 interacts with both methyltransferases (Figure 13C, D, data not shown).

To investigate a role of Mad2I2 in the regulation of H3K9me2, NIH3T3 cells were transfected with a vector encoding a GFP-fused Mad2l2 protein. The expression of Mad212-GFP resulted in a down-regulation of G9a at both protein and mRNA levels (Figure 4E, S5E). Corresponding to the decreased levels of the methyltransferases, a decreased level of $\mathrm{H} 3 \mathrm{~K} 9 \mathrm{me2}$, but not of $\mathrm{H} 3 \mathrm{~K} 4 \mathrm{me} 2$ was observed in Mad2l2-overexpressing cells (Figure 4F, S5F). The H3K9me2 level in the absence of Mad2l2 was studied in mutant MEFs, and turned out to be higher than in wild-type control cells (Figure 4F). Collectively, mutant PGCs failed to suppress $\mathrm{H} 3 \mathrm{~K} 9 \mathrm{me} 2$ and the corresponding methyltransferases. The observations in fibroblasts suggest that inhibitory interactions of Mad2l2 with G9a and GLP are involved in the downregulation of $\mathrm{H} 3 \mathrm{~K} 9 \mathrm{me} 2$. 
A

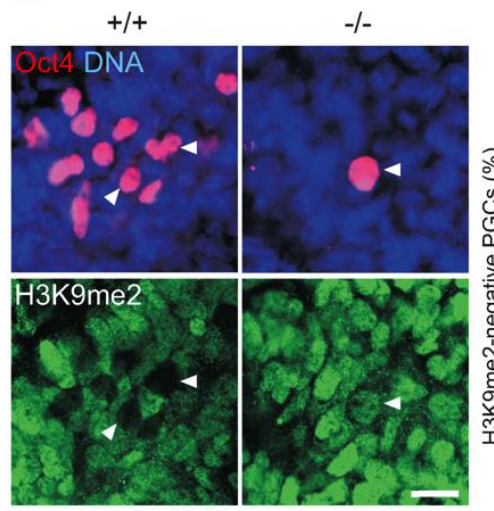

C

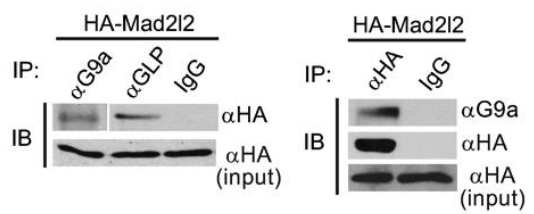

B

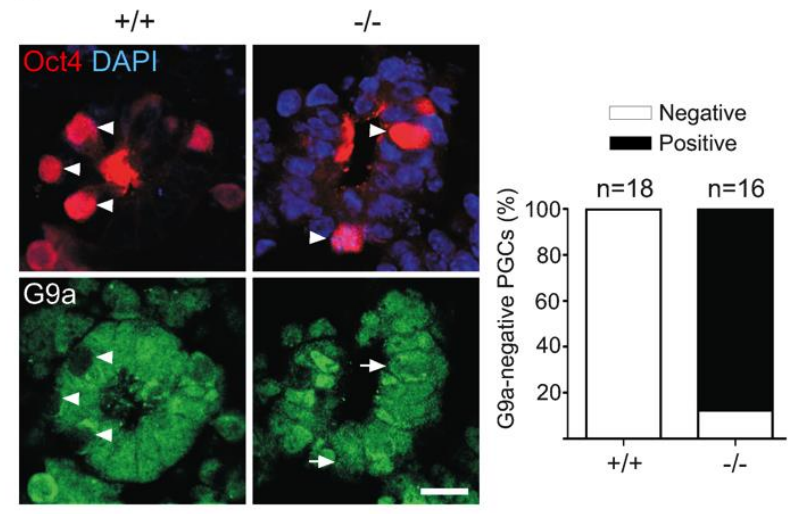

E

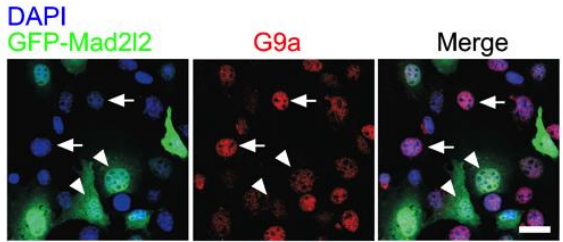

$\mathbf{F}$

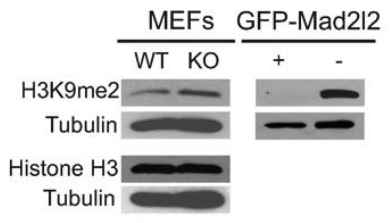

Figure 13. Mad2I2 deficient PGCs fail to downregulate H3K9me2.

(A) The majority of Mad2I2 ${ }^{+/+}$PGCs suppressed successfully H3K9me2 (arrowheads), while many Mad2/2/- PGCs maintained this epigenetic mark at levels similar to neighboring somatic cells (arrowhead). Data were obtained by whole mount staining at E9.0. Right panel: quantification of H3K9me2-negative PGCs (white bars), and of PGCs expressing H3K9me2 at a similar level to their neighboring somatic cells (black bars); $n$ represents total number of PGCs counted at least in three embryos per genotype.

(B) G9a expression was absent from all Mad2l2 ${ }^{++}$PGCs at E9.0 (arrowheads, 0\%, 0/18). Most Mad2l2 ${ }^{-/}$PGCs were positive for G9a (arrowheads, 87\%, 14/16). Right panel: quantification of G9a-negative (white bars) and G9a-positive (black bar) PGCs.

(C) Protein extracts from HA-Mad2I2 transfected NIH3T3 cells were co-immunoprecipitated

(IP) by antibodies against G9a, GLP, or IgG (as negative control). Immunoblotting (IB) was performed on $20 \%$ of gel-separated immunoprecipitates (upper blot), or $1 \%$ input (lower blot) by using anti-HA antibody.

(D) Reciprocally, the same protein extract was co-immunoprecipitated (IP) by antibodies against the HA-tag, or IgG (as negative control). Immunoblotting (IB) was performed on $20 \%$ of the immunoprecipitates (upper blots), or $1 \%$ input (lower blot) by using anti-G9a or antiHA antibodies.

(E) Immunocytochemistry detects a downregulation of G9a in GFP-Mad2I2 over-expressing NIH3T3 cells (arrowheads) in comparison to untransfected cells (arrows).

(F) Western blot analysis of H3K9me2 and Histone $\mathrm{H} 3$ levels in wild type versus knockout MEFs (loss-of function), and in GFP-Mad2I2 over-expressing FACS-sorted NIH3T3 cells versus non-transfected cells (gain-of-function). 

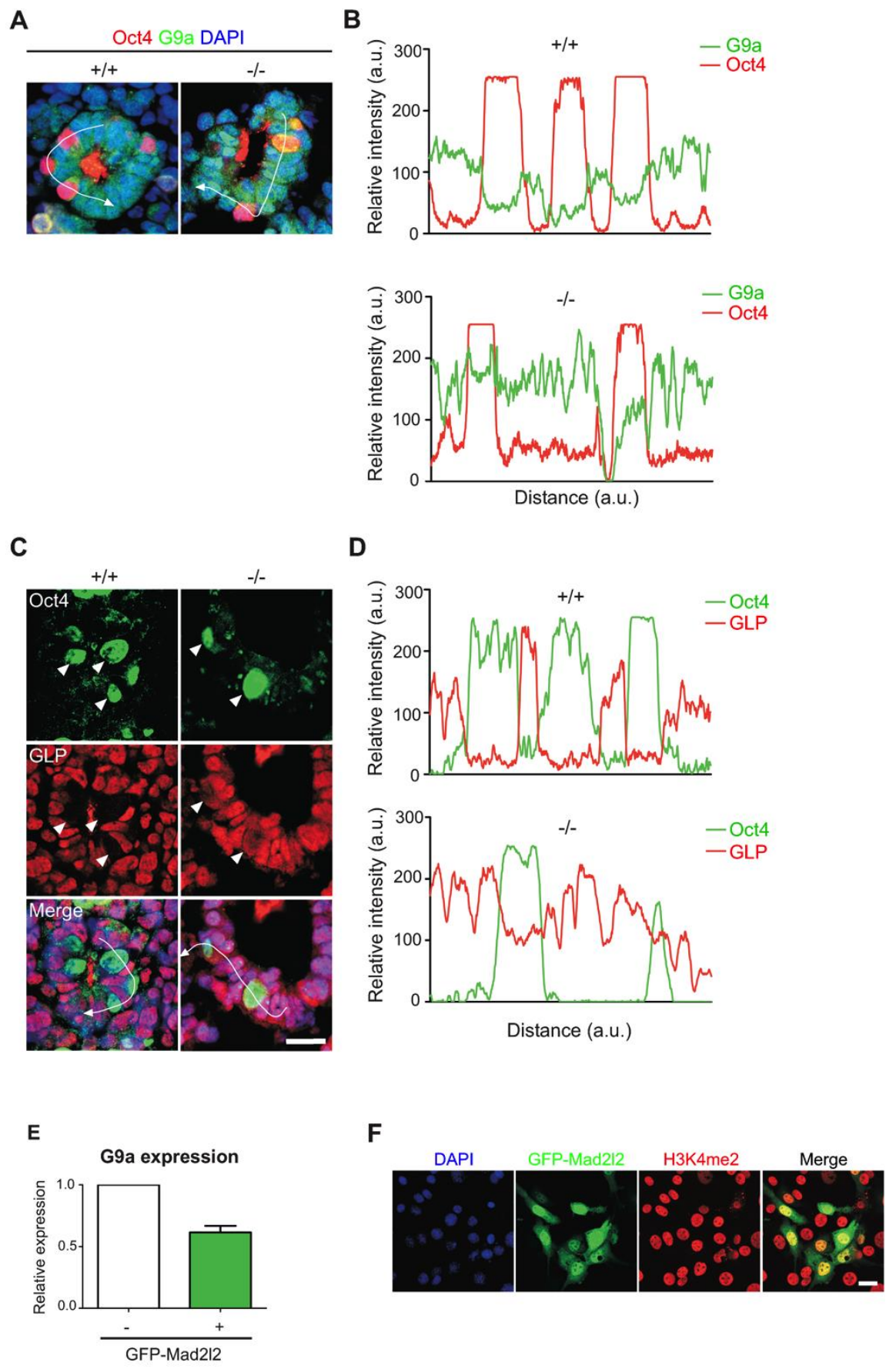

Figure 14. Mad2/2 is associated with downregulation of $\mathrm{H} 3 \mathrm{~K} 9 \mathrm{me2}$.

(A) The merged image of Oct4 and G9a double staining on E9.0 tissue section from Figure 4B. The arrow lines represent the path from which the signal intensity was measured.

(B) Line-scan profile of relative intensity of G9a and Oct4 fluorescent signals in (A).

(C) The majority of PGCs in Mad212+/+ embryos suppressed GLP (arrowheads, 93.7\%, 15/16), whereas Mad212/- PGCs maintained GLP expression (arrowheads, 90.9\%, 10/11).

(D) Line-scan profile of relative intensity of GLP and Oct4 fluorescent signals in (C).

(E) qRT-PCR analysis of G9a expression in FACS sorted NIH3T3 cells. GFP-Mad212 overexpression downregulates the G9a level to around half the value in non-transfected cells.

(F) Immunocytochemistry analysis of H3K4me2 in GFP-Mad212 transfected NIH3T3 cells. Overexpression of Mad2l2 does not influence the level of H3K4me2. 


\section{Mad212 regulates the cell cycle via inhibitory binding to Cdk1}

To address the cell cycle status of Mad212-- PGCs, the cytoplasmic localization of Cyclin B1 was confirmed in the majority of wild type PGCs on E9.0, indicating that they were in the G2 phase of the cell cycle (Seki et al., 2007). In Oct4-positive Mad212/- PGCs, on the other hand, the Cyclin B1 protein was either localized in the nucleus, in the cytoplasm or not present at all (Figure 15A). Thus, it appeared that mutant PGCs did not arrest in G2 phase of their cell cycle. To test whether ectopic expression of Mad2I2 can arrest the cell cycle, NIH3T3 cells were transfected with a HA-Mad2I2 encoding vector. Expressing cells did not enter mitosis (Figure15 B), as evident by the complete absence of $\mathrm{pH} 3$ or Cyclin $\mathrm{B} 1$ from nuclei, as well as the presence of unseparated centrosomes (Jackman et al., 2003; Lindqvist et al., 2007). Several pathways regulating the entry into mitosis converge at the Cdk1, which needs to be dephosphorylated and associated with phosphorylated Cyclin B1 to be active (Lindqvist et al., 2009; Pines and Hunter, 1991). Since the Mad2l2 protein contains a protein-binding HORMA domain, it was hypothesized that Mad2l2 might interact physically with Cdk1 or Cyclin B1 to regulate the G2/M transition. Proteins from HA-Mad2I2 transfected NIH3T3 cells were precipitated with antibodies against Cdk1, pCdk1 (phosphorylated Cdk1), Cyclin B1, and the HA tag. Co-precipitate analysis revealed a physical interaction of Mad2l2 with Cdk1, but not pCdk1 or Cyclin B1 (Figure 15C-E). A regulatory effect of Mad2l2 on the kinase activity of Cdk1/Cyclin B1 was investigated in an in vitro assay, containing recombinant GSTMad212, Cyclin B1 and Cdk1, as well as the specific substrate Cdc7 (Zhan et al., 1999). GST-Mad2l2, but not GST alone could specifically attenuate the kinase activity of Cdk1-Cyclin B1 in a concentration-dependent manner (Figure 15F). Together, mutant PGCs failed to prolong the G2 phase of their cell cycle. The experiments in fibroblasts suggest that Mad212 functions in prolongation of the cell cycle through interaction with and inhibition of Cdk1. 
A
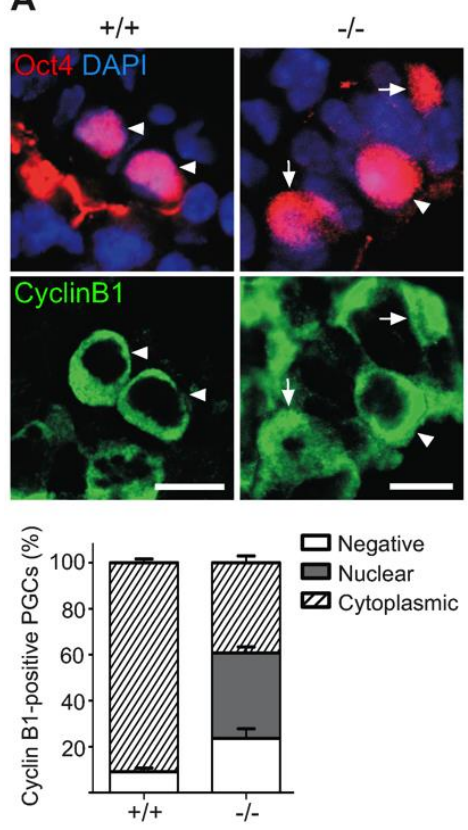

B

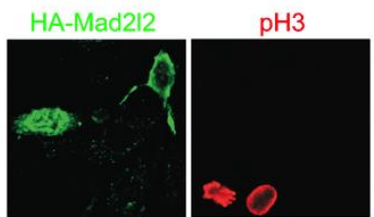

HA-Mad2I2

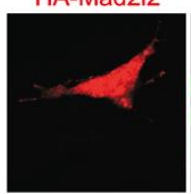

HA-Mad2I2

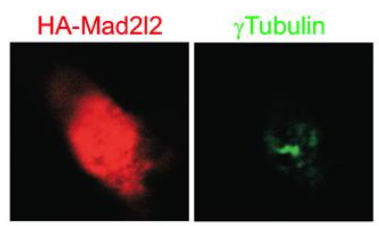

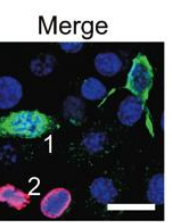

Merge
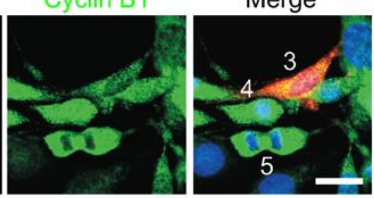

Merge

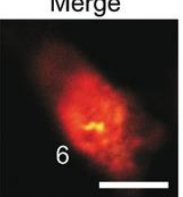

C

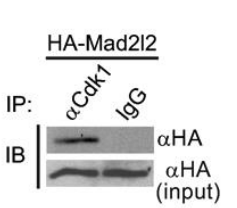

D

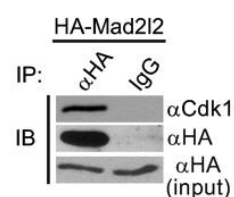

E

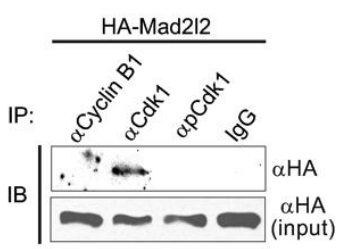

$\mathbf{F}$

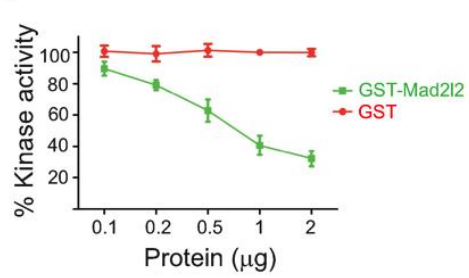

Figure 15. Mad2I2 deficiency affects the cell cycle in PGCs.

(A) Immunohistochemistry on transverse sections of E9.0 embryos (upper panel). Cytoplasmic staining of Cyclin B1 in Mad2I2 ${ }^{++}$PGCs (arrowheads, 90.9\%) indicated that the majority had arrested in the G2 phase of their cycle (lower panel). Mad2l2/- PGCs expressed Cyclin B1 in the nucleus (37\%, arrows), in the cytoplasm (39.3\%, arrowhead), or were negative (23.66\%), suggesting active cycling. Scale bars, $10 \mu \mathrm{m}$.

(B) HA-Mad2I2 transfected NIH3T3 fibroblasts never expressed $\mathrm{pH} 3(0 \%, 0 / 70$; e.g. cell number \#1, upper panel), and always displayed Cyclin B1 in the cytoplasm (100\%, 40/40; $\# 3$, middle panel). Some of the non-transfected cells entered the mitotic prophase (\#2, \#4) or anaphase (\#5), and displayed nuclear pH3 (\#2) or nuclear Cyclin B1 (\#4, \#5). HA-Mad2I2 expressing cells displayed two unseparated centrosomes detectable by $\gamma$ Tubulin $(100 \%, 7 / 7$; \#6, lower panel). Scale bars, $20 \mu \mathrm{m}$ (upper and middle panels), $10 \mu \mathrm{m}$ (lower panel).

(C) HA-Mad2I2 was co-immunoprecipitated with Cdk1 from HA-Mad2I2 over-expressed protein extract.

(D) Cdk1 was co-immunoprecipitated with Mad2l2 from the same protein extract.

(E) Cdk1 antibody co-immunoprecipitated HA-Mad2I2 from transfected NIH3T3 cells, but not antibodies against Cyclin B1, pCdk1, and rabbit IgG. In C-E, $50 \%$ of the immunoprecipitates, or $1.5 \%$ of total cell lysate (input) were loaded.

(F) Recombinant GST-Mad2I2 attenuates the kinase activity of Cdk1-Cyclin B1 (2.5 mUnits) in vitro, while GST alone is not effective. Mean values of three independent experiments with duplicate measurements, and standard deviations are indicated. 


\section{Mad212 facilitates H3K27me3 upregulation via blocking Ezh2}

\section{phosphorylation}

H3K27me3 was highly elevated in the majority of wild-type PGCs at E9.0, while its level in Mad212 ${ }^{-/}$PGCs was mostly indistinguishable from surrounding somatic cells (Figure 16A). Ezh2, the relevant methyltransferase, is expressed in PGCs at a similar level to that of in neighboring somatic cells at least during their specification (Yabuta et al., 2006). Inhibited version of Ezh2 was completely suppressed in all wild type PGCs at E8.5, while above $30 \%$ of knockout PGCs contained such inactive Ezh2 proteins phosphorylated on Threonin residue 487 (Figure 16B). To address whether Mad2I2 is involved in H3K27me3 upregulation, gain-of-function experiments with a GFP-Mad2l2 fusion protein were performed in NIH3T3 cells. Immunocytochemistry showed a very high level of H3K27me3 in all GFP-positive cells, while surrounding, untransfected cells had mostly low levels, with some exceptions possibly dependent on the state of their cell cycle (Figure 16C). Given the inhibitory function of Mad2l2 on the kinase activity of Cdk1, it was asked if it might attenuate the inhibitory phosphorylation of Ezh2 (Figure 16D, E). The highest level of pEzh2 was observed in mitotic cells correlating with the highest activity of Cdk1/Cyclin B1 (Figure 16D) (Wei et al., 2011). In contrast, Mad2I2 over-expressing cells showed the lowest level of pEzh2, even less than that in untransfected interphase cells (Figure 16D). Consistently, western blot analysis confirmed the drastic suppression of pEzh2 in Mad212 over-expressing FACS-sorted fibroblasts, while the overall level of Ezh2 itself remained unchanged (Figure 16E). The loss-offunction situation was analyzed in Mad2l2 deficient MEFs, which showed an increased level of pEzh2 (Figure 16E). In summary, Mad212-- PGCs failed to acquire a high level of H3K27me3. The data in fibroblasts and in a cell free system demonstrated the capacity of Mad2/2 to suppress the kinase activity of Cdk1/Cyclin B1, and thus to support the activity of Ezh2, and in effect a transfer of methyl groups to K27 of histone 3. In the absence of Mad2I2, on the other hand, Cdk1/Cyclin B1 can phosphorylate and thereby inactivate Ezh2. This mechanism would explain the failure of Mad212 deficient PGCs to acquire an epigenetic status dominated by H3K27me3. 
A

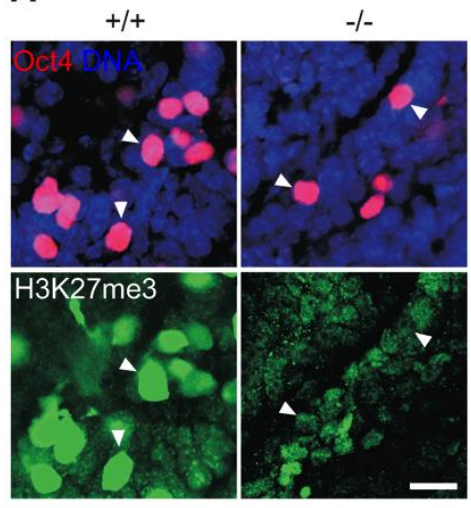

C DAPI

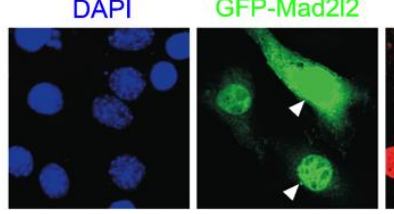

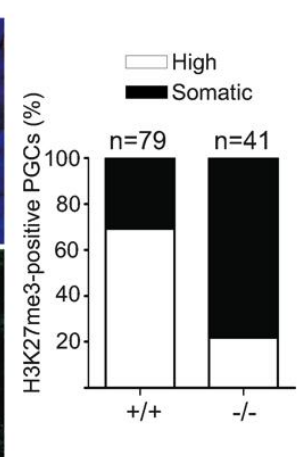

D

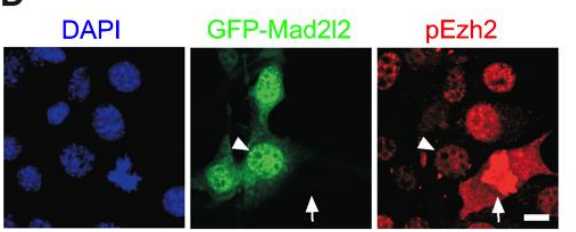

B

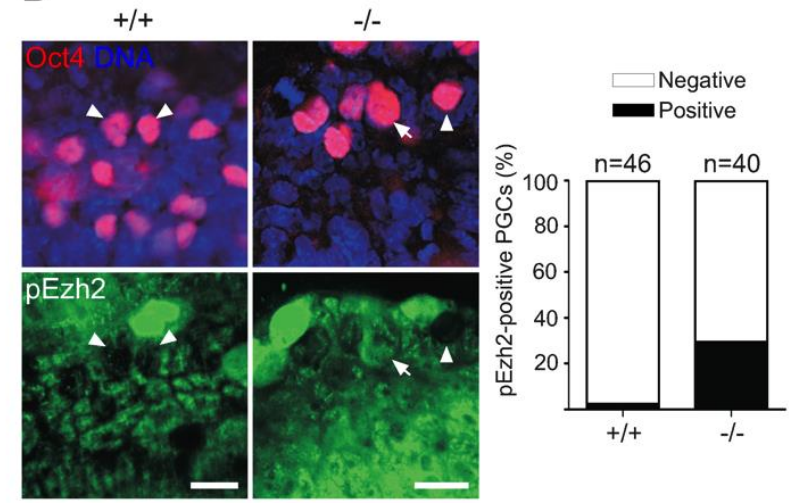

E

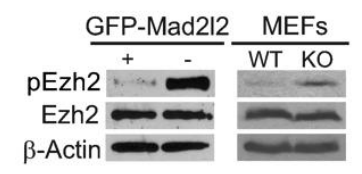

Figure 16. Mad2I2 promotes H3K27me3 in PGCs.

(A) The majority of Mad2I2 ${ }^{+/+}$PGCs had upregulated H3K27me3 by E9.0 (arrowheads), whereas many Mad212 ${ }^{--}$PGCs failed to upregulate above the basal level in somatic cells (arrowhead). Data were obtained by whole mount staining at E9.0. Right panel: Quantification of PGCs strongly positive for H3K27me3 (white bars). Black bars show the percentage of PGCs that express H3K27me3 at a level similar to their neighboring somatic cells. $n$ represents total number of PGCs counted at least in three embryos per genotype. Scale bar, $20 \mu \mathrm{m}$.

(B) The majority of ${\mathrm{Mad} 2 \mathrm{I} 2^{+/+}}$PGCs suppress the phosphorylation of Ezh2 (pEzh2; arrowheads), whereas above $30 \%$ of Mad2I2 ${ }^{--}$PGCs failed to downregulate pEzh2 (arrow). Data were obtained by whole mount staining at E8.5. Right panel: quantification of pEzh2positive PGCs (black bars). White bars show the percentage of PGCs suppressing pEzh2; $n$ represents total number of PGCs counted at least in three embryos per genotype. Scale bar, $20 \mu \mathrm{m}$.

(C) Immunocytochemistry demonstrates the upregulation of H3K27me3 in GFP-Mad2I2 overexpressing NIH3T3 cells (arrowheads).

(D) Immunocytochemistry analysis shows suppression of phosphorylation on Ezh2 at T487 (white arrowhead) in comparison to surrounding, untransfected interphase cells. The highest level of pEzh2 was detected in mitotic cell with high level of Cdk1 activity (arrow).

(E) Western blot analysis of pEzh2 and Ezh2 levels in GFP-Mad2I2 over-expressing, FACSsorted NIH3T3 cells versus non-expressing cells (gain-of-function), and wild type versus knockout MEFs (loss-of-function). 


\section{Spontaneous differentiation of Mad212\% ESCs in LIF/Serum}

Blastocysts harvested from heterozygous intercross were plated on inactivated MEF feeders and fed with LIF/Serum/2i medium to derive ESCs. The wild type and heterozygous ESCs appeared prior to knockout ones and grew faster. All together, 89 lines were established, out of which 12 were knockout. After the forth passage, cultures were shifted to conventional LIF/Serum medium. Here, knockout lines started to differentiate spontaneously to epithelial-like Oct4-GFP- cells. They first appeared at the periphery of colonies and then expanded, upon further passaging (Figure 17A). This phenotype was not restricted to an individual line, but was common to different extents in various knockout lines (Figure 18A). Knockout cells express lower levels of Sox2, Oct4, E-Ras, and Nanog proteins than the control ESCs, as determined by western blotting (Figure 17B, C and Figure 18B). Flowcytometry analysis (Figure 17D) of cell cycle status showed that LIF/Serum control cells manifest a typical ESC profile $(\sim 30.7 \%, 30.5 \%, 35.3 \%$ for $\mathrm{G} 1, \mathrm{~S}$ and G2/M fractions, respectively). However, Mad212 ${ }^{-/}$ESCs showed a differentiated profile (Smith et al., 2010), with an increased G1 fraction observed at the expense of S phase cells $(\sim 41.4 \%, 22.0 \%, 34.3 \%$ for $\mathrm{G} 1, \mathrm{~S}$ and $\mathrm{G} 2 / \mathrm{M}$ fractions, respectively). Western blot analysis of cell cycle-related proteins Cyclin B1 and Geminin showed no difference between knockout and control cells. Although there was a slight increase in phosphorylation of histone $\mathrm{H} 2 \mathrm{AX}(\gamma \mathrm{H} 2 \mathrm{AX})$, no elevated apoptosis rate was observed in knockout ESCs. Moreover, no activation of checkpoint proteins, Chk1 and Chk2, was evident (Figure 18C). This rules out an implication of DNA damage in the appearance of differentiated cells in Mad2/2/ ESC cultures.

To test the pluripotency of ESCs, they were injected into 8-cell embryos, which were culture overnight, and then transferred back to the uterus of foster mothers. Chimera formation potential of ESCs was judged by the fur color: The host blastocysts were of FVB background (with white fur) and the ESCs were of mixed background (black or agouti). Each of the two control ESC lines successfully incorporated into the inner cell mass (ICM) and embryos as indicated by chimeric color of the pups. However, knockout ESCs cultured in LIF/Serum failed to incorporate into ICM, stayed rather in the periphery of host blastocyst, lost their Oct4-GFP signal, and failed to hatch from blastocysts. Finally, transferring them back to the foster mothers did not lead to formation of any chimera (Figure 17E). These 
results indicate that LIF/Serum Mad212 ${ }^{-/}$ESCs are spontaneously differentiated and do not fulfill the criteria of authentic pluripotent ESCs.

A

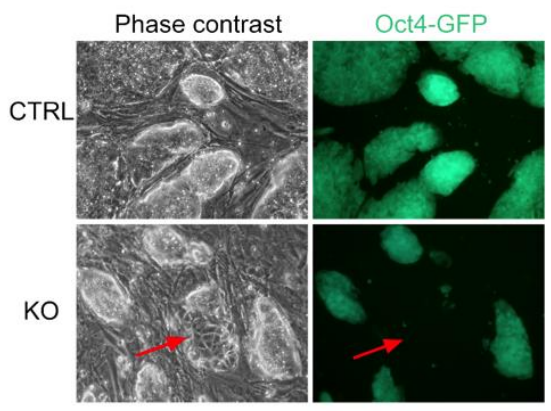

C

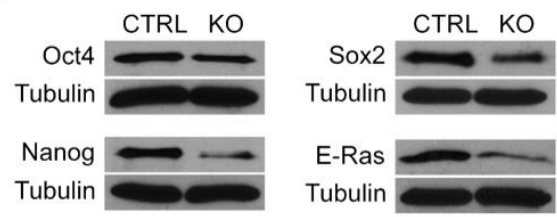

B

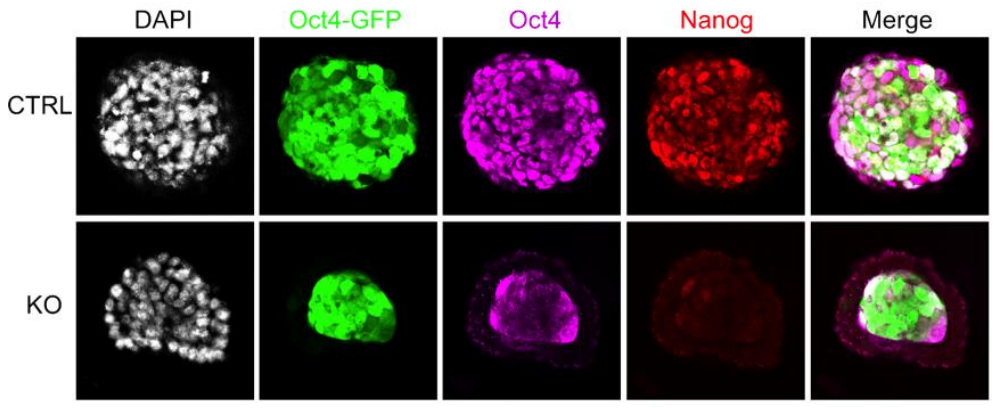

D

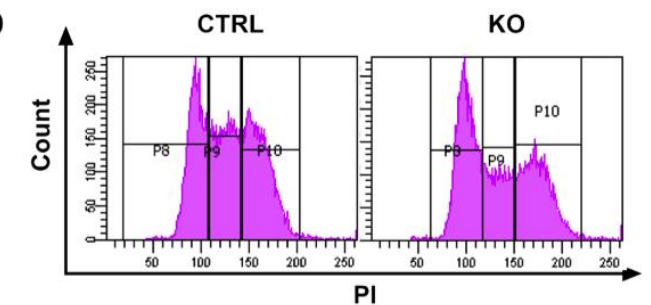

E

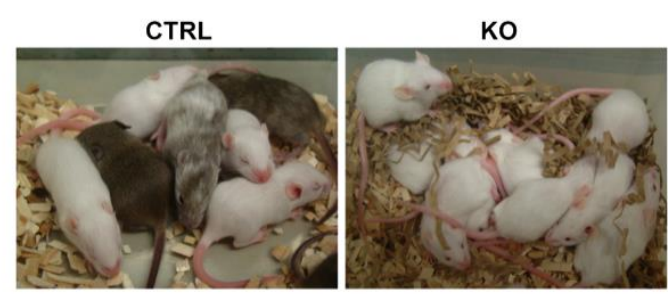

Figure 17. Mad212/-- ESCs are unstable and lose their pluripotency.

(A) Phase contrast and its corresponding Oct4-GFP expression in control (CTRL) versus knock out (KO) ESCs. Red arrows point to Oct4-GFP-negative epithelial differentiating cells in $\mathrm{KO}$ culture.

(B) Immunofluorescent staining of CTRL and KO ESCs with antibodies against Oct4 and Nanog. Differentiating cells in the periphery of $\mathrm{KO}$ colony lack expression of Nanog and Oct4. Moreover, undifferentiated cells at the center of $\mathrm{KO}$ colony are mostly devoid of Nanog.

(C) Western blot analysis of pluripotency related markers in CTRL and KO cell crude lysate.

(D) Flowcytometry analysis of ES cell cycle shows differentiating profile in KO culture.

(E) KO ESCs fail to generate chimeric pups. 
A

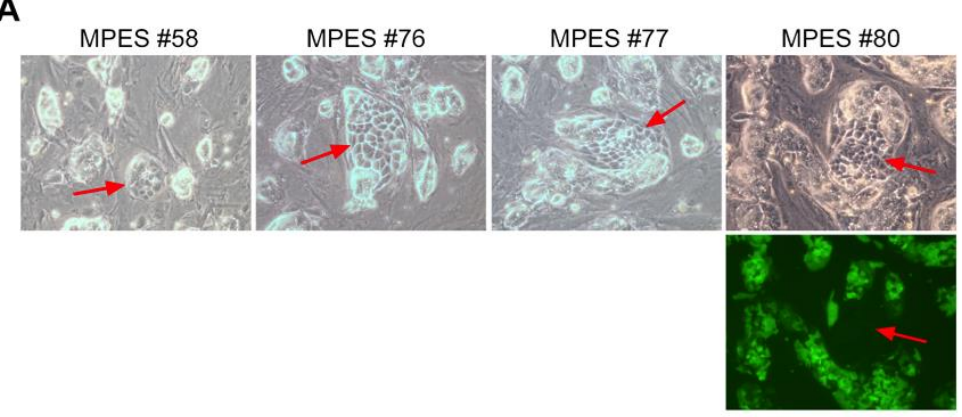

B

C
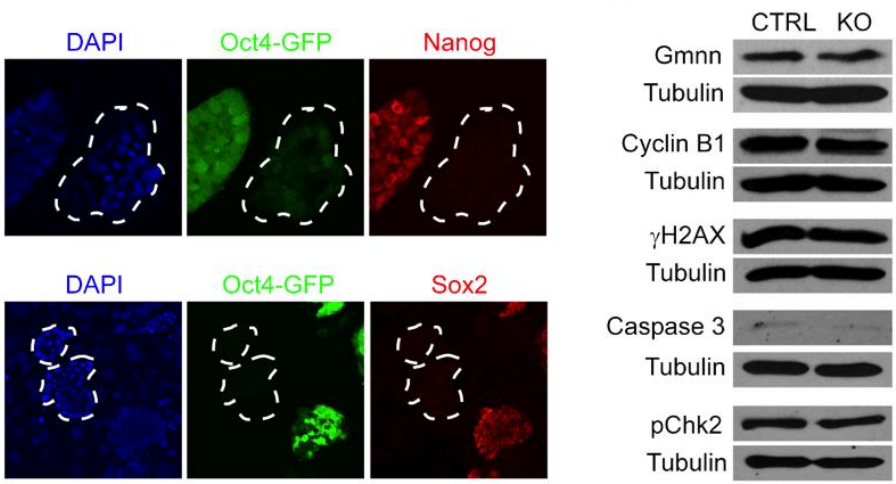

Figure 18. Characterization of various knockout ESC lines.

(A) Different knockout cell lines generate differentiating cells (red arrows), which lack expression of Oct4-GFP.

(B) Expansion of knock out cultures leads to total loss of pluripotency in ESC colonies. Dotted lines encircle totally differentiated colonies that lack expression of Nanog, Sox2, and Oct4-GFP.

(C) A normal expression of cell cycle- and DNA damage checkpoint-related proteins in knock out ESCs.

\section{Mad212\%- ESCs deviate to primitive endoderm in LIF/Serum}

Upon the second fate decision during embryonic development, pluripotent epiblast cells are segregated from primitive endoderm cells (Zernicka-Goetz et al., 2009). To address the identity of differentiated cells in Mad2I2/- ESCs cultures, first expression of two primitive endoderm-specific markers, Gata4 and Sox17, was examined by immunocytochemistry. Differentiating $\mathrm{Mad}_{2} \mathrm{I}^{-/-}$cells in the periphery of colonies uniformly expressed Gata4 and Sox17 and lacked Oct4-GFP (Figure 19A, B). In contrast, control cells only occasionally express these markers, which is consistent with the dynamic heterogeneity of gene expression observed in ESCs (Niakan et al., 2010; Singh et al., 2007). Western blot analysis revealed greater levels of Gata4 and Sox17 protein expressions in Mad2I2/- ESC cultures (Figure 19C). This observation was also confirmed in other knockout ESCs. In contrast, no appreciable levels of other lineage-specific markers including mesoderm (Brachyury), ectoderm (Sox1), or 
extraembryonic ectoderm (Cdx2), were detected in knockout ESCs (data not shown). Thus, differentiating cells in the Mad212-/- ESC cultures possess the characteristics of primitive endoderm cells.

A

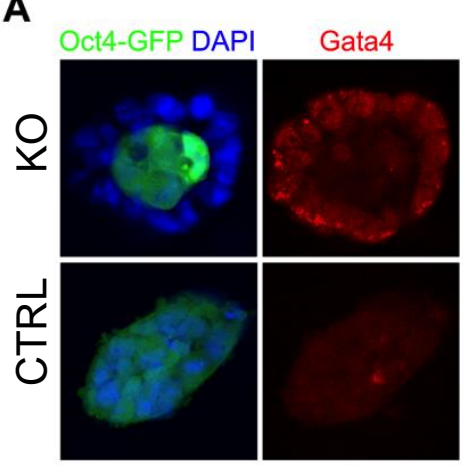

B

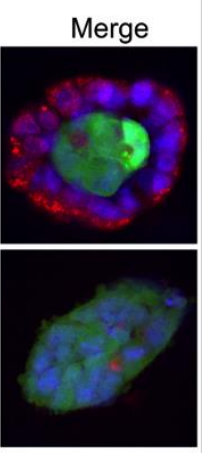

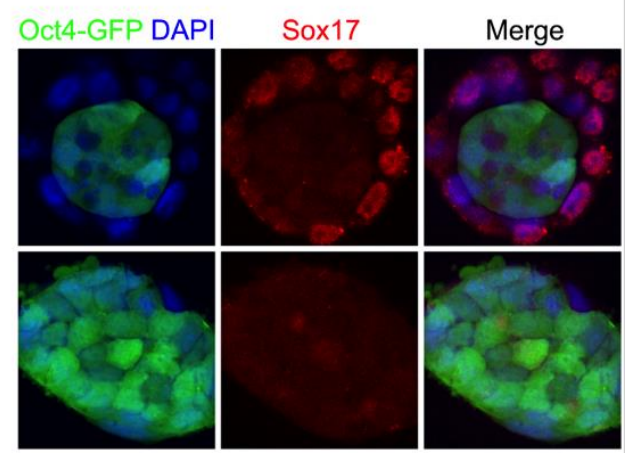

C

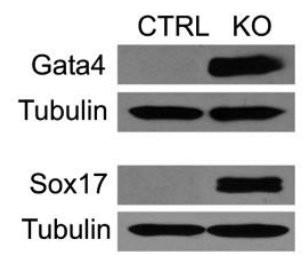

Figure 19. Mad212 ${ }^{-/}$ESCs deviate into primitive endoderm.

Expression of Gata4 (A) and Sox17 (B) in the differentiating cells at the periphery of KO ESC colony.

(C) Western blot analysis of Gata4 and Sox17 expression in crude protein lysates from CTRL and knockout cultures.

\section{Culture in LIF/2i can block differentiation priming in Mad212\% ESCs}

Embryonic development of primitive endoderm can be blocked by treatment of ex vivo-cultured blastocysts with two inhibitor chemicals, CHIR99021 (hereafter, CHIR) and PD184352 (hereafter, PD) that block GSK3 and Erk pathway, respectively (Nichols et al., 2009; Ying et al., 2008). This causes an increase in the number of Nanog-expressing epiblast cells at the expense of Gata4-expressing primitive endoderm cells. A potential effect of these two inhibitors (2i) on spontaneous differentiation of knockout cells was questioned by shifting ESC cultures to LIF/2i medium, which consists of N2B27 medium supplemented with LIF and 2i (Wray et al., 2011; Ying et al., 2008). After 2-3 passages, no differentiated cell was observed in Mad212/- cultures (Figure 20A). Consistently, expression of Gata4 and Sox17 was undetectable by western blot analysis (Figure 20B, compare lanes \#5 and 6). However, expression of Sox2, Oct4, and Nanog did not appear back to the control's 
levels (Figure 21B, and 21C). No differentiation was observed in knockout cultures up to the $20^{\text {th }}$ passages (data not shown). These data suggest that upon culture in LIF/2i condition, knockout ESCs acquire properties of the authentic pluripotent stem cells.
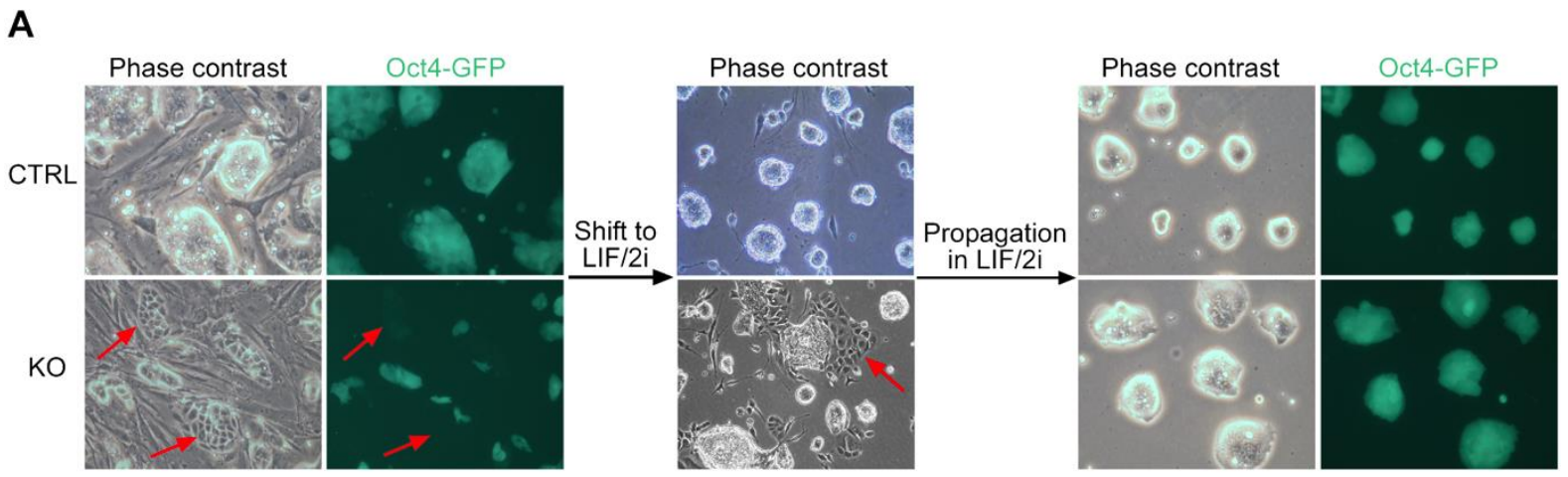

B
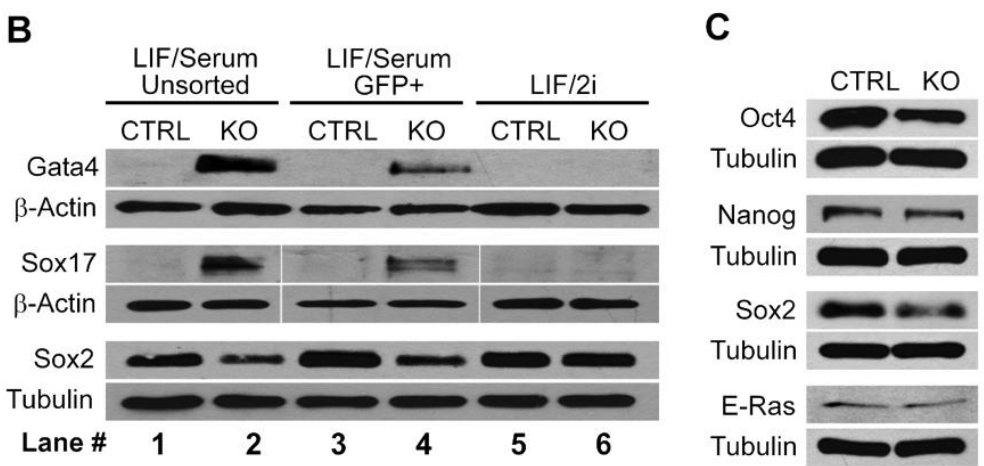

Figure 20. Growth of ESC cultures in LIF/2i eliminates differentiation.

(A) Upon shifting from LIF/Serum condition to LIF/2i, differentiating cells (red arrows in the left panels) persist in culture (red arrow in the middle panels), but disappear after adaptation to LIF/2i (left panel).

(B) Western blot analysis of Gata4, Sox17, and Sox2 expression in the unsorted bulk culture (lanes \#1 and 2), in FACS-sorted (lanes \#3 and 4), or in LIF/2i-adapted (lanes \#5 and 6), cultures of control and knock out ESCs.

(C) Western blot analysis of pluripotency-related markers expression in LIF/2i cultures.

Finally, we asked whether Oct4-GFP-positive undifferentiated Mad2/2/- cell in LIF/Serum have originally been primed for differentiation toward primitive endoderm and also if LIF/2i can block this priming. Western blot analysis of FACS-sorted GFPpositive cells still represented expression of Gata4 and Sox17, and downregulation of Sox2 (Figure 20B, compare lanes \#3-4 to 1-2) though less prominent than unsorted cells. This points to a less differentiated entity of GFP-positive cells than the GFP-negative ones in Mad2I2/- ESC cultures. Altogether, GFP-positive cells in 
Mad212 ${ }^{-/}$ESC cultures are primed for differentiation toward primitive endoderm and culture in LIF/2i can block this priming.

\section{Aberrant histone modifications in Mad212\% ESCs}

Since Mad2l2 is involved in regulation of two suppressive histone modifications H3K9me2 and H3K27me3 in PGCs, their levels were tested in ESCs. In general levels of all examined histone modifications were higher in LIF/Serum condition than in LIF/2i, which is consistent with other reports (Marks et al., 2012). In both conditions, higher levels of $\mathrm{H} 3 \mathrm{~K} 9 \mathrm{me} 2$ and $\mathrm{H} 3 \mathrm{~K} 27 \mathrm{me} 3$ were detected in knockout cells (Figure 21 A). This is in line with general elevation of these histone modifications during differentiation of ES cells (Hawkins et al., 2010; Meshorer et al., 2006; Wen et al., 2009). Besides, two activating histone modifications, H3K4me2 and H3K4me3, were upregulated in knockout cells that can be explained by an activation of gene expression probably at lineage-specific loci. Therefore, configuration of histone modifications in knockout ESCs points to a differentiating feature of these cells.

\section{FGF/Erk inhibitor is sufficient to block differentiation in Mad212\%}

\section{ESCs}

To determine which inhibitor can effectively rescue primitive endoderm differentiation, ESCs were treated with individual or combined inhibitors. To obtain the undifferentiated cells, ESCs were sorted by fluorescent activated cell sorting (FACS). A more critical gating divided ESCs into three distinct populations based on Oct4-GFP expression: highly positive cells $\left(\mathrm{GFP}^{++}\right)$, weak positive $\left(\mathrm{GFP}^{+}\right)$, and negative cells (GFP') (Figure 21B). The later population was mostly consisting of either differentiated cells or MEF feeder cells. Mad212 ${ }^{-1} \mathrm{GFP}^{+}$cells failed to form ESC colonies upon plating in either LIF/Serum or LIF/2i regime, which implies a lineage-primed status of these cells, whereas majority of control $\mathrm{GFP}^{+}$cells form normal ESC colonies within 3-4 days after plating (data not shown), the later can be explained by fluctuated expression of pluripotency-related markers in metastable ESCs. Equal numbers of the GFP ${ }^{++}$cells, the most undifferentiated cells, from control and knockout cultures were plated on fresh MEFs with LIF/Serum medium overnight. The day after, the medium was replaced by LIF/Serum and supplemented with CHIR, PD, or both. During the next 4-6 days, appearance of differentiating cells 
was monitored and western blot analysis was performed to analyze the expression of primitive endoderm markers, Gata4 and Sox17. Differentiating, epithelial-like cells reappeared in LIF/Serum Mad2/2/- ESC cultures and, to a lesser extend, in CHIRtreated cells but not in 2i- or PD-treated cultures (Figure 21C). Increased levels of Gata4 and Sox17 were detected in protein extracts of Mad212-- cultures with or without CHIR, compared to 2i- or PD-treated cells (Figure 21D). These data prove the primitive endoderm identity of differentiated cells in Mad2I2 ${ }^{-1}$ ESC cultures (Nichols et al., 2009) and also suggest that PD is sufficient to rescue this phenotype.

\section{Analysis of Mad2l2 interacting proteins in ESCs}

Since Mad2l2 functions via protein-protein interaction, co-immunoprecipitation (CoIP) followed by mass-spectrometry was performed to identify Mad2I2-interacting partners in the context of ESC. To exclude non-specific interactions, two negative control samples were prepared by: (i) immunoprecipitation of knockout ESCs with anti-Mad2I2 antibody, and (ii) immunoprecipitation of control ESCs with mouse IgG. Subtracting the false positive proteins from the list of proteins detected in the immunoprecipitation of control ESCs with anti-Mad2I2 antibody generated a short list of 17 interacting partners in ESCs. These include Mad2/2 itself, 3 hypothetical proteins, 2 unnamed proteins, and 11 remaining proteins that are listed in Table 1 as Mad2I2 interacting partners in ESCs. Some of these interacting partners harbor the PxxxPP motif ( 3 proteins) or it derivatives ( 3 proteins) and 5 other proteins lack it (Table 1). None of the known interacting partners of Mad2l2 was detected in Mad2l2 co-immunoprecipitated proteins in ESCs. However, Cdk1 was detected in the immunoprecipitate of Mad2l2 from testis protein extract (data not shown). Taken together, Mad2l2 interacting partners are unique in the ESCs and differ from that in other tissues.

Figure 21. Inhibition of Erk pathway by PD is sufficient to block primitive endoderm differentiation in Mad2/2 ${ }^{-/-}$ESCs.
(A) Abnormal chromatin configuration in Mad212 ${ }^{-/}$ESCs.
(B) Schematic distribution of Oct4-GFP-expressing cells in FACS analysis.
(C) Treatment of Oct4-GFP ${ }^{++}$ESCs with $\mathrm{CH}$, PD, or both. Note to the differentiating cells in not-treated, or $\mathrm{CH}$-treated cultures (red arrows).
(D) Western blot analysis of Gata4 and Sox17 in cells obtained from (C). 
A

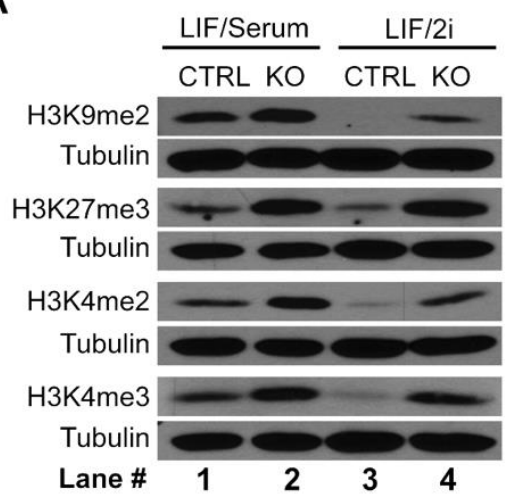

B

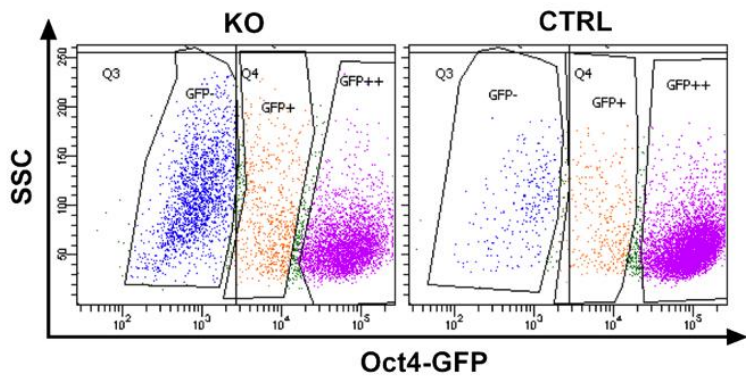

C
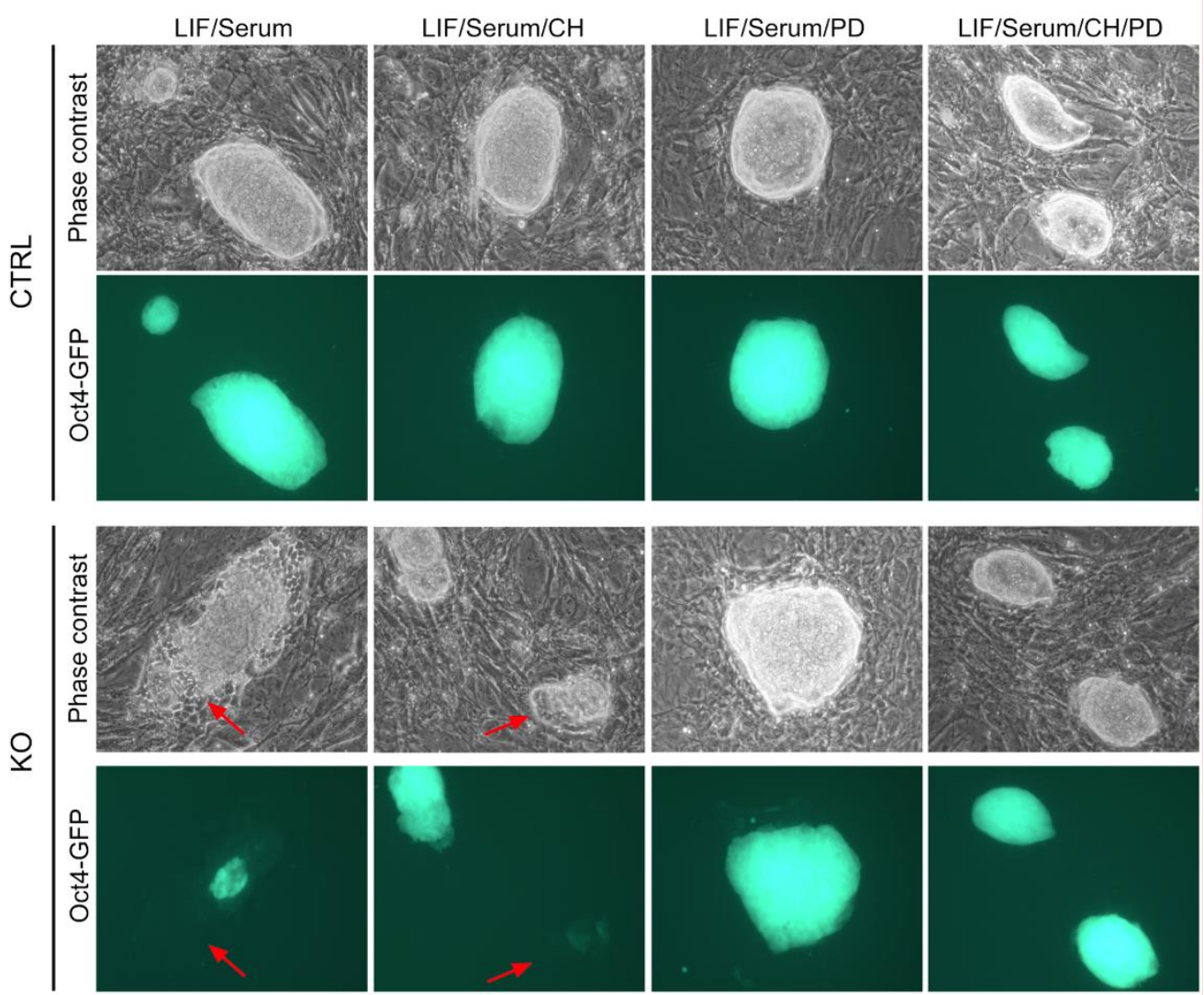

D

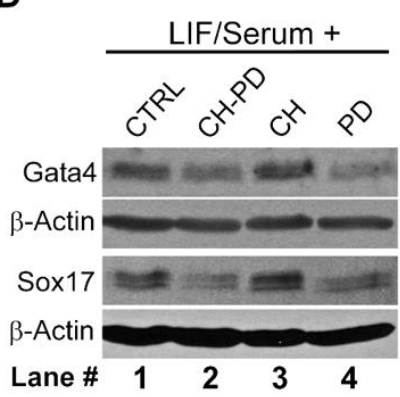


Table 3. Mad2I2 interacting partners in ESCs

\begin{tabular}{|c|c|l|c|c|c|}
\hline \# & Symbol & \multicolumn{1}{|c|}{ Gene name } & $\begin{array}{c}\text { Accession } \\
\text { Number }\end{array}$ & $\begin{array}{c}\text { Molecular } \\
\text { Weight } \\
\text { (kDa) }\end{array}$ & $\begin{array}{c}\text { PxxxpP } \\
\text { motif }\end{array}$ \\
\hline 1 & Mad212 & MAD2 mitotic arrest deficient-like 2 & 126090494 & 24 & No \\
\hline 2 & CETN2 & Centrin-2 & 10257421 & 20 & No \\
\hline 3 & Cep55 & Centrosomal protein 55, isoform CRA_a & 148709849 & 55 & PLQREP \\
\hline 4 & LMTK2 & $\begin{array}{l}\text { serine/threonine-protein kinase LMTK2 } \\
\text { precursor }\end{array}$ & 124487401 & 161 & PPASPP \\
\hline 5 & SYN2 & Synapsin-2 isoform Ila & 161168987 & 63 & $\begin{array}{c}\text { PERRPP, } \\
\text { PPQRPP }\end{array}$ \\
\hline 6 & AAK1 & AP2 associated kinase 1 & 187954745 & 103 & PGLEPP \\
\hline 7 & MTMR7 & myotubularin-related protein 7 & 103472017 & 76 & PKEISP \\
\hline 8 & Dusp21 & Dual specificity phosphatase 21 & 58037325 & 22 & PVSDAP, \\
\hline 9 & Asf1b & ASF1 anti-silencing function 1 homolog B & 148678973 & 28 & No \\
\hline 10 & Ppp3r2 & calcineurin subunit B type 2 & 51591899 & 21 & No \\
\hline 11 & Thoc6 & THO complex 6 homolog, isoform CRA_a & 148690308 & 24 & No \\
\hline
\end{tabular}




\section{Discussion}

\section{Mad2l2 as a checkpoint component protein}

Checkpoints coordinate the progression of the cell cycle with extra- or intracellular events. In principal they are known to exist in all phases of the cycle, and many molecular players and pathways were previously identified. The Mad2l2 protein has been discussed as a mitotic checkpoint component, and a phylogenetic analysis of its HORMA domain indicated that it was recruited to function at checkpoints before the divergence of eukaryotes (Aravind and Koonin, 1998). One way Mad2l2 could exert its function is through binding and thus inhibition of Cdh1, the substrate recognizing protein of $\mathrm{APC} / \mathrm{C}$ from late anaphase through $\mathrm{G} 1$ phase (Chen and Fang, 2001; Pfleger et al., 2001). Cdh1 dissociates from the core APC/C complex at the G1-S transition, and remains inactive and phosphorylated during $S$ and $G 2$ phase (Bassermann et al., 2008; Bassermann and Pagano, 2010). Only in case of genotoxic stress Cdh1 becomes dephosporylated in the G2 phase, active APC-Cdh1 becomes reconstituted, and now they can inhibit mitotic entry by promoting the degradation of the Plk1 kinase as part of the G2/M DNA damage checkpoint. The observed phenotypes of Mad2l2 deficient and overexpressing fibroblasts, and of Mad212 ${ }^{-/}$PGCs point to a so far not described function of Mad212 regulating the entry to mitosis. Based on the data in this study, ectopic overexpression blocked the entry almost completely, whereas Mad2l2 deficient fibroblasts after DNA damage progressed into mitosis and became apoptotic. The incapability of Mad2l2 deficient MEFs to survive cisplatin treatment can be explained by two mechanisms. First, DNA repair might be impaired due to the lack of Mad212 as an accessory, but not catalytic subunit of the translesion repair polymerase zeta (Gan et al., 2008). Mad2I2 (Rev7) from yeast was previously shown to increase the activity of Rev3 by a factor of 30, but neither protein is required for survival (Nelson et al., 1996). In mice, on the other hand, Rev3 is essential for embryonic development (Bemark et al., 2000; Esposito et al., 2000; Wittschieben et al., 2000). Since an active repair polymerase Rev3 is still present in the described Mad2l2 mutants, a delay of the translesion repair process might be more likely than a complete abrogation of the cell cycle. The compromised phenotype of somatic cells may indeed reflect such a non-essential function during normal development. The possibility that the lack a Mad212 as a 
polymerase zeta subunit contributes to the observed phenotype is not excluded. However, also under DNA damage conditions, a transient arrest of the cell cycle at the G2/M DNA damage checkpoint would have been expected, giving time for translesion repair at a possibly decreased rate. Instead, cisplatin exposed cells entered mitosis, where they underwent programmed cell death (the second possible mechanism). This indicates a defective G2/M checkpoint in the absence of Mad212, rather than a lack of polymerase activity.

\section{The timing of PGC loss in Mad212 mutants points to a failure of} epigenetic reprogramming

Several mutations are known to affect or terminate the development of PGCs (Saitou, 2009b). In principal, every step proved to be sensible, particularly the primary induction by BMP signaling, the early specification, the migration to the developing gonad, and the pre- or postnatal oogenesis or spermiogenesis. The early BMP response genes Prdm1 and Prdm14 are crucial for PGC specification directly after induction. Numbers of mutant PGCs are drastically reduced already on E 8.0, and only few mutant PGCs survive to E9.5 (Ohinata et al., 2005; Yamaji et al., 2008). Similar kinetics for PGC loss was observed in mice lacking the transcription factor Tcfap2c, which mostly phenocopy the Prdm $1^{-/}$mice (Weber et al., 2010). A slightly later timing, shifted by about one day, was found for the Mad2l2 mutants. Although embryos at EHF stage were relatively small, they harbored stage-adequate numbers of PGCs expressing Prdm1 and the commitment marker Dppa3, arguing for a normal specification in the epiblast. A reduction of PGC numbers was observed in the LHF stage, and there was no survival beyond E9.5. At this point of development PGCs would normally have undergone a major epigenetic reprogramming, would recover from their cell cycle arrest, and resume transcription. This timing suggests a failure of epigenetic reprogramming in Mad2I2-- PGCs. In principle, it is conceivable that wrongly developed PGCs might either revert to a somatic fate, or undergo apoptosis. Thus, PGCs are lost without evidence for apoptosis in mutants of the Prdm1, the Prdm14, and the Tcfap2c gene, whereas mutations in the Oct4, the Kit and the Mad2l2 genes remove wrongly programmed PGCs by apoptosis (Kehler et al., 2004; Ohinata et al., 2005; Runyan et al., 2006; Weber et al., 2010; Yamaji et al., 2008). In contrast, somatic Mad2l2 ${ }^{-/}$cells, which do not rely on the specific epigenetic 
reprogramming, develop normally, and the resulting pups live until the adulthood. This points to a highly specialized function of Mad2l2 in the unique development of germ cells.

\section{Mad212 is involved in downregulation of H3K9me2}

H3K9 methylation is critical for formation of heterochromatin and transcriptional silencing. At the onset of PGC development, H3K9me2 is the dominant epigenetic mark in the genome of embryonic cells (Seki et al., 2005; Seki et al., 2007). This modification requires the activity of two methyltranferases G9a and GLP. G9a, the major mammalian H3K9 methyltransferase, plays a critical role in germ cell development, in particular gametogenesis. The specific deletion of G9a in PGCs after E9.5 leads to germ cell loss during the meiotic prophase, and thus to sterility of both males and females (Tachibana et al., 2007). During the $S$ phase of the cell cycle, G9a binds to DNA methyltransferase DNMT1 and loads on to the DNA at replication foci, ensuring a coordination of DNA methylation and $\mathrm{H} 3 \mathrm{~K} 9$ methylation in heterochromatin regions (Esteve et al., 2006). Nascent PGCs leave the $S$ phase of their cycle and enter G2 at around E8.0. At this time, the de novo methylation of the daughter chromatin is suppressed, and both Prdm1 and Prdm14 were suggested to be involved (Hackett et al., 2012c). In parallel, the maintained activity of histone demethylases like Jmjd1a erases further the remaining H3K9me2 (Yamane et al., 2006). The results in this study indicate that similar to Prdm14 deficient PGCs, Mad2/2/- PGCs fail to suppress H3K9me2. Maintenance of H3K9me2 high level in Prdm14 mutant PGCs was attributed to a failure in downregulation of GLP. Both G9a and GLP are capable of catalyzing H3K9 methylation, although G9a possesses a more critical enzymatic activity than GLP in vivo (Tachibana et al., 2008). The binding of Mad2l2 to the two histone methyltransferases G9a and GLP was identified in a systematic analysis of human protein complexes, and represented a first hint for an involvement of Mad2l2 in the generation of epigenetic modifications (Hutchins et al., 2010). We confirmed this evidence by co-immunoprecipitation of both G9a and GLP with HA-Mad2I2 from transfected fibroblasts, where the level of H3K9me2 was significantly downregulated. Noteworthy, both G9a (PXXXPP) and GLP (PXXXYP) have the sequence motif suggested to be responsible for Mad2l2 binding (Hanafusa et al., 2010). G9a and GLP can form homo- and heteromeric complexes in vitro (Tachibana et al., 2008; Tachibana et al., 2005). The disruption of a heterodimer by 
a competing interacting protein abolishes histone methyltransferase activity of the complex. Indeed, several proteins bind to G9a or GLP, and alter their activities (Heo et al., 2012; Shinkai and Tachibana, 2011). Interestingly, Prdm1 binds to G9a and recruits it to assemble silent chromatin (Gyory et al., 2004). Mad2I2, interacting with both G9a and GLP may disrupt their heterodimer complex, and consequently provoke downregulation of de novo H3K9 methylation. In conclusion, the presence of Mad2I2 acts against an epigenetic status dominated by H3K9me2.

\section{Mad2l2 inhibits Cdk1, the key regulator of mitotic entry and epigenetic modification}

Cdk1 is a central regulatory kinase in several processes, particularly in cell cycle control and in epigenetic reprogramming. The study in transfected fibroblasts and in a cell-free system suggests that Mad2l2 can bind directly to dephosporylated Cdk1, and thus inhibit its kinase activity. Possibly this interaction involves the Cdk1 sequence PXXXPy, which is related to the previously identified Mad2I2 binding motif PXXXPP (Hanafusa et al., 2010). The entry into mitosis is mediated by a complex network of proteins that finally activate the Cdk1-Cyclin B1 complex (Lindqvist et al., 2009). One of the first functions of Cdk1-Cyclin B1 is the phosphorylation and therefore disruption of Eg5, a protein involved in centrosome adhesion (Smith et al., 2011). Overexpression of Mad2l2 abrogated centrosome separation, and caused a cell cycle arrest at the G2 phase. Dephosphorylated Cdk1 in association with phosphorylated Cyclin B1 translocates to the nucleus and initiates prophase by the phosphorylation of a variety of substrates (Lindqvist et al., 2009). Thus, via direct binding to Cdk1, Mad2l2 would have the capacity to inhibit Cdk1, and thus to block the entry into mitosis. Inhibition and/or disruption of the Cdk1-Cyclin B1 complex through direct interaction were previously observed for Gadd45 proteins, stress factors implicated in the activation of the G2/M DNA damage checkpoint (Vairapandi et al., 2002; Wang et al., 1999; Zhan et al., 1999). Gadd45a is significantly expressed in PGCs at the time of fate specification and probably also during the G2 arrest (Kurimoto et al., 2008a; Mochizuki and Matsui, 2010). However, its genetic inactivation in mice did not affect the PGCs, pointing to the redundancy of Gadd45 in PGC development (Hollander et al., 1999). The function of Mad2I2, however, is non- 
redundant and absolutely required for cell cycle arrest in PGCs, probably in order to supply extra time for epigenetic reprogramming of the chromatin.

\section{Mad2l2 functions in upregulation of H3K27me3}

Released from repression by genome-wide H3K9me2, PGCs repress RNA Pol-II dependent de novo transcription until they acquire the alternative repressive histone mark, H3K27me3. This ensures the maintenance of separate PGC and somatic programs, established previously via combinational functions of Prdm1, Prdm14, and Tcfap2c (Magnusdottir et al., 2012). In the absence of Mad2l2, PGCs fail to upregulate H3K27me3. In transfected fibroblasts, Mad2I2 can promote the activation of Ezh2, presumably by inhibitory interaction with Cdk1. Ezh2, as the catalytic subunit of PRC2, downregulates the expression of typical somatic developmental genes including members of Hox, Sox, and Fox gene families. In a normal PGC shortly after induction by BMPs, an inhibition of Cdk1 by Mad2l2 would prevent the inhibitory phosphorylation of Ezh2, and thus allow for the trimethylation of histone 3 on residue K27. In conclusion, the presence of Mad2l2 favors an epigenetic status dominated by H3K27me3, which would be typical for PGCs after the G2 arrest.

\section{Mad212 coordinates epigenetic transition and cell cycle}

Taken together the following model is proposed for the involvement of Mad2l2 in epigenetic reprogramming and cell cycle control in PGCs (Figure 22). Mad2I2 halts the cell cycle of PGCs in the G2 phase early after induction by direct interaction with Cdk1, and thus allows the epigenetic transition from a H3K9me2 to a H3K27me3 status. Mad2l2 interferes directly with the activity and possibly also the expression of G9a and GLP, the methyltransferases generating H3K9me2. It allows for the activity of Ezh2, the methyltransferase generating H3K27me3, again by the inactivation of Cdk1. Thus, Mad2l2 is instrumental for the proceeding to a further advanced epigenetic status of PGCs. In the absence of Mad2I2, the de-regulation of cell cycle and epigenetic reprogramming results in a fast elimination of all PGCs. 


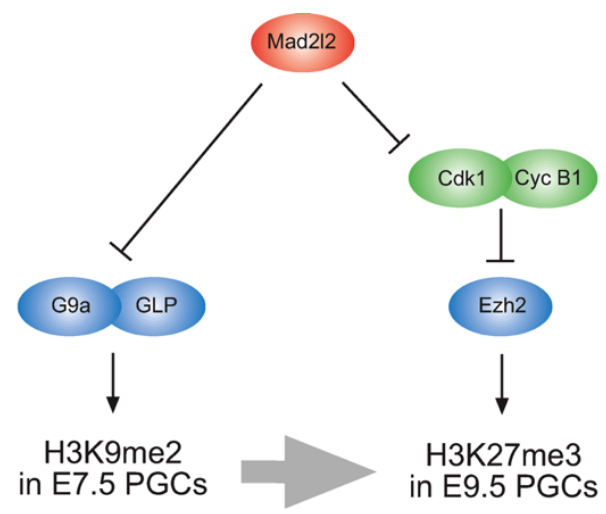

Figure 22. A model describing the function of Mad2I2 in PGC development.

$\mathrm{H} 3 \mathrm{~K} 9 \mathrm{me} 2$ is the dominant histone mark in specified PGCs at E7.5. Mad2I2 suppresses expression and activity of the histone methyltransferases G9a and GLP, and consequently $\mathrm{H} 3 \mathrm{~K} 9 \mathrm{me} 2$. It binds to and inhibits $\mathrm{Cdk} 1$, which leads to a suppression of the inhibitory phosphorylation of Ezh2. Thus, the PRC2 component Ezh2 becomes active, and can catalyze the trimethylation of histone $\mathrm{H} 3$ on residue $\mathrm{K} 27$. The inhibition of Cdk1 by Mad2I2 prohibits at the same time the entry of PGCs into mitosis, so that the epigenetic transition can occur during an arrest of the cell cycle in the G2 phase.

\section{Mad212\% ESCs are unstable and deviate into primitive endoderm cells}

Depletions of several genes have been reported to associate with a loss of selfrenewal and pluripotency of ESCs (see introduction). More specifically, there are studies showing spontaneous differentiation of ESCs to primitive endoderm upon knockout or knockdown of an individual gene (Forrai et al., 2006; Ma et al., 2011; Tsuneyoshi et al., 2008) or members of a gene family (Smith et al., 2010). Although these genes appeared to function differently, a common observation is the loss of expression of pluripotency-related markers including Nanog, Oct4, and Sox2, and upregulation of primitive endodermal markers Gata4/6 and Sox17. For example, siRNA-mediated downregulation of Prdm14 causes primitive endoderm differentiation in mouse (Ma et al., 2011) and human ESCs (Tsuneyoshi et al., 2008). In contrast, overexpression of Prdm14 impairs primitive endoderm differentiation during embryoid body differentiation. Prdm14 behaves similar to Nanog and Oct4 in occupying the genomic loci associated with pluripotency- or primitive endodermrelated transcription factors and induce or suppress transcription in those genomic regions, respectively (Ma et al., 2011).

Co-deletion of C-Myc and N-Myc results in primitive endoderm differentiation of mouse ESCs and iPSCs (Smith et al., 2010). Mechanistically, Myc proteins sustain pluripotency by at least two means. First, they repress Gata6, the master 
regulator of primitive endoderm development. Second, they contribute to the cell cycle through regulation of miR-17-92 miRNA cluster (Smith et al., 2010).

Suppressor of cytokine signaling-3 (SOCS-3) deficient ESCs also differentiate spontaneously when cultured in conventional LIF/Serum medium due to a deregulation of LIF signaling (Forrai et al., 2006). Similar to findings in this study, primitive endoderm differentiation in SOCS-3 ${ }^{-/-}$ESCs can be blocked by inhibition of Erk signaling pathway using PD or U0126. SOCS-3 ${ }^{-/-}$ESCs exhibit less proliferation rate even if they are cultured in LIF/2i, an observation which is in line with that in Mad2I2 $^{-/-}$ESCs. This implies that activation of Erk pathway launches primitive endoderm differentiation (Canham et al., 2010). It also confirms the identity of differentiated cells in Mad2I2 deficient ESCs as primitive endoderm.

Another consequence of lineage differentiation in ESCs is a set of changes in chromatin configuration. Pluripotent ESCs harbor low levels of total H3K9me2 and $\mathrm{H} 3 \mathrm{~K} 27$ me3, the two major repressive histone marks associated with silent loci and heterochromatin, respectively. Mad2I2/-- ESCs, in both LIF/Serum and LIF/2i conditions, contain higher levels of these two marks. This seems to be rather a consequence of priming for differentiation than the cause of it. Since none of the known Mad2l2 interacting partners in fibroblasts, including Cdk1 or histone modifying enzymes GLP and G9a, could be detected in co-immunoprecipitates of Mad2I2 in ESCs, the misregulation of histone modifications in Mad2I2 deficient ESCs is less likely to be a direct effect of the absence of Mad2I2.

Nanog and Gata4/6 play pivotal roles for the segregation of pluripotent epiblast and primitive endoderm in the early blastocyst (see introduction). Recently Gata4 was reported to block somatic cell reprogramming by direct repression of Nanog, endorsing their mutual inhibition (Serrano et al., 2013). Therefore, fine-tuning of Nanog and Gata4 expression is critical for the maintenance of pluripotency in ESCs as well as for its induction, which appeared to be deficient in Mad2I2/- ESCs.

\section{Mad2l2 association with stem cell coactivator complex may safeguard} Nanog expression and pluripotency of ESCs

Mad2I2 interacting partners differ from one cell type to another. The observed phenotype in Mad2I2-/- ESCs cannot be explained by Mad2l2 interactions with previously known partners in this study, including Cdk1, G9a, or GLP, and other reports, like TCF4, or Elk1. The most related interacting partner to the phenotype of 
Mad2I2/- ESCs is Centrin-2. Centrin-2 was originally identified as a protein involved in nucleotide excision repair (NER) response to DNA damage. Recently, it has been reported to function in regulation of Nanog expression in ESCs (Fong et al., 2011). Centrin-2, the component of the trimeric Xeroderma pigmentosum group $C$ (XPC)RAD23B-Centrin 2 (CETN2) NER complex, is involved as a cofactor in Oct4/Sox2dependent expression of Nanog in ESCs (Fong et al., 2011). These three proteins of the "stem cell coactivator complex" (SCC) are highly enriched in pluripotent ESCS and are downregulated upon differentiation. They interact physically with Oct4 and Sox2 and thereby are targeted to their cognate promoters. Specifically, SCC is recruited to the Nanog and Oct4 promoters and also to the other genomic regions occupied by Oct4 and Sox2 (Fong et al., 2011). Indeed, SCC target sites overlap those of Oct4 and Sox2 (with $~ 70 \%$ similarity in binding preference). Depletion of SCC proteins by shRNA in ESCs results in downregulation of Nanog and other pluripotency-related proteins as well as in loss of self renewal as indicated by appearance of flattened, fibroblastic, AP-negative cells at the periphery of collapsing ESC colonies, a phenotype which is identical to that in Mad2/2 ${ }^{-/}$ESCs. During the induction of pluripotent stem cells from MEFs, down regulation of SCC proteins results in a significant decrease in the number of reprogrammed cells, albeit CETN2 seems to be less crucial in these processes. Altogether, SCC components are essential to sustain and induce pluripotent ESCs, a function that is independent of their role as nucleotide excision repair (Fong et al., 2011). Interaction of Mad2I2 with CETN2 suggests its implication in stability/activity of SCC in ESCs. Mechanistically, among other possibilities, a model for the role of Mad2l2 in pluripotency of mouse ESCs is proposed (Figure 18): In wild type cells, Mad2l2 in association with other SCC proteins supports expression of Nanog. In the absence of Mad2I2, on the other hand, SCC complex is less effective/stable and as a result, expression of Nanog is not activated efficiently, while the cells are probably still expressing other pluripotency-related transcription factors like Oct4. These transient Oct4 ${ }^{+} / \mathrm{Nanog}^{-}$ cells are unstable and primed for differentiation. Hence they rapidly slip through differentiation and first become Oct $4^{+} / \mathrm{Nanog}^{-} / \mathrm{Gata}^{+}$(similar to primitive endoderm cells at the early blastocysts) and then Oct $4^{-} / \mathrm{Nanog}^{-} / \mathrm{Gata}^{+} / \mathrm{Sox} 17^{+}$cells (similar to fully differentiated primitive endoderm cells at the late blastocysts). During commitment to primitive endoderm lineage, Mad212 ${ }^{-/}$cells acquire a typical differentiated cell cycle and gene expression profiles, epigenetic signature that is 
distinct from those in undifferentiated wild type ESCs (Figure 18). Thus, Mad2I2 is essential for self-renewal in mouse ESCs and safeguards their pluripotency.

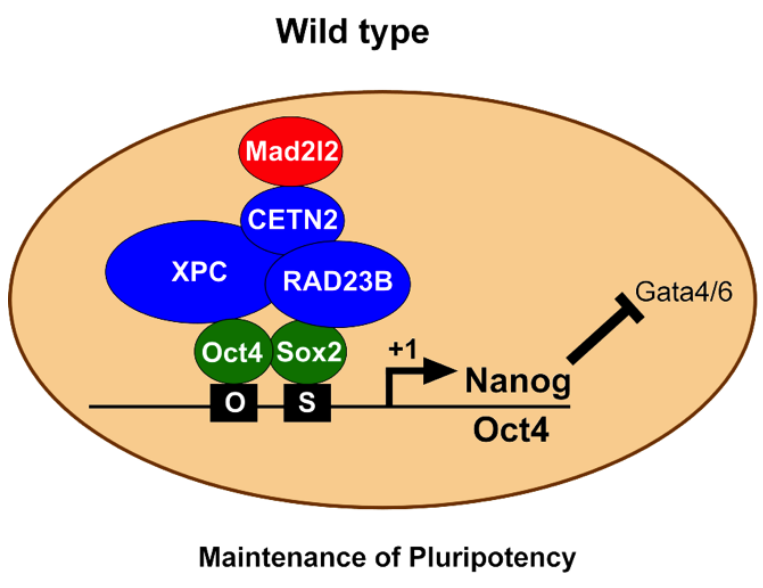

Figure 23. A model for function of Mad2I2 in pluripotency of mouse ESCs

Left: in wild type ESCs, Mad2I2 associates with CETN2 and functions together with other components of SCC complex as a cofactor for Oct4 and Sox2 to activate expression of Nanog, all of which collectively support pluripotency of ESCs. Right: in the absence of Mad2I2, SCC complex is less stable/active to launch expression of Nanog. Therefore Nanog is no longer available to antagonize Gata4/6 expression. This causes transient appearance of $\mathrm{Oct}^{+} / \mathrm{Nanog}^{-} / \mathrm{Gata}^{+}$cells, which further differentiate into Oct $4^{-} / \mathrm{Nanog}^{-} / \mathrm{Gata}^{+} / \mathrm{Sox} 17^{+}$ primitive endoderm cells. These cells lack characteristics of pluripotent cells including typical cell cycle profile, low abundance of repressive histone marks, chimera formation potential, etc. Modified from (Etchegaray and Mostoslavsky, 2011).

\section{Context-dependent regulation of Mad212 function}

Mad2l2 is widely expressed in different tissues with no obvious sign of regulation at the transcriptional level. Yet, Mad2I2 might be regulated by post-translational modification, including phosphorylation, or by homo-dimerization (Murakumo et al., 2001). Alternatively, the fact that Mad2l2 interacts with a wide variety of proteins suggests that indeed its function, rather than its expression, is regulated simply by the accessibility of its interacting partner(s) in a given tissue or cell type. For instance, in fibroblasts and probably also in PGCs, Mad2I2 binds to Cdk1, G9a and GLP, and thereby influences the cell cycle and the modification of histones. In contrast, in ESCs, Cdk1, G9a and GLP are most probably not accessible or not expressed at appreciable levels and instead, CETN-2 is expressed at high level and is available for Mad2l2 interaction. As a result, Mad2l2 functions depend on its context, and on the presence of other interactors. 


\section{Mad212: a connection between DNA damage, epigenetic}

\section{reprogramming, and pluripotency}

In conclusion, Mad2l2 is essential for epigenetic reprogramming of mouse early PGCs as well as for pluripotency of mouse ESCs. These functions of Mad2/2 appear unrelated, only in the first glance, to its well-documented role in DNA repair. However, these functions are likely to have evolved together, and can be considered as the two sides of a same coin: the "genome integrity/fidelity". Mad2l2 is an accessory subunit of DNA polymerase zeta, which points to its role in genome integrity upon DNA damage introduction. It is also essential for genome fidelity of PGCs and pluripotent cells. Both cell types are under an intensive selective pressure to ensure no transmission of genetically or epigenetically defective cells to the next generation or to the embryo proper, respectively. As the result, DNA damagesusceptible Mad212 ${ }^{-/}$PGCs fail to undergo epigenetic reprogramming, and are eliminated before having chance to contribute to the germline development. This happens by prompt apoptosis of all Mad2/2/- PGCs. In contrast, this phenotype has a less penetrance in pluripotent cells, since only half of the early Mad212 ${ }^{-1}$ embryos are lost in vivo. In ESCs, non-authentic Mad212 ${ }^{-/}$cells are eliminated by spontaneous differentiation and loss of pluripotency, in order to avoid a possibility for the generation of DNA damage-susceptible individuals. Thus, Mad2l2 is a molecule in which mechanisms underlying PGC development, pluripotency, and DNA damage are connected to ensure development of authentic PGCs and pluripotent stem cells. 


\section{References}

Ahmed, K., Dehghani, H., Rugg-Gunn, P., Fussner, E., Rossant, J., and Bazett-Jones, D.P. (2010). Global chromatin architecture reflects pluripotency and lineage commitment in the early mouse embryo. PLoS One 5, e10531.

Aravind, L., and Koonin, E.V. (1998). The HORMA domain: a common structural denominator in mitotic checkpoints, chromosome synapsis and DNA repair. Trends Biochem Sci 23, 284-286.

Azuara, V., Perry, P., Sauer, S., Spivakov, M., Jorgensen, H.F., John, R.M., Gouti, M., Casanova, M., Warnes, G., Merkenschlager, M., et al. (2006). Chromatin signatures of pluripotent cell lines. Nat Cell Biol 8, 532-538.

Bartolomei, M.S., and Ferguson-Smith, A.C. (2011). Mammalian genomic imprinting. Cold Spring Harb Perspect Biol 3.

Bassermann, F., Frescas, D., Guardavaccaro, D., Busino, L., Peschiaroli, A., and Pagano, M. (2008). The Cdc14B-Cdh1-PIk1 axis controls the G2 DNA-damage-response checkpoint. Cell 134, 256-267.

Bassermann, F., and Pagano, M. (2010). Dissecting the role of ubiquitylation in the DNA damage response checkpoint in G2. Cell Death Differ 17, 78-85.

Baynton, K., Bresson-Roy, A., and Fuchs, R.P. (1999). Distinct roles for Rev1p and Rev7p during translesion synthesis in Saccharomyces cerevisiae. Mol Microbiol 34, 124-133.

Bemark, M., Khamlichi, A.A., Davies, S.L., and Neuberger, M.S. (2000). Disruption of mouse polymerase zeta (Rev3) leads to embryonic lethality and impairs blastocyst development in vitro. Curr Biol 10, 1213-1216.

Bernstein, B.E., Mikkelsen, T.S., Xie, X., Kamal, M., Huebert, D.J., Cuff, J., Fry, B., Meissner, A., Wernig, M., Plath, K., et al. (2006). A bivalent chromatin structure marks key developmental genes in embryonic stem cells. Cell 125, 315-326.

Bridges, B.A. (1999). DNA repair: Polymerases for passing lesions. Curr Biol 9, R475-477.

Canham, M.A., Sharov, A.A., Ko, M.S., and Brickman, J.M. (2010). Functional heterogeneity of embryonic stem cells revealed through translational amplification of an early endodermal transcript. PLoS biology 8, e1000379.

Chang, L., and Karin, M. (2001). Mammalian MAP kinase signalling cascades. Nature 410, 37-40.

Chazaud, C., Yamanaka, Y., Pawson, T., and Rossant, J. (2006). Early lineage segregation between epiblast and primitive endoderm in mouse blastocysts through the Grb2-MAPK pathway. Dev Cell 10, 615-624.

Chen, J., and Fang, G. (2001). MAD2B is an inhibitor of the anaphase-promoting complex. Genes Dev 15, 1765-1770.

Cheung, H.W., Chun, A.C., Wang, Q., Deng, W., Hu, L., Guan, X.Y., Nicholls, J.M., Ling, M.T., Chuan Wong, Y., Tsao, S.W., et al. (2006). Inactivation of human MAD2B in 
nasopharyngeal carcinoma cells leads to chemosensitization to DNA-damaging agents. Cancer research 66, 4357-4367.

Covello, K.L., Kehler, J., Yu, H., Gordan, J.D., Arsham, A.M., Hu, C.J., Labosky, P.A., Simon, M.C., and Keith, B. (2006). HIF-2alpha regulates Oct-4: effects of hypoxia on stem cell function, embryonic development, and tumor growth. Genes Dev 20, 557-570.

Dame, C., Kirschner, K.M., Bartz, K.V., Wallach, T., Hussels, C.S., and Scholz, H. (2006). Wilms tumor suppressor, $\mathrm{Wt} 1$, is a transcriptional activator of the erythropoietin gene. Blood 107, 4282-4290.

De Felici, M., and Farini, D. (2012). The control of cell cycle in mouse primordial germ cells: old and new players. Curr Pharm Des 18, 233-244.

de Sousa Lopes, S.M., Hayashi, K., and Surani, M.A. (2007). Proximal visceral endoderm and extraembryonic ectoderm regulate the formation of primordial germ cell precursors. BMC Dev Biol 7, 140.

Dietrich, J.E., and Hiiragi, T. (2007). Stochastic patterning in the mouse pre-implantation embryo. Development 134, 4219-4231.

Doitsidou, M., Reichman-Fried, M., Stebler, J., Koprunner, M., Dorries, J., Meyer, D., Esguerra, C.V., Leung, T., and Raz, E. (2002). Guidance of primordial germ cell migration by the chemokine SDF-1. Cell 111, 647-659.

Efroni, S., Duttagupta, R., Cheng, J., Dehghani, H., Hoeppner, D.J., Dash, C., Bazett-Jones, D.P., Le Grice, S., McKay, R.D., Buetow, K.H., et al. (2008). Global transcription in pluripotent embryonic stem cells. Cell Stem Cell 2, 437-447.

Esposito, G., Godindagger, I., Klein, U., Yaspo, M.L., Cumano, A., and Rajewsky, K. (2000). Disruption of the Rev3l-encoded catalytic subunit of polymerase zeta in mice results in early embryonic lethality. Curr Biol 10, 1221-1224.

Esteve, P.O., Chin, H.G., Smallwood, A., Feehery, G.R., Gangisetty, O., Karpf, A.R., Carey, M.F., and Pradhan, S. (2006). Direct interaction between DNMT1 and G9a coordinates DNA and histone methylation during replication. Genes Dev 20, 3089-3103.

Etchegaray, J.P., and Mostoslavsky, R. (2011). eNERgizing pluripotent gene transcription. Cell Stem Cell 9, 285-286.

Evans, M.J., and Kaufman, M.H. (1981). Establishment in culture of pluripotential cells from mouse embryos. Nature 292, 154-156.

Fong, Y.W., Inouye, C., Yamaguchi, T., Cattoglio, C., Grubisic, I., and Tjian, R. (2011). A DNA repair complex functions as an Oct4/Sox2 coactivator in embryonic stem cells. Cell 147, 120-131.

Forrai, A., Boyle, K., Hart, A.H., Hartley, L., Rakar, S., Willson, T.A., Simpson, K.M., Roberts, A.W., Alexander, W.S., Voss, A.K., et al. (2006). Absence of suppressor of cytokine signalling 3 reduces self-renewal and promotes differentiation in murine embryonic stem cells. Stem Cells 24, 604-614.

Friedberg, E.C., and Gerlach, V.L. (1999). Novel DNA polymerases offer clues to the molecular basis of mutagenesis. Cell 98, 413-416. 
Gan, G.N., Wittschieben, J.P., Wittschieben, B.O., and Wood, R.D. (2008). DNA polymerase zeta (pol zeta) in higher eukaryotes. Cell Res 18, 174-183.

Gaspar-Maia, A., Alajem, A., Meshorer, E., and Ramalho-Santos, M. (2011). Open chromatin in pluripotency and reprogramming. Nat Rev Mol Cell Biol 12, 36-47.

Goudarzi, M., Banisch, T.U., Mobin, M.B., Maghelli, N., Tarbashevich, K., Strate, I., van den Berg, J., Blaser, H., Bandemer, S., Paluch, E., et al. (2012). Identification and Regulation of a Molecular Module for Bleb-Based Cell Motility. Dev Cell.

Grossmann, K.F., Brown, J.C., and Moses, R.E. (1999). Cisplatin DNA cross-links do not inhibit S-phase and cause only a G2/M arrest in Saccharomyces cerevisiae. Mutat Res 434, 29-39.

Gu, Y., Runyan, C., Shoemaker, A., Surani, A., and Wylie, C. (2009). Steel factor controls primordial germ cell survival and motility from the time of their specification in the allantois, and provides a continuous niche throughout their migration. Development 136, 1295-1303.

Guo, G., Huss, M., Tong, G.Q., Wang, C., Li Sun, L., Clarke, N.D., and Robson, P. (2010). Resolution of cell fate decisions revealed by single-cell gene expression analysis from zygote to blastocyst. Dev Cell 18, 675-685.

Gyory, I., Wu, J., Fejer, G., Seto, E., and Wright, K.L. (2004). PRDI-BF1 recruits the histone H3 methyltransferase G9a in transcriptional silencing. Nature immunology 5, 299-308.

Hackett, J.A., Sengupta, R., Zylicz, J.J., Murakami, K., Lee, C., Down, T.A., and Surani, M.A. (2012a). Germline DNA Demethylation Dynamics and Imprint Erasure Through 5Hydroxymethylcytosine. Science.

Hackett, J.A., Zylicz, J.J., and Surani, M.A. (2012b). Parallel mechanisms of epigenetic reprogramming in the germline. Trends Genet.

Hackett, J.A., Zylicz, J.J., and Surani, M.A. (2012c). Parallel mechanisms of epigenetic reprogramming in the germline. Trends Genet 28, 164-174.

Hajkova, P. (2011). Epigenetic reprogramming in the germline: towards the ground state of the epigenome. Philos Trans R Soc Lond B Biol Sci 366, 2266-2273.

Hajkova, P., Ancelin, K., Waldmann, T., Lacoste, N., Lange, U.C., Cesari, F., Lee, C., Almouzni, G., Schneider, R., and Surani, M.A. (2008). Chromatin dynamics during epigenetic reprogramming in the mouse germ line. Nature $452,877-881$.

Hajkova, P., Jeffries, S.J., Lee, C., Miller, N., Jackson, S.P., and Surani, M.A. (2010). Genome-wide reprogramming in the mouse germ line entails the base excision repair pathway. Science 329, 78-82.

Hanafusa, T., Habu, T., Tomida, J., Ohashi, E., Murakumo, Y., and Ohmori, H. (2010). Overlapping in short motif sequences for binding to human REV7 and MAD2 proteins. Genes to cells : devoted to molecular \& cellular mechanisms.

Hanawalt, P.C. (1994). Transcription-coupled repair and human disease. Science 266, 1957-1958. 
Hawkins, R.D., Hon, G.C., Lee, L.K., Ngo, Q., Lister, R., Pelizzola, M., Edsall, L.E., Kuan, S., Luu, Y., Klugman, S., et al. (2010). Distinct epigenomic landscapes of pluripotent and lineage-committed human cells. Cell Stem Cell 6, 479-491.

Hawkins, R.D., Hon, G.C., Yang, C., Antosiewicz-Bourget, J.E., Lee, L.K., Ngo, Q.M., Klugman, S., Ching, K.A., Edsall, L.E., Ye, Z., et al. (2011). Dynamic chromatin states in human ES cells reveal potential regulatory sequences and genes involved in pluripotency. Cell Res 21, 1393-1409.

Hendzel, M.J., Wei, Y., Mancini, M.A., Van Hooser, A., Ranalli, T., Brinkley, B.R., BazettJones, D.P., and Allis, C.D. (1997). Mitosis-specific phosphorylation of histone H3 initiates primarily within pericentromeric heterochromatin during $\mathrm{G} 2$ and spreads in an ordered fashion coincident with mitotic chromosome condensation. Chromosoma 106, 348-360.

Heo, K., Kim, J.S., Kim, K., Kim, H., Choi, J., Yang, K., and An, W. (2012). Cell-penetrating $\mathrm{H} 4$ tail peptides potentiate p53-mediated transactivation via inhibition of G9a and HDAC1. Oncogene.

Hollander, M.C., Sheikh, M.S., Bulavin, D.V., Lundgren, K., Augeri-Henmueller, L., Shehee, R., Molinaro, T.A., Kim, K.E., Tolosa, E., Ashwell, J.D., et al. (1999). Genomic instability in Gadd45a-deficient mice. Nat Genet 23, 176-184.

Hong, C.F., Chou, Y.T., Lin, Y.S., and Wu, C.W. (2009). MAD2B, a novel TCF4-binding protein, modulates TCF4-mediated epithelial-mesenchymal transdifferentiation. The Journal of biological chemistry 284, 19613-19622.

Hopf, C., Viebahn, C., and Puschel, B. (2011). BMP signals and the transcriptional repressor BLIMP1 during germline segregation in the mammalian embryo. Dev Genes Evol 221, 209223.

Hutchins, J.R., Toyoda, Y., Hegemann, B., Poser, I., Heriche, J.K., Sykora, M.M., Augsburg, M., Hudecz, O., Buschhorn, B.A., Bulkescher, J., et al. (2010). Systematic analysis of human protein complexes identifies chromosome segregation proteins. Science 328, 593-599.

Hyafil, F., Morello, D., Babinet, C., and Jacob, F. (1980). A cell surface glycoprotein involved in the compaction of embryonal carcinoma cells and cleavage stage embryos. Cell 21, 927934.

Jackman, M., Lindon, C., Nigg, E.A., and Pines, J. (2003). Active cyclin B1-Cdk1 first appears on centrosomes in prophase. Nat Cell Biol 5, 143-148.

Jaenisch, R., and Young, R. (2008). Stem cells, the molecular circuitry of pluripotency and nuclear reprogramming. Cell 132, 567-582.

Jansen, J.G., Langerak, P., Tsaalbi-Shtylik, A., van den Berk, P., Jacobs, H., and de Wind, N. (2006). Strand-biased defect in $C / G$ transversions in hypermutating immunoglobulin genes in Rev1-deficient mice. J Exp Med 203, 319-323.

Kehler, J., Tolkunova, E., Koschorz, B., Pesce, M., Gentile, L., Boiani, M., Lomeli, H., Nagy, A., McLaughlin, K.J., Scholer, H.R., et al. (2004). Oct4 is required for primordial germ cell survival. EMBO reports 5, 1078-1083.

Kikuchi, S., Hara, K., Shimizu, T., Sato, M., and Hashimoto, H. (2012). Structural Basis of Recruitment of DNA Polymerase zeta by Interaction between REV1 and REV7 Proteins. The Journal of biological chemistry $287,33847-33852$. 
Kurimoto, K., Yabuta, Y., Ohinata, Y., Shigeta, M., Yamanaka, K., and Saitou, M. (2008a). Complex genome-wide transcription dynamics orchestrated by Blimp1 for the specification of the germ cell lineage in mice. Genes Dev 22, 1617-1635.

Kurimoto, K., Yamaji, M., Seki, Y., and Saitou, M. (2008b). Specification of the germ cell lineage in mice: a process orchestrated by the PR-domain proteins, Blimp1 and Prdm14. Cell Cycle 7, 3514-3518.

Kyriakis, J.M., and Avruch, J. (2001). Mammalian mitogen-activated protein kinase signal transduction pathways activated by stress and inflammation. Physiological reviews $81,807-$ 869.

Lanner, F., and Rossant, J. (2010). The role of FGF/Erk signaling in pluripotent cells. Development 137, 3351-3360.

Lawrence, C.W., Das, G., and Christensen, R.B. (1985). REV7, a new gene concerned with UV mutagenesis in yeast. Molecular \& general genetics : MGG 200, 80-85.

Li, Z., Fei, T., Zhang, J., Zhu, G., Wang, L., Lu, D., Chi, X., Teng, Y., Hou, N., Yang, X., et al. (2012). BMP4 Signaling Acts via dual-specificity phosphatase 9 to control ERK activity in mouse embryonic stem cells. Cell Stem Cell 10, 171-182.

Lin, Y., Wong, K., and Calame, K. (1997). Repression of c-myc transcription by Blimp-1, an inducer of terminal B cell differentiation. Science 276, 596-599.

Lindqvist, A., Rodriguez-Bravo, V., and Medema, R.H. (2009). The decision to enter mitosis: feedback and redundancy in the mitotic entry network. J Cell Biol 185, 193-202.

Lindqvist, A., van Zon, W., Karlsson Rosenthal, C., and Wolthuis, R.M. (2007). Cyclin B1Cdk1 activation continues after centrosome separation to control mitotic progression. PLoS biology 5, e123.

Ma, Z., Swigut, T., Valouev, A., Rada-Iglesias, A., and Wysocka, J. (2011). Sequencespecific regulator Prdm14 safeguards mouse ESCs from entering extraembryonic endoderm fates. Nat Struct Mol Biol 18, 120-127.

Magnusdottir, E., Gillich, A., Grabole, N., and Surani, M.A. (2012). Combinatorial control of cell fate and reprogramming in the mammalian germline. Curr Opin Genet Dev.

Marks, H., Kalkan, T., Menafra, R., Denissov, S., Jones, K., Hofemeister, H., Nichols, J., Kranz, A., Stewart, A.F., Smith, A., et al. (2012). The transcriptional and epigenomic foundations of ground state pluripotency. Cell 149, 590-604.

McLaren, A. (2000). Establishment of the germ cell lineage in mammals. Journal of cellular physiology 182, 141-143.

McLaren, A., and Lawson, K.A. (2005). How is the mouse germ-cell lineage established? Differentiation 73, 435-437.

Medendorp, K., van Groningen, J.J., Vreede, L., Hetterschijt, L., van den Hurk, W.H., de Bruijn, D.R., Brugmans, L., and van Kessel, A.G. (2009). The mitotic arrest deficient protein MAD2B interacts with the small GTPase RAN throughout the cell cycle. PLoS One 4, e7020. 
Medendorp, K., Vreede, L., van Groningen, J.J., Hetterschijt, L., Brugmans, L., Jansen, P.A., van den Hurk, W.H., de Bruijn, D.R., and van Kessel, A.G. (2010). The mitotic arrest deficient protein MAD2B interacts with the clathrin light chain A during mitosis. PLoS One 5, e15128.

Meshorer, E., Yellajoshula, D., George, E., Scambler, P.J., Brown, D.T., and Misteli, T. (2006). Hyperdynamic plasticity of chromatin proteins in pluripotent embryonic stem cells. Dev Cell 10, 105-116.

Miki, T., Yasuda, S.Y., and Kahn, M. (2011). Wnt/beta-catenin signaling in embryonic stem cell self-renewal and somatic cell reprogramming. Stem Cell Rev 7, 836-846.

Mochizuki, K., and Matsui, Y. (2010). Epigenetic profiles in primordial germ cells: global modulation and fine tuning of the epigenome for acquisition of totipotency. Dev Growth Differ 52, 517-525.

Murakumo, Y., Ogura, Y., Ishii, H., Numata, S., Ichihara, M., Croce, C.M., Fishel, R., and Takahashi, M. (2001). Interactions in the error-prone postreplication repair proteins hREV1, hREV3, and hREV7. The Journal of biological chemistry 276, 35644-35651.

Murakumo, Y., Roth, T., Ishii, H., Rasio, D., Numata, S., Croce, C.M., and Fishel, R. (2000). A human REV7 homolog that interacts with the polymerase zeta catalytic subunit hREV3 and the spindle assembly checkpoint protein hMAD2. The Journal of biological chemistry 275, 4391-4397.

Nelson, J.R., Lawrence, C.W., and Hinkle, D.C. (1996). Thymine-thymine dimer bypass by yeast DNA polymerase zeta. Science $272,1646-1649$.

Niakan, K.K., Ji, H., Maehr, R., Vokes, S.A., Rodolfa, K.T., Sherwood, R.I., Yamaki, M., Dimos, J.T., Chen, A.E., Melton, D.A., et al. (2010). Sox17 promotes differentiation in mouse embryonic stem cells by directly regulating extraembryonic gene expression and indirectly antagonizing self-renewal. Genes Dev 24, 312-326.

Nichols, J., Silva, J., Roode, M., and Smith, A. (2009). Suppression of Erk signalling promotes ground state pluripotency in the mouse embryo. Development 136, 3215-3222.

Nishioka, N., Inoue, K., Adachi, K., Kiyonari, H., Ota, M., Ralston, A., Yabuta, N., Hirahara, S., Stephenson, R.O., Ogonuki, N., et al. (2009). The Hippo signaling pathway components Lats and Yap pattern Tead4 activity to distinguish mouse trophectoderm from inner cell mass. Dev Cell 16, 398-410.

Niwa, H., Ogawa, K., Shimosato, D., and Adachi, K. (2009). A parallel circuit of LIF signalling pathways maintains pluripotency of mouse ES cells. Nature 460, 118-122.

Niwa, H., Toyooka, Y., Shimosato, D., Strumpf, D., Takahashi, K., Yagi, R., and Rossant, J. (2005). Interaction between Oct3/4 and Cdx2 determines trophectoderm differentiation. Cell 123, 917-929.

Nyberg, K.A., Michelson, R.J., Putnam, C.W., and Weinert, T.A. (2002). Toward maintaining the genome: DNA damage and replication checkpoints. Annu Rev Genet 36, 617-656.

Ohinata, Y., Ohta, H., Shigeta, M., Yamanaka, K., Wakayama, T., and Saitou, M. (2009). A signaling principle for the specification of the germ cell lineage in mice. Cell 137, 571-584. 
Ohinata, Y., Payer, B., O'Carroll, D., Ancelin, K., Ono, Y., Sano, M., Barton, S.C., Obukhanych, T., Nussenzweig, M., Tarakhovsky, A., et al. (2005). Blimp1 is a critical determinant of the germ cell lineage in mice. Nature 436, 207-213.

Park, S.H., Park, S.H., Kook, M.C., Kim, E.Y., Park, S., and Lim, J.H. (2004). Ultrastructure of human embryonic stem cells and spontaneous and retinoic acid-induced differentiating cells. Ultrastruct Pathol 28, 229-238.

Pfleger, C.M., Salic, A., Lee, E., and Kirschner, M.W. (2001). Inhibition of Cdh1-APC by the MAD2-related protein MAD2L2: a novel mechanism for regulating Cdh1. Genes Dev 15, 1759-1764.

Pines, J., and Hunter, T. (1991). Human cyclins A and B1 are differentially located in the cell and undergo cell cycle-dependent nuclear transport. J Cell Biol 115, 1-17.

Pirouz, M., Klimke, A., and Kessel, M. (2012). The reciprocal relationship between primordial germ cells and pluripotent stem cells. J Mol Med (Berl) 90, 753-761.

Pitulescu, M.E., Teichmann, M., Luo, L., and Kessel, M. (2009). TIPT2 and geminin interact with basal transcription factors to synergize in transcriptional regulation. BMC Biochem 10, 16.

Plusa, B., Frankenberg, S., Chalmers, A., Hadjantonakis, A.K., Moore, C.A., Papalopulu, N., Papaioannou, V.E., Glover, D.M., and Zernicka-Goetz, M. (2005). Downregulation of Par3 and aPKC function directs cells towards the ICM in the preimplantation mouse embryo. Journal of cell science $118,505-515$.

Popp, C., Dean, W., Feng, S., Cokus, S.J., Andrews, S., Pellegrini, M., Jacobsen, S.E., and Reik, W. Genome-wide erasure of DNA methylation in mouse primordial germ cells is affected by AID deficiency. Nature 463, 1101-1105.

Qi, X., Li, T.G., Hao, J., Hu, J., Wang, J., Simmons, H., Miura, S., Mishina, Y., and Zhao, G.Q. (2004). BMP4 supports self-renewal of embryonic stem cells by inhibiting mitogenactivated protein kinase pathways. Proc Natl Acad Sci U S A 101, 6027-6032.

Rogatsch, H., Jezek, D., Hittmair, A., Mikuz, G., and Feichtinger, H. (1996). Expression of vimentin, cytokeratin, and desmin in Sertoli cells of human fetal, cryptorchid, and tumouradjacent testicular tissue. Virchows Arch 427, 497-502.

Roux, P.P., and Blenis, J. (2004). ERK and p38 MAPK-activated protein kinases: a family of protein kinases with diverse biological functions. Microbiology and molecular biology reviews : MMBR 68, 320-344.

Runyan, C., Schaible, K., Molyneaux, K., Wang, Z., Levin, L., and Wylie, C. (2006). Steel factor controls midline cell death of primordial germ cells and is essential for their normal proliferation and migration. Development 133, 4861-4869.

Saga, Y. (2008). Mouse germ cell development during embryogenesis. Curr Opin Genet Dev 18, 337-341.

Saitou, M. (2009a). Germ cell specification in mice. Curr Opin Genet Dev 19, 386-395.

Saitou, M. (2009b). Specification of the germ cell lineage in mice. Front Biosci 14, 10681087. 
Saitou, M., Kagiwada, S., and Kurimoto, K. (2012). Epigenetic reprogramming in mouse preimplantation development and primordial germ cells. Development 139, 15-31.

Saitou, M., and Yamaji, M. (2012). Primordial germ cells in mice. Cold Spring Harb Perspect Biol 4.

Sakaguchi, K., Herrera, J.E., Saito, S., Miki, T., Bustin, M., Vassilev, A., Anderson, C.W., and Appella, E. (1998). DNA damage activates p53 through a phosphorylation-acetylation cascade. Genes Dev 12, 2831-2841.

Sancar, A. (1994). Mechanisms of DNA excision repair. Science 266, 1954-1956.

Sasaki, H., and Matsui, Y. (2008). Epigenetic events in mammalian germ-cell development: reprogramming and beyond. Nat Rev Genet 9, 129-140.

Schaniel, C., Ang, Y.S., Ratnakumar, K., Cormier, C., James, T., Bernstein, E., Lemischka, I.R., and Paddison, P.J. (2009). Smarcc1/Baf155 couples self-renewal gene repression with changes in chromatin structure in mouse embryonic stem cells. Stem Cells 27, 2979-2991.

Seki, Y., Hayashi, K., Itoh, K., Mizugaki, M., Saitou, M., and Matsui, Y. (2005). Extensive and orderly reprogramming of genome-wide chromatin modifications associated with specification and early development of germ cells in mice. Developmental biology $278,440-$ 458.

Seki, Y., Yamaji, M., Yabuta, Y., Sano, M., Shigeta, M., Matsui, Y., Saga, Y., Tachibana, M., Shinkai, Y., and Saitou, M. (2007). Cellular dynamics associated with the genome-wide epigenetic reprogramming in migrating primordial germ cells in mice. Development 134 , 2627-2638.

Serrano, F., Calatayud, C.F., Blazquez, M., Torres, J., Castell, J.V., and Bort, R. (2013). Gata4 blocks somatic cell reprogramming by directly repressing nanog. Stem Cells 31, 7182.

Sharma, S., Hicks, J.K., Chute, C.L., Brennan, J.R., Ahn, J.Y., Glover, T.W., and Canman, C.E. (2012). REV1 and polymerase zeta facilitate homologous recombination repair. Nucleic acids research $40,682-691$.

Shinkai, Y., and Tachibana, M. (2011). H3K9 methyltransferase G9a and the related molecule GLP. Genes Dev 25, 781-788.

Singh, A.M., Hamazaki, T., Hankowski, K.E., and Terada, N. (2007). A heterogeneous expression pattern for Nanog in embryonic stem cells. Stem Cells 25, 2534-2542.

Smallwood, A., Esteve, P.O., Pradhan, S., and Carey, M. (2007). Functional cooperation between HP1 and DNMT1 mediates gene silencing. Genes Dev 21, 1169-1178.

Smith, E., Hegarat, N., Vesely, C., Roseboom, I., Larch, C., Streicher, H., Straatman, K., Flynn, H., Skehel, M., Hirota, T., et al. (2011). Differential control of Eg5-dependent centrosome separation by Plk1 and Cdk1. The EMBO journal 30, 2233-2245.

Smith, K.N., Singh, A.M., and Dalton, S. (2010). Myc represses primitive endoderm differentiation in pluripotent stem cells. Cell Stem Cell 7, 343-354.

Sokol, S.Y. (2011). Maintaining embryonic stem cell pluripotency with Wnt signaling. Development 138, 4341-4350. 
Surani, M.A., Hayashi, K., and Hajkova, P. (2007). Genetic and epigenetic regulators of pluripotency. Cell 128, 747-762.

Szabo, P.E., Hubner, K., Scholer, H., and Mann, J.R. (2002). Allele-specific expression of imprinted genes in mouse migratory primordial germ cells. Mech Dev 115, 157-160.

Tachibana, M., Matsumura, Y., Fukuda, M., Kimura, H., and Shinkai, Y. (2008). G9a/GLP complexes independently mediate $\mathrm{H} 3 \mathrm{~K} 9$ and DNA methylation to silence transcription. The EMBO journal 27, 2681-2690.

Tachibana, M., Nozaki, M., Takeda, N., and Shinkai, Y. (2007). Functional dynamics of H3K9 methylation during meiotic prophase progression. The EMBO journal 26, 3346-3359.

Tachibana, M., Ueda, J., Fukuda, M., Takeda, N., Ohta, T., Iwanari, H., Sakihama, T., Kodama, T., Hamakubo, T., and Shinkai, Y. (2005). Histone methyltransferases G9a and GLP form heteromeric complexes and are both crucial for methylation of euchromatin at H3K9. Genes Dev 19, 815-826.

Takahashi, K., Murakami, M., and Yamanaka, S. (2005). Role of the phosphoinositide 3kinase pathway in mouse embryonic stem (ES) cells. Biochemical Society transactions 33, 1522-1525.

Takaoka, K., and Hamada, H. (2012). Cell fate decisions and axis determination in the early mouse embryo. Development 139, 3-14.

Tam, P.P., and Snow, M.H. (1981). Proliferation and migration of primordial germ cells during compensatory growth in mouse embryos. J Embryol Exp Morphol 64, 133-147.

Tanaka, S.S., Kojima, Y., Yamaguchi, Y.L., Nishinakamura, R., and Tam, P.P. (2011). Impact of WNT signaling on tissue lineage differentiation in the early mouse embryo. Dev Growth Differ 53, 843-856.

Torpey, L.E., Gibbs, P.E., Nelson, J., and Lawrence, C.W. (1994). Cloning and sequence of REV7, a gene whose function is required for DNA damage-induced mutagenesis in Saccharomyces cerevisiae. Yeast 10, 1503-1509.

Tsuneyoshi, N., Sumi, T., Onda, H., Nojima, H., Nakatsuji, N., and Suemori, H. (2008). PRDM14 suppresses expression of differentiation marker genes in human embryonic stem cells. Biochem Biophys Res Commun 367, 899-905.

Vairapandi, M., Balliet, A.G., Hoffman, B., and Liebermann, D.A. (2002). GADD45b and GADD45g are cdc2/cyclinB1 kinase inhibitors with a role in $S$ and G2/M cell cycle checkpoints induced by genotoxic stress. Journal of cellular physiology 192, 327-338.

Van Sloun, P.P., Varlet, I., Sonneveld, E., Boei, J.J., Romeijn, R.J., Eeken, J.C., and De Wind, N. (2002). Involvement of mouse Rev3 in tolerance of endogenous and exogenous DNA damage. Molecular and cellular biology 22, 2159-2169.

Vinot, S., Le, T., Ohno, S., Pawson, T., Maro, B., and Louvet-Vallee, S. (2005). Asymmetric distribution of PAR proteins in the mouse embryo begins at the 8-cell stage during compaction. Developmental biology 282, 307-319.

Wang, X.W., Zhan, Q., Coursen, J.D., Khan, M.A., Kontny, H.U., Yu, L., Hollander, M.C., O'Connor, P.M., Fornace, A.J., Jr., and Harris, C.C. (1999). GADD45 induction of a G2/M cell cycle checkpoint. Proc Natl Acad Sci U S A 96, 3706-3711. 
Watanabe, K., and Dai, X. (2011). A WNTer revisit: new faces of beta-catenin and TCFs in pluripotency. Science signaling 4, pe41.

Weber, S., Eckert, D., Nettersheim, D., Gillis, A.J., Schafer, S., Kuckenberg, P., Ehlermann, J., Werling, U., Biermann, K., Looijenga, L.H., et al. (2010). Critical function of AP-2 gamma/TCFAP2C in mouse embryonic germ cell maintenance. Biol Reprod 82, 214-223.

Wei, Y., Chen, Y.H., Li, L.Y., Lang, J., Yeh, S.P., Shi, B., Yang, C.C., Yang, J.Y., Lin, C.Y., Lai, C.C., et al. (2011). CDK1-dependent phosphorylation of EZH2 suppresses methylation of H3K27 and promotes osteogenic differentiation of human mesenchymal stem cells. Nat Cell Biol 13, 87-94.

Wen, B., Wu, H., Shinkai, Y., Irizarry, R.A., and Feinberg, A.P. (2009). Large histone H3 lysine 9 dimethylated chromatin blocks distinguish differentiated from embryonic stem cells. Nat Genet 41, 246-250.

West, J.A., Viswanathan, S.R., Yabuuchi, A., Cunniff, K., Takeuchi, A., Park, I.H., Sero, J.E., Zhu, H., Perez-Atayde, A., Frazier, A.L., et al. (2009). A role for Lin28 in primordial germ-cell development and germ-cell malignancy. Nature 460, 909-913.

Wittschieben, J., Shivji, M.K., Lalani, E., Jacobs, M.A., Marini, F., Gearhart, P.J., Rosewell, I., Stamp, G., and Wood, R.D. (2000). Disruption of the developmentally regulated Rev3l gene causes embryonic lethality. Curr Biol 10, 1217-1220.

Wray, J., Kalkan, T., Gomez-Lopez, S., Eckardt, D., Cook, A., Kemler, R., and Smith, A. (2011). Inhibition of glycogen synthase kinase-3 alleviates Tcf3 repression of the pluripotency network and increases embryonic stem cell resistance to differentiation. Nat Cell Biol 13, 838-845.

Xie, W., Yang, X., Xu, M., and Jiang, T. (2012). Structural insights into the assembly of human translesion polymerase complexes. Protein Cell 3, 864-874.

Yabuta, Y., Kurimoto, K., Ohinata, Y., Seki, Y., and Saitou, M. (2006). Gene expression dynamics during germline specification in mice identified by quantitative single-cell gene expression profiling. Biol Reprod 75, 705-716.

Yamaji, M., Seki, Y., Kurimoto, K., Yabuta, Y., Yuasa, M., Shigeta, M., Yamanaka, K., Ohinata, Y., and Saitou, M. (2008). Critical function of Prdm14 for the establishment of the germ cell lineage in mice. Nat Genet 40, 1016-1022.

Yamane, K., Toumazou, C., Tsukada, Y., Erdjument-Bromage, H., Tempst, P., Wong, J., and Zhang, Y. (2006). JHDM2A, a JmjC-containing H3K9 demethylase, facilitates transcription activation by androgen receptor. Cell 125, 483-495.

Yang, S.H., Sharrocks, A.D., and Whitmarsh, A.J. (2003). Transcriptional regulation by the MAP kinase signaling cascades. Gene 320, 3-21.

Ying, Q.L., Nichols, J., Chambers, I., and Smith, A. (2003). BMP induction of Id proteins suppresses differentiation and sustains embryonic stem cell self-renewal in collaboration with STAT3. Cell 115, 281-292.

Ying, Q.L., Wray, J., Nichols, J., Batlle-Morera, L., Doble, B., Woodgett, J., Cohen, P., and Smith, A. (2008). The ground state of embryonic stem cell self-renewal. Nature 453, 519U515. 
Young, R.A. (2011). Control of the embryonic stem cell state. Cell 144, 940-954.

Yuan, J., Adamski, R., and Chen, J. (2010). Focus on histone variant H2AX: to be or not to be. FEBS Lett 584, 3717-3724.

Zernicka-Goetz, M., Morris, S.A., and Bruce, A.W. (2009). Making a firm decision: multifaceted regulation of cell fate in the early mouse embryo. Nat Rev Genet 10, 467-477.

Zhan, Q., Antinore, M.J., Wang, X.W., Carrier, F., Smith, M.L., Harris, C.C., and Fornace, A.J., Jr. (1999). Association with Cdc2 and inhibition of Cdc2/Cyclin B1 kinase activity by the p53-regulated protein Gadd45. Oncogene 18, 2892-2900.

Zhang, L., Yang, S.H., and Sharrocks, A.D. (2007). Rev7/MAD2B links c-Jun N-terminal protein kinase pathway signaling to activation of the transcription factor Elk-1. Molecular and cellular biology $27,2861-2869$. 


\section{Curriculum Vitae}

\section{Personal Information:}

Surname: Pirouz

First name: Mehdi

Gender: Male

Nationality: Iranian

Date of birth: 8.30.1982

Place of Birth: Kermanshah, Iran

Occupation: PhD student, Max Planck Institute for Biophysical Chemistry, Goettingen, Germany

Address: Max Planck Institute for Biophysical Chemistry, Goettingen, Germany

Tel: +49551 2011752

Email: mpirouz1@gwdg.de

\section{Educational background:}

\begin{tabular}{|c|c|c|c|c|}
\hline Degree & Field & University & Date & Average \\
\hline M.Sc & Cell and Molecular Biology & Shiraz University (Shiraz, Iran) & 2004-07 & $\begin{array}{l}17.16 \text { Out of } 20 \\
\text { (Grade of Thesis: } 19.70 \text { out of } 20 \text { ) }\end{array}$ \\
\hline \multicolumn{5}{|c|}{$\begin{array}{l}\text { MSc thesis subject: Simultaneous effect of extracellular matrix and embryonic pancreas dynamic co-culture on } \\
\text { differentiation of insulin-secreting cells from mouse embryonic stem cells }\end{array}$} \\
\hline B.Sc & Cell and Molecular Biology & The University of Tehran (Tehran, Iran) & 2000-04 & $\begin{array}{c}16.23 \text { Out of } 20 \\
\text { (Grade of Thesis: } 19.00 \text { out of } 20 \text { ) }\end{array}$ \\
\hline
\end{tabular}

\section{Teaching experiences:}

\begin{tabular}{|c|c|c|c|}
\hline Course & Location (University) & Level & Date \\
\hline Manipulation of mouse Primordial Germ Cells & Developmental Biology program (Goettingen, Germany) & Ph.D. & 2012 \\
\hline Stem Cells and Tissue Engineering & Molecular Biology program (Goettingen, Germany) & Ph.D. & 2010-2012 \\
\hline Cell Culture techniques & M.Sc. program, Royan institute (Tehran, Iran) & M.Sc. & 2007-2008 \\
\hline Laboratory of Genetics & B.Sc. program, Shiraz University (Shiraz, Iran) & B.Sc. & 2004-2005 \\
\hline
\end{tabular}

\section{Interests:}

1) Mechanisms of Primordial Germ Cell (PGC) development

2) Genetic and epigenetic regulation of pluripotency and differentiation

3) Direct reprogramming of somatic cells 


\section{Research Experiences:}

\section{Cell culture, embryology and microscopy}

1. Derivation, culture and differentiation of mouse embryonic stem cells (ESCs)

2. Culture and differentiation of human ESCs and mouse epiblast stem cells (EpiSCs)

3. Isolation, culture and expansion of mouse spermatogonial stem cells (SSCs)

4. Manipulation of mouse embryos at different stages

5. Confocal microscopy

\section{Advanced Molecular biology}

6. Gene cloning

7. Retroviral transduction

8. Knock down experiments using siRNA

9. Western blot, Immunocytochemistry, Immunohistochemistry and whole mount staining

10. Chromatin-Immunoprecipitation (ChIP)

11. Co-Immunoprecipitation (Co-IP)

12. Analysis of protein-DNA interaction by electrophoretic mobility shift assay (EMSA)

13. Analysis of gene expression by RNA-sequencing and qRT-PCR

14. Assessing promoter activity by luciferase assay

\section{Publications:}

\section{9-a) Articles:}

1. Pirouz M et al. Mad2l2-deficient mouse embryonic stem cells deviate into primitive endoderm. In preparation.

2. Pirouz M, Pilarski S, Kessel M. Mad2l2 is essential for primordial germ cell development in mice. In revision

3. Pirouz M Klimke A, Kessel M. The reciprocal relationship between primordial germ cells and pluripotent stem cells. J Mol Med (Berl). 2012 Jul; 90(7): 753-61

4. Shakeri M, Kohram H, Shahverdi A, Shahneh AZ, Tavakolifar F, Pirouz M, Shahrebabak HM, Koruji M, Baharvand H. Behavior of mouse spermatogonial stem-like cells on an electrospun nanofibrillar matrix. ¿Assist Reprod Genet. 2012 Dec 30

5. Farrokhi A, Pirouz M, Jafary H, Baharvand H. Effect of extracellular matrix on differentiation to beta cells. 2008, Yakhteh (The Cell), 12:340-345.

6. Jafary H, Larijani B, Farrokhi A, Pirouz M, Mollamohammadi S, Baharvand H. Differential effect of activin on mouse embryonic stem cell differentiation into insulin-secreting cells under nestin-positive selection and spontaneous differentiation protocols. 2008 Feb;32(2):278-86.

\section{9-b) Books:}

1. Pirouz M, H. Baharvand, Differentiation of stem cells to gametes. A chapter of the book "Differentiation and Applications of Stem Cell" book edited in Persian. House of Biology press 2008, ISBN: 966-483-191-3.

2. Pirouz M, H. Baharvand, et al.; The origin of embryonic stem cells. A chapter of the book "Embryonic Stem Cells" book edited in Persian. House of Biology press 2008, ISBN: 978-9642605-18-7.

3. Khodadadi, L, Pirouz M, Baharvand H. et al., Stem cells and diabetes. A chapter of the book "Differentiation and Applications of Stem Cell" book edited in Persian. House of Biology press 2008, ISBN: 966-483-191-3.

4. Lewin B; Genes VII, Oxford publication. Translated in Persian by Bastin H, Pirouz M, et al.; UIH press 2004, ISBN: 964-452-170-6. 


\section{Presentation in international conferences:}

1. Pirouz M, Pilarski S, Kessel M. "Mad2l2 Regulates Epigenetic Transition in Early Mouse Primordial Germ Cells", poster presentation, Germline-Immortality through Totipotency, Heidelberg, Germany, October 2012.

2. Pirouz M, Pilarski S, Kessel M. "Mad2l2 Is Essential for Epigenetic Reprogramming in Murine Primordial Germ Cells", oral presentation, Berlin, Germany, September 2011.

3. Pirouz M, Pilarski S, Kessel M. "Mad2l2 Is Essential for Embryonic Development of Primordial Germ Cells", oral presentation. 4th International Symposium Stem Cell, Development and Regulation, Amsterdam, Netherlands, October 2010.

4. Baharvand H, Hosseini Salekdeh S.Gh, Zare Mehrjerdi N, Taei A, Nasr-Esfahani MH, Totonchi M, Hatami M, Kiani S, Pakzad M, Karbalaie Kh, Mollamohammadi S, Farrokhi A, Shahsavani M, Rezaei M, Seifi A, Azizi H, Hemessi K, Pirouz M, Tanhaei S, Pournasr B, Moradmand B, Pouya A, Nemati Sh, Karamali F, Rabbani R, "Embryonic Stem Cell Research at Royan Institute". Royan international twin congress. Aug 27-29, 2008, Tehran, Iran. Oral presentation.

5. M. Pirouz, T. Valadbeigy, H. Baharvand. "Spontaneous differentiation of human embryonic stem cells leads to promiscuous progress through meiosis". 5th Annual Meeting of the International Society for Stem Cell Research. June 17- June 20, 2007, Australia. Poster presentation.

\section{Presentation in Workshops:}

1. Speaker in "workshop of human embryonic stem cell joint to the Royan international twin congress" September 1-3, 2007, Tehran, Iran.

2. Scientific staff and executive member in "workshop of human embryonic stem cell joint to the Royan international twin congress" September 1-3, 2007, Tehran, Iran.

\section{Attended International Conferences:}

1. $3^{\text {rd }}$ International Congress on Stem Cells and Tissue Formation, Dresden, Germany, July 2010.

2. $5^{\text {th }}$ International Meeting of Stem Cell Network North Rhine Westphalia. Aachen, Germany. March 2009.

3. $2^{\text {nd }}$ International Workshop on Molecular Andrology. Giessen, Germany. May 2009.

\section{Honors, Awards and Achievements:}

1. Holder of Max Planck Society stipend during the period of $\mathrm{PhD}$

2. Lab manager, differentiation lab, Royan institute, Tehran, Iran; 2007-2009

3. Awarded a travel grant from $5^{\text {th }}$ Annual Meeting of the International Society for Stem Cell Research (ISSCR) in 2007, Australia.

4. Selected as the first winner of Royan institute's award of the best speaker (Feb. 2005)

5. $\quad$ Ranked as $3^{\text {rd }}$ student in MSc program among 30 students, 2007.

6. Ranked $618^{\text {th }}$ nationwide in the National University Entrance Exam among approximately 550,000 participants, 2000.

\section{Projects:}

\begin{tabular}{|l|l|c|c|c|}
\hline \multicolumn{1}{|c|}{ Title } & Position & Date & Institution \\
\hline 1 & Analysis of Role of Mad2I2 in PGC development & PhD student & 2009-present & $\begin{array}{l}\text { Max Planck Institute, } \\
\text { Goettingen, Germany }\end{array}$ \\
\hline 2 & Analysis of Role of Mad212 in pluripotent stem cells & PhD student & 2011-present & $\begin{array}{l}\text { Max Planck Institute, } \\
\text { Goettingen, Germany }\end{array}$ \\
\hline 3 & Isolation, culture and expansion of mouse & $\begin{array}{l}\text { Research } \\
\text { assistant }\end{array}$ & 2007-2009 & Royan Institute, Iran \\
\hline
\end{tabular}


spermatogonial stem cells

4

In vitro differentiation of human ES cells to germ cells

Effect of Extracellular matrix on differentiation of

5 mouse embryonic stem cells to insulin-producing cells

M.Sc student

2005-2006

Royan Institute, Iran

Differential effect of Activin on differentiation of mouse

ES cells to insulin-producing cells

M.Sc student

\section{Computer skills:}

1. EndNote

2. Basic Bioinformatics tools

3. WinMDI (analytical flowcytometry)

4. Molecular biology software: Perl Primer, Gene Runner, Ape

5. ImageJ software

6. REST (Relative Expression Software Tool)

7. Statistical software: SPSS, Prism

8. Scaffold (protein analysis)

9. Microsoft office

10. Graphic software: Adobe Photoshop, Adobe Illustrator, Freehand

\section{Extra Curricular Activities:}

1. Professional player of Iranian traditional music instruments (Tar, and Setar)

2. Playing chess

3. Swimming

4. Playing football

\section{Language skills:}

1. Persian (Mother tongue)

2. English (fluent)

3. German (elementary)

\section{References:}

1. Professor Dr. Michael Kessel

Developmental Biology research group, Molecular Cell Biology Department, Max Planck Institute for biophysical chemistry, Goettingen, Germany

mkessel1@gwgd.de

www.uni-goettingen.de/en/57991.html

2. Professor Dr. Wolfgang Engel

Director of Human Genetic department, Medical University of Goettingen, Germany wengel@gwdg.de

www.uni-goettingen.de/en/57938.htm.

3. Professor Dr. Gregor Eichele

Director of Max Planck Institute for Biophysical Chemistry, Goettingen, Germany,

Director of Genes and Behavior Department, Max Planck Institute for Biophysical Chemistry Goettingen, Germany

gregor.eichele@mpibpc.mpg.de

http://www.genesandbehavior.org 